\title{
SYNTHESIS AND CHARACTERISATION OF
} HETEROCYCLES DERIVED FROM QUINOXALINES

\author{
AND MUCOBROMIC ACID
}

THESIS SUBMITTED TO THE

( $($ C $H I N$ UNIVERSITY OF SCIENCE AND TECHNOLOGY

IN PARTIAL FULFILMENT OF THE

REQUIREMENTS FOR THE DEGREE OF

DOCTOR OF PHILOSOPHY

$\| \mathbb{N}$

CHEMISTRY

IN THE FACULTY OF SCIENCE

BY

SINDHU RAMACHANDRAN C. V.

DEPARTMENT OF APPLIED CHEMISTRY

COCHIN UNIVERSITY OF SCIENCE AND TECHNOLOGY

KOCHI -682022

May 1998 


\section{CERTIFICATE}

This is to certify that the thesis herewith is an authentic record of research work carried out by the author under my supervision, in partial fulfilment of the requirements for the degree of Doctor of Philosophy of Cochin University of Science and Technology, and further that no part thereof has been presented before for any other degree.

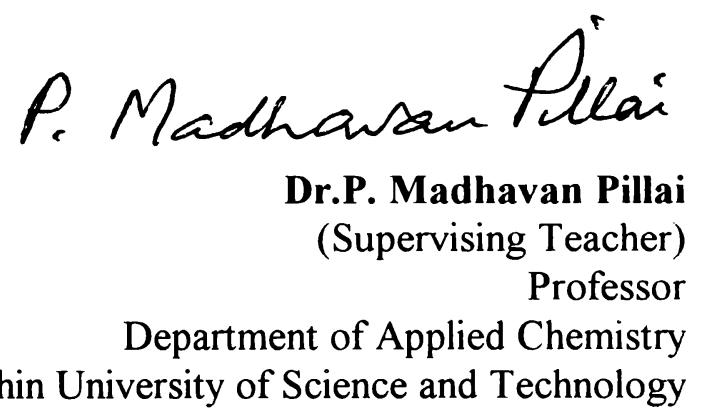

Kochi -22

18-5-'98 


\section{CONTENTS}

$\begin{array}{lll}\text { Chapter 1. INTRODUCTION } & 1\end{array}$

Chapter 2. HISTORICAL REVIEW 5

2.1. Quinoxalines 5

2.1.1. Synthesis of quinoxaline derivatives 5

2.1.1.1. Condensation of $o$-diamines and dicarbonyl compounds 6

2.1.1.2. Intramolecular condensation $\quad 8$

2.1.1.3. Ring transformation $\quad 8$

2.1.2. Reactions of quinoxalines 9

2.1.2.1. Substitutions 9

2.1.2.2. Reductions 10

2.1.2.3. Oxidation reactions 11

$\begin{array}{lll}\text { 2.1.2.4. Biological studies } & 12\end{array}$

2.1.3. Condensed quinoxalines 13

$\begin{array}{lll}\text { 2.1.3.1. Synthesis of pyrazoloquinoxalines } & 14\end{array}$

2.1.3.2. Substitution reactions 21

2.1.3.3. Oxidation reactions 24

2.1.3.4. Ring opening reactions 25

2.1.3.5. Miscellaneous reactions 26

2.1.3.6. Biological studies 28

2.2. Mucobromic acid and its reactions 31

Chapter 3. RESULTS AND DISCUSSION 42

3.1. Synthesis and reactions of 2-phenylpyrazolo[3,4-b]quinoxaline 42

$3.2 \quad$ Reactions of mucobromic acid 51

3.3. Reactions of 5-chloro-3,4-dibromocrotonolactone 64

3.4. Reactions of 5-benzoyloxy-3,4-dibromocrotonolactone 68

3.5. Reactions of 3,4-dibromocrotonolactone 71

$\begin{array}{ll}\text { 3.6. Discussion of spectral data } & 77\end{array}$ 
Chapter 4. EXPERIMENTAL PROCEDURES 84

4.1.
Ethyl 2-Hydroxyquinoxaline-3-carboxylate

Ethyl 2-Chloroquinoxaline-3-carboxylate

Ethyl 2-Phenylhydrazinoquinoxaline-3-carboxylate 85

3-oxo-2-phenylpyrazolino[3,4-b]quinoxaline 85

3-Chloro-2-phenylpyrazolo[3,4-b]quinoxaline 86

3-amino-2-phenylpyrazolo[3,4-b]quinoxaline 86

3-Methoxy-2-phenylpyrazolo[3,4-b]quinoxaline 87

3-Ethoxy-2-phenylpyrazolo[3,4-b]quinoxaline 88

3-Morpholino-2-phenylpyrazolo[3,4-b]quinoxaline 88

3-Pyrrolidino-2-phenylpyrazolo[3,4-b]quinoxaline $\quad 89$

3-Piperidino-2-phenylpyrazolo[3,4-b]quinoxaline $\quad 89$

2-Phenylpyrazolo[3,4-b]quinoxaline 90

3-Chloro-2-phenylpyrazolo[3,4-b]pyrazine dicarboxylic acid 90

Mucobromic acid 91

3,4-Dibromocrotonolactone 92

3,4-Dibromo-5-ethoxycrotonolactone 92

4,5-Dibromo-6-pyridazone 93

4,5-Dibromo-6-chloropyridazine 93

1-Carboxamido-3,4-dibromo-5-hydroxy-3-pyrroline 2-one 93

4-Azido-3-bromo-5-hydroxycrotonolactone 94

4-Azido-3-bromocrotonolactone 95

5-Benzoyloxy-3,4-dibromocrotonolactone 95

3,4-Dibromo-5-chlorocrotonolactone 96

3,4-Dibromo-5-hydroxy-1-methyl-3-pyrroline-2-one 96

3,4-Dibromo-1-(3-hydroxypropyl)-5-hydroxy-3-pyrrolin-2-one 98

3,4-Dibromo-1-(2-hydroxyethyl)-5-hydroxy-3-pyrrolin-2-one 99 


\section{Chapter 5. Summary and Conclusions}

\section{References}




\section{INTRODUCTION}

Heterocyclic chemistry is of great interest for its diversity in synthetic procedures and for its wide physiological activities. Here we are reporting the synthesis of some heterocycles with possible physiological activity starting from a) quinoxaline b) mucobromic acid.

Quinoxaline or 1,4-diazine is an important heterocyclic system with very wide biological activities. From quinoxaline derivative we have prepared 2-phenylpyrazolo[3,4-b]quinoxaline derivatives. Pyrazolo[3,4-b]quinoxalines were prepared by Ohle and coworkers in $1941^{4}$, starting from glucose, $o$-phenylenediamine, and phenylhydrazine in acetic acid. These compounds have a characteristic yellow colour and hence they are known as flavazoles. These flavazoles are known to exhibit a wide range of activities like analgesic, antiinflammatory, tuberculostatic, antileukemic and immunochemical properties which gave inspiration for the synthesis of a new series of flavazoles with a view to testing their pharmacological activities.

Detailed information about the synthesis and reactions of 1-phenylpyrazolo$[3,4-b] q u i n o x a l i n e s$ are available. ${ }^{34,34,38}$ We are reporting the synthesis of 2-phenylpyrazolo[3,4-b]quinoxaline and its various 3-substituted derivatives starting from the known ethyl 2-hydroxyquinoxaline-3-carboxylate. This starting compound on treatment with $\mathrm{POCl}_{3}$ followed by $\mathrm{PhNHNH}_{2}$ gave ethyl-2-phenyl- 
hydrazinoquinoxaline-3-carboxylate. This compound undergoes cyclisation at temperature above its melting point to give 3-oxo-2-phenylpyrazolino[3,4-b]quinoxaline.

3-Oxo-2-phenylpyrazolino[3,4-b]quinoxaline on treatment with $\mathrm{POCl}_{3}$ gave 3chloro-2-phenylpyrazolo[3,4-b]quinoxaline which is taken as the starting material for the further reactions. The chloro compound was subjected to substitution reactions with urea, secondary amines, ethanol in presence of potassium carbonate, methanol in ammonia etc., to give the corresponding 3-substituted products. The products were characterised by spectral methods and elemental analysis.

In addition to the substitution reactions the compound was subjected to reduction using sodium borohydride in isopropanol and the product was 2-phenylpyrazolo[3,4-b]quinoxaline. Oxidation of the chloro compound with aqueous $\mathrm{KMnO}_{4}$ gave pyrazolopyrazine dicarboxylic acid.

Some of the synthesised compounds were screened for their activity against enteric pathogens and it was found that 3-amino-2-phenylpyrazolo[3,4-b]quinoxaline was found to show some activity against some enteric pathogens like Vibreo cholerae inaba, V. Cholerae ogawa and V. Cholerae 0139. 
In the second part of the work mucobromic acid was taken as the starting material for the preparation of physiologically active compounds. Mucobromic acid is a $\gamma$-aldehydic acid, which can exist as 3,4-dibromo-5-hydroxycrotonolactone or as 2,3-dibromo-3-formylacrylic acid. The reactions of mucohalic acid and their esters were carried out by Hill. Some studies on the reactions of 3,4-dibromocrotonolactone with primary amines were also reported to yield 5-hydroxy-5-methyl-4bromocrotonolactam. Very little information was available on the reactions of unsaturated lactones and here we are reporting the reactions of 5-hydroxy, 5-alkoxy, 5-halogeno and 5-unsubstituted crotonolactones with various nucleophiles.

The unsaturated lactones exhibit activities like antibiotic, antitumor, cardiac haemorrhagic and insecticidal properties. The reactions of mucohalic acid derivatives with penicillamine have been shown to give fused thiazolidines, which are structurally related to penicillins.<smiles>[R]OC(=O)C1SC(C)(C)C2C([X])=C([X])C(=O)N12</smiles>

Dickens and Jones demonstrated a correlation between physiological activity and the structure of lactones. They classified the various types into groups as given 
below. Compounds of the type I and II are found to be physiologically active whereas related lactones of group III failed to show any activity.<smiles>C=C1CCO1</smiles><smiles>[R]C1C=CC(=O)O1</smiles><smiles>[R]C1=CCC(=O)O1</smiles><smiles>O=C1CCN1</smiles><smiles>[R]=C1C=CC(=O)O1</smiles><smiles>[R]C1CCC(=O)O1</smiles>

Group I

Group II

Four derivatives of mucobromic acid were prepared and characterised. Reactions of mucobromic acid and its derivatives with various nucleophile were carried out with a view to understanding the position of attack of the nucleophile on the lactone, structure and biological activity of the products formed. In these reactions two types of products were formed 1) substituted crotonolactones and 2) substituted crotonolactams. The identification of the products were carried out by detailed spectral and analytical methods. The large number of new compounds obtained by these reactions are being submitted for evaluating their biological activities. 


\section{HISTORICAL REVIEW}

\subsection{QUINOXALINES}

Quinoxaline, or 1,4-benzodiazine (1) is an important structural unit among nitrogen heterocycles and in general is easily be prepared. The synthesis of a large number of its derivatives have been reported in recent years because of their biological importance. $^{24-29}$

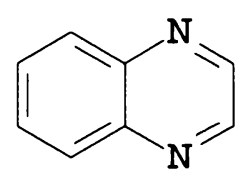

\subsubsection{SYNTHESIS OF QUINOXALINE DERIVATIVES}

Some of the important methods used for the preparation of quinoxaline derivatives are 1. Condensation of aromatic diamines and dicarbonyl compounds.

2. Intramolecular cyclisation of $\mathrm{N}$-substituted aromatic o-diamines.

3. Ring transformation of benzodiazapines etc. 


\subsubsection{Condensation of $o$-diamines and dicarbonyl compounds}

Condensation of aromatic diamine and $\alpha$-dicarbonyl compound is a very facile and widely used method for the synthesis of quinoxalines and alkyl substituted quinoxalines $^{1}(2)$<smiles>Nc1ccccc1N</smiles><smiles>[R]C(=O)C([R])=O</smiles>

Condensation of mesoxalic acid and o-phenylenediamine proceeds as expected, producing 2-hydroxyquinoxaline-3-carboxylic acid (3) however, with sodium mesooxalate an anomalous reaction occurs ${ }^{2}$. The initial products 2-hydroxyquinoxaline-3carboxylic acid (3) and 1,2-dihydrobenzimidazole-2,2-dicarboxylic acid (4) undergo an intermolecular hydrogen transfer reaction to yield 1,2,3,4-tetrahydro-2oxoquinoxaline-3-carboxylic acid (5) and benzimidazole-2-carboxylic acid (6).<smiles>Nc1ccccc1N</smiles><smiles>O=C(O[Na])O[Na]</smiles><smiles>O=C(O)c1nc2ccccc2nc1O</smiles><smiles>O=C(O)C1(C(=O)O)Nc2ccccc2N1</smiles> 
<smiles>O=C(O)C1Nc2ccccc2NC1=O</smiles>

5<smiles>O=C(O)c1nc2ccccc2[nH]1</smiles>

6

Quinoxaline-2-ones (7) are obtained in excellent yields by the condensation of n-butyl glyoxalate and o-phenylenediamine ${ }^{3}$.<smiles>Nc1ccccc1N</smiles><smiles>CCCCCCCCC(=O)C=O</smiles>

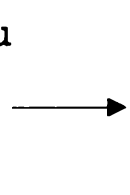<smiles>O=c1cnc2ccccc2[nH]1</smiles>

7

Quinoxaline derivatives are also prepared from osones, hydrazones and dehydro-Lascorbic $\operatorname{acid}^{4}$. Here the carbohydrate is acting as the carbonyl compound. Glucose condenses with o-phenylenediamine to yield 2-(D-arabino-tetrahydroxybutyl)quinoxaline $(8)^{5}$.

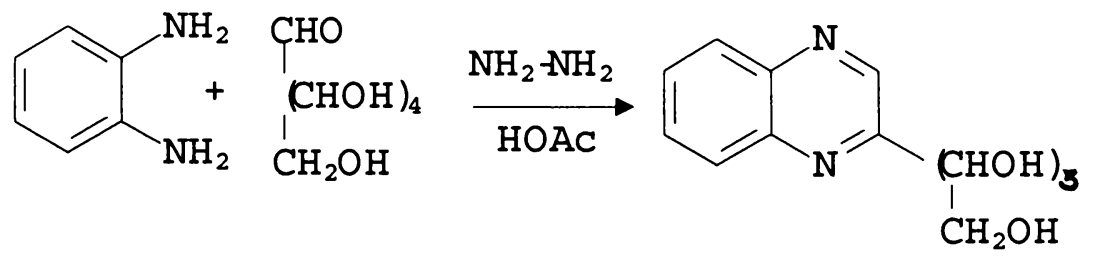




\subsubsection{Intramolecular cyclisation}

Reductive cyclisation of the $\alpha$-amino acid intermediate 9 formed from an amino acid and an $o$-nitrohalogenobenzene is an unambiguous method for the synthesis of quinoxaline-2-one ${ }^{6}$.

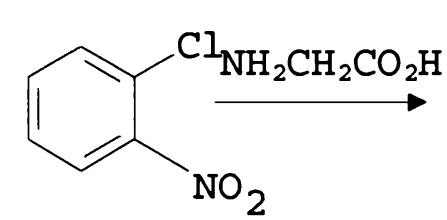<smiles>O=C(O)CNc1ccccc1[N+](=O)[O-]</smiles>

9

\subsubsection{Ring transformations}

Quinoxalines can also be synthesised by degradative reaction of larger ring systems. 1,2-Dihydro-2-oxoquinoxaline-3-carboxylic acid (10) is isolated from alkaline hydrolysis of a fused alloxazine ${ }^{7}$.<smiles>CCCC(=O)c1nc2ccc(N)cc2[nH]c1=O</smiles> 
The 1,5-benzodiazepine on UV irradiation in benzene undergoes oxidative ring contraction to 2-benzoyl-3-methylquinoxaline (11) .

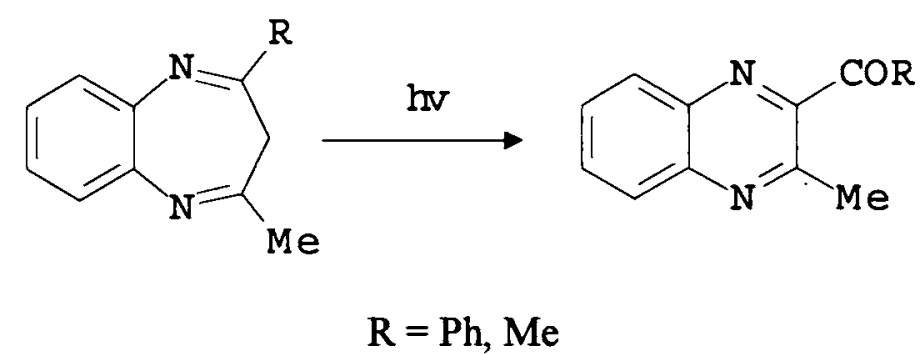

11

\subsubsection{REACTIONS OF QUINOXALINES}

\subsubsection{Substitutions}

Pyridine is generally reluctant to take part in electrophilic substitution reaction, so introducing one more nitrogen would make the quinoxaline derivative less reactive towards electrophiles. If active substituents are present in the benzene ring the reaction becomes more facile. Quinoxalines are easily attacked by nucleophiles, for eg. two molecules of Grignard Reagent can be added across quinoxaline molecule to give compound $12^{9}$.

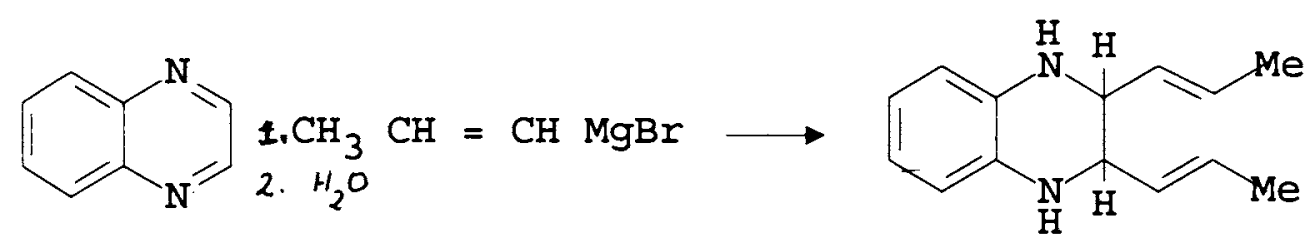

12

6-Substituted quinoxalines undergo unusual reactions with nucleophiles. Thus 2,3-diphenyl-6-nitroquinoxaline (13) with $\mathrm{KCN}$ in methanol gives substitution in 
position 5, with the displacement of nitro group to give compound 14 along with 5amino-isoxazolo[3,4-f]quinoxaline $(15)^{10}$.<smiles>COc1ccc2nc(-c3ccccc3)c(-c3ccccc3)nc2c1C#N</smiles><smiles>Nc1[nH]nc2ccc3nc(-c4ccccc4)c(-c4ccccc4)nc3c12</smiles>

15

\subsubsection{Reductions}

Catalytic reduction of 2-acetyl-3-methylquinoxaline in methanol gives a deep crimson solution from which red brown needles of 2-acetyl-1,4-dihydro-3methylquinoxaline (16) was isolated ${ }^{11}$. Reduction of quinoxaline with sodium in THF at $20{ }^{\circ} \mathrm{C}$ yields the 1,4-dihydroquinoxaline ${ }^{12}$. 


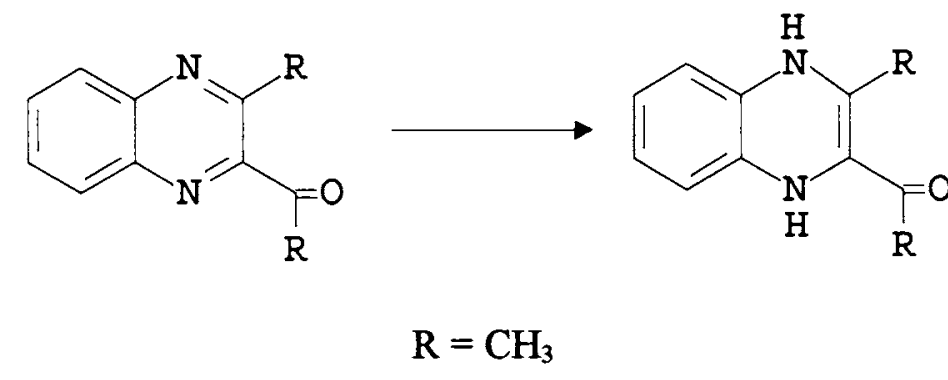

16

When quinoxaline is reduced with $\mathrm{LiAlH}_{4}$ in ether 1,2,3,4-tetrahydroquinoxaline is obtained ${ }^{13}$. Sodium borohydride in acetic acid ${ }^{14}$ and hydrogen in the presence of $\mathrm{Pt}^{15}$ have been used to reduce 6-substituted quinoxalines to 1,2,3,4-tetrahydro compounds. Hydrogenation of quinoxaline or 1,2,3,4-tetrahydroquinoxaline over a $5 \%$ rhodium-onalumina catalyst at $100{ }^{\circ} \mathrm{C}$ and 136 atmospheres pressure or over freshly prepared Raney Ni gives meso (cis)-decahydroquinoxaline $(17)^{16}$.<smiles>C1CC[C@H]2NCCNC2C1</smiles>

17

\subsubsection{Oxidation reactions}

A number of methods have been used for $\mathrm{N}$-oxidation of quinoxalines. With one equivalent of peracetic acid quinoxaline gives 1-oxide, while with excess of the reagent 1,4-dioxide is formed ${ }^{17}$. Substituents at 2-position generally inhibit 1-oxide formation, for eg. 2-alkoxy and 2-carbethoxy quinoxaline furnishes the 4-oxide only ${ }^{18}$. The electrolytic oxidation of quinoxaline at copper anode gives pyrazine-2,3-dicarboxylic 
acid in excellent yield ${ }^{19}$. A similar conversion is also effected by oxidation with alkaline $\mathrm{KMnO}_{4}$.

\subsubsection{BIOLOGICAL STUDIES}

A number of reports are present in literature about the wide spread use of quinoxalines as antihypertensive agents and animal growth promoters ${ }^{20,}{ }^{21}$. It was found that several highly mutagenic and carcinogenic quinoxalines have been identified in heated meat and fried fish ${ }^{22}$. Certain condensed quinoxalines exhibit antibacterial, analgesic, tuberculostatic, antileukemic activities ${ }^{23}$.

Biologically active polypeptides such as levomycin and echinomycin have been shown to possess one or more quinoxalinyl residues ${ }^{24}$. The 2,3,7-trichloro-6methylsulfamoylquinoxaline (18) is a patented anticancer agent ${ }^{25}$.<smiles>CNS(=O)(=O)c1cc2nc(Cl)c(Cl)nc2cc1Cl</smiles>

18

2-Phenyl-3-piperidinoquinoxaline (19) and its derivatives are selective herbicides ${ }^{26}$. 


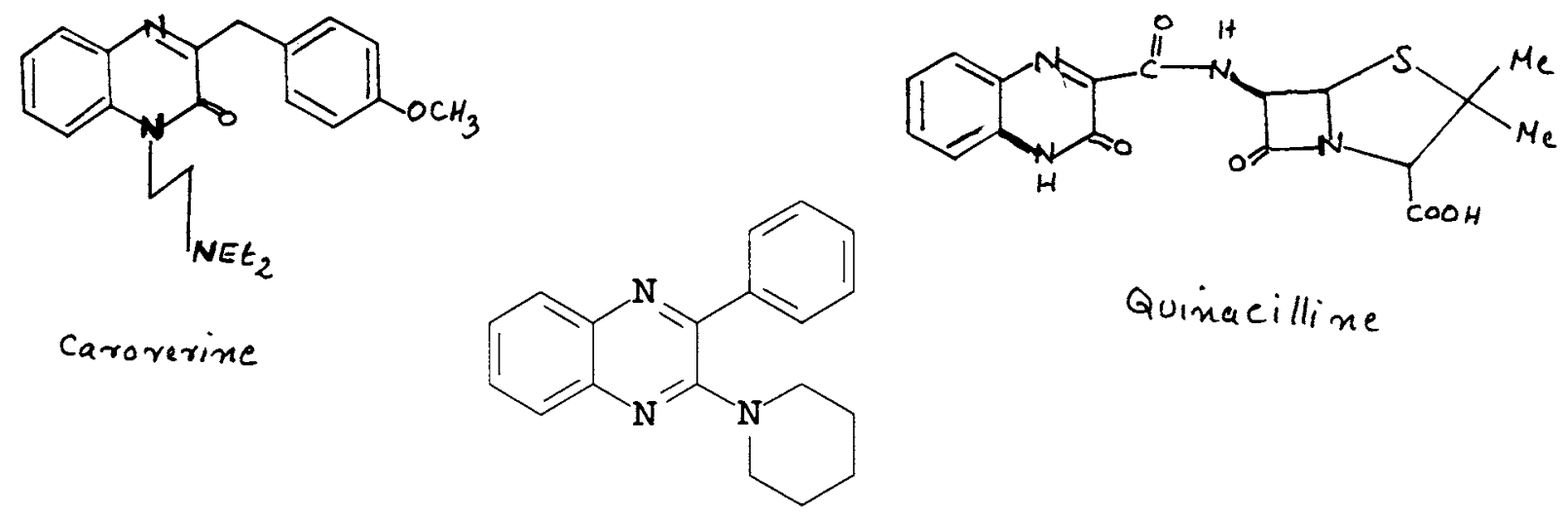

19

Caroverine and Quinacilline are used as antibacterial agents ${ }^{27,28}$. N-[2(pinethylamino)ethyl]carboxamide derivatives of fused tetracyclic quinoxalines are found to be 3-fold more cytotoxic than DACA in human leukemia cell lines with in vivo activity in colon 38 comparable to that of DACA and doxorubicin ${ }^{29}$. S-(Methylsulphonylamino)quinoxaline-2,3-dione was useful as anxiolytics, anticonvulsants, analgesics and neusoprotectants $\mathbf{s}^{30}$.

\subsubsection{CONDENSED QUINOXALINES}

Certain condensed quinoxalines like pyrazoloquinoxalines (20) are reported to exhibit antibacterial, antiinflammatory, analgesic and tuberculostatic activities ${ }^{23,31}$. Triazoloquionoxalines (21) are found to be both medicinally and industrially important as they are widely used as drugs, optical brighteners and polymer additives ${ }^{32}$.<smiles>c1ccc2nc3[nH]ncc3nc2c1</smiles>

20<smiles>c1ccc2c(c1)ncc1cnnn12</smiles>

21 


\subsubsection{SYNTHESIS OF PYRAZOLOQUINOXALINES}

Flavazole ring system was first prepared by Ohle \& Co-workers ${ }^{33}$ by the treatment of 3-(D-arabino-tetrahydroxybutyl)quinoxaline (22) with phenyl hydrazine in acetic acid when 1-phenyl-3-(D-erythro-1,2,3-trihydroxypropyl)-1H-pyrazolo[3,4b]quinoxaline (23) was obtained in $97 \%$ yield. The ring system was referred to as flavazoles because of their yellow colour similar to flavanoids.

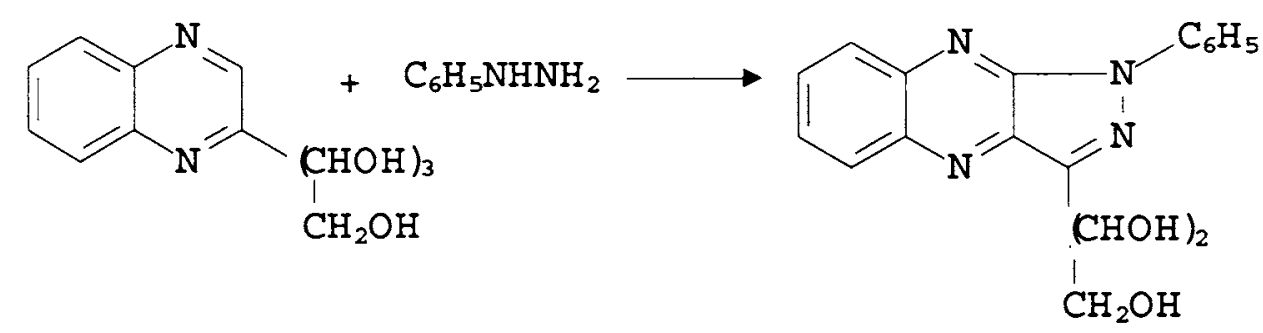

1H-Pyrazolo[3,4-b]quinoxaline (23) of glucose, o-phenylenediamine and phenylhydrazine in presence of an acid ${ }^{34}$. All reducing sugars which have no substituents in positions 2 and 3 undergo this reaction. The flavazole derivatives thus obtained have a well defined crystalline nature, so they can be easily identified by $\mathrm{X}$-ray diffraction pattern and melting points ${ }^{35,36}$.

Compound 23 was oxidised with chromic anhydride in acetic acid to 1-phenyl1H-pyrazolo[3,4-b]quinoxaline-3-carboxylic acid (24). The same acid can be 
synthesised independently by the condensation of o-phenylene diamine with 1-phenyl4,5-dioxo-2-pyrazoline-3-carboxylic acid (25).

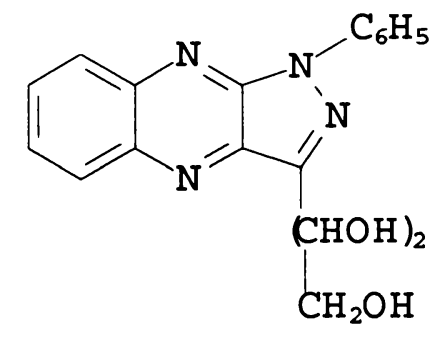

23<smiles>Nc1ccccc1N1N=C(C(=O)O)C(=O)C1=O</smiles>

25

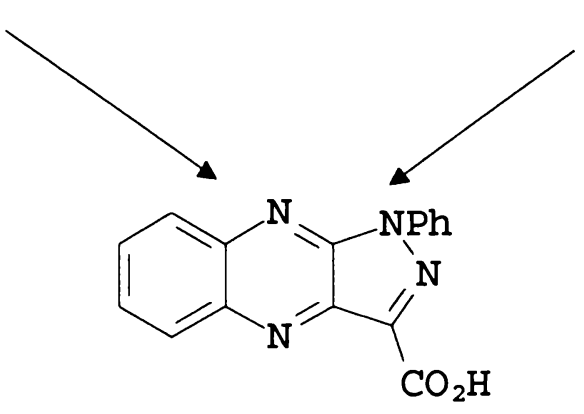

24

1-Phenyl-1H-pyrazolo[3,4-b]quinoxaline (26) was later prepared by Henske and co-workers, by oxidative cyclisation of quinoxaline-2-carboxaldehyde phenylhydrazone using phenyl hydrazine in acetic $\operatorname{acid}^{37}$.

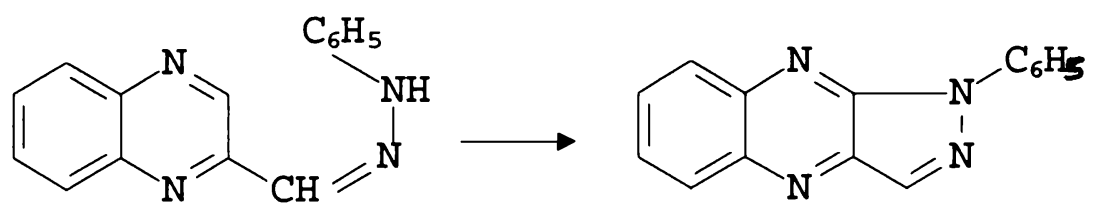


3-Methyl-1-phenyl-4,5-dioxo-2-pyrazoline (27) was condensed with o-phenylenediamine to give 3-methyl-1-phenyl-1H-pyrazolo[3,4-b]quinoxaline $(28)^{38}$.<smiles>Nc1ccccc1N</smiles><smiles></smiles>

Klincar reported the preparation of 3-methyl-7-nitro-1-phenyl-1H-pyrazolo[3,4b]quinoxaline (31) by the condensation of 4-nitro-o-phenylenediamine (29) with the aminal $30^{39}$.<smiles>Nc1ccc([N+](=O)[O-])cc1N</smiles>

29

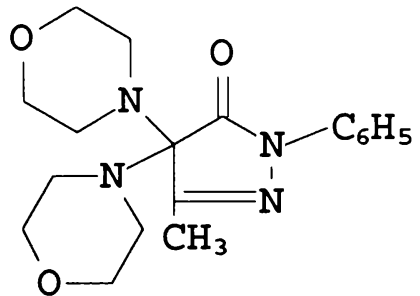

30<smiles>CCCCCCCCCn1nc(C)c2nc3ccc([N+](=O)[O-])cc3nc21</smiles> 
Pyrazoloquinoxalines with various groups such as chloro, amino, hydroxy, chloromethyl, trichloromethyl, N-pyrrolidyl, and N-pyrrolidylmethyl at position 3 have been reported by P. M. Pillai and P. Ramabhadran ${ }^{40}$. They also gave new methods for oxidative cyclisation (a) using azobenzene, (b) heating the phenyl hydrazone above its melting point in an atmosphere of oxygen.

Pyrazoloquinoxaline (32) was also prepared starting from pyruvic acid ${ }^{41}$. oPhenylenediamine with pyruvic acid gave 2-hydroxy-3-methylquinoxaline (33) which with $\mathrm{POCl}_{3}$ gave 2-chloro-3-methylquinoxaline (34). Subsequent bromination of $\mathbf{3 4}$ gave the dibromo derivative 35. This dibromo derivative on treatment with hydrazine provided 32

Romenko and Burnistrov prepared pyrazoloquinoxaline by reaction of 2-chloroquinoxaline-3-carboxaldehyde (36) with hydrazine in $71 \%$ yield $^{42}$. Pharmacological activity of 7,8-dimethylpyrazoloquinoxaline with sugar residues at position 3 was studied by N.P.Bu Hoi and co-workers ${ }^{43}$. 1-Methylpyrazoloquinoxaline (37) has been prepared by the alkylation of $1 \mathrm{H}$-pyrazoloquinoxaline using alkyl halide and potassium carbonate in $\mathrm{DMF}^{44}$. 


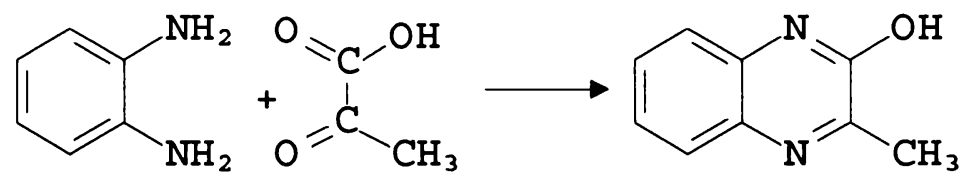

33

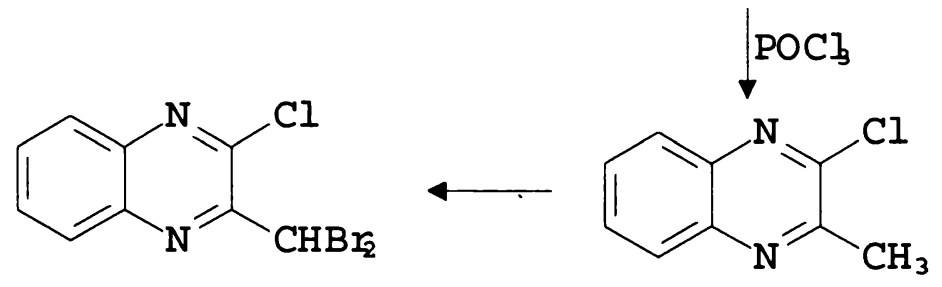

35

34
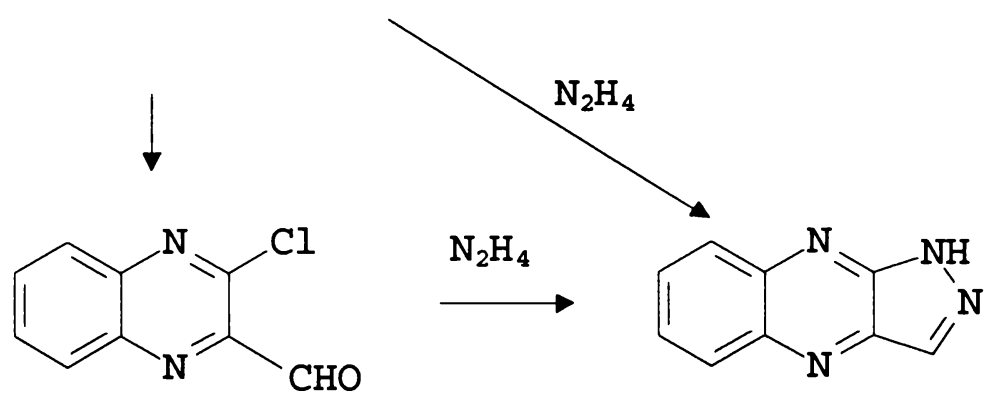

36

32

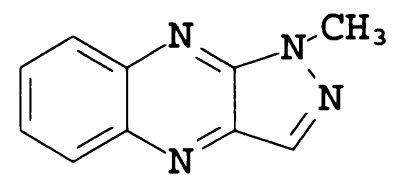

37 
Ke Yoshida and Hirotaka Otamasu has reported the preparation of 3aminopyrazoloquinoxaline from ethyl-2-hydroxyquinoxaline-3-carboxylate (38) ${ }^{44}$. Compound 38 was treated with ammonium carbonate to give an amide 39. This amide with $\mathrm{POCl}_{3}$ or $\mathrm{PCl}_{5}$ gave 2-chloroquinoxaline-3-carbonitrile (40) in $85 \%$ yield. Refluxing $\mathbf{4 0}$ with hydrazine gave 3-aminopyrazoloquinoxaline (41).<smiles>CCC(=O)c1nc2ccccc2nc1O</smiles>

38<smiles>CC(=O)c1nc2ccccc2nc1O</smiles>

39<smiles>N#Cc1nc2ccccc2nc1Cl</smiles>

40<smiles>Nc1n[nH]c2nc3ccccc3nc12</smiles>

41

Wittig reaction of carboxaldehyde ${ }^{45} \mathbf{4 2}$ with carbo-ethoxymethylidine triphenylphosphorane gave the condensation product $43^{46}$. Cyclisation of 43 with alkali gave two products namely pyridazone 44 and pyrazoloquinoxaline 45 . 
<smiles>CCCCCCCCCCN=C(C=O)c1nc2ccccc2nc1O</smiles>

42<smiles>CCCCCCCCn1nc(-c2nc3ccccc3[nH]c2=O)ccc1=O</smiles><smiles>CCOC(=O)C=CC(=Nc1ccccc1)c1nc2ccccc2nc1O</smiles>

43

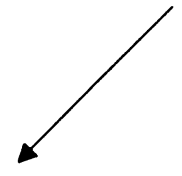

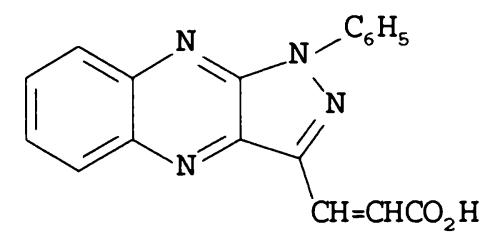

The following derivatives 46-50 of 3-formylpyrazoloquinoxalines were prepared to study their tuberculostatic activity ${ }^{47}$.<smiles>[R]c1cc2nc3[nH]nc(C=NN)c3nc2cc1[R]</smiles><smiles>[R]c1cc2nc3[nH]nc(C=N[NH3+])c3nc2cc1[R]</smiles>

$\mathrm{R}=\mathrm{H}, \mathrm{CH}_{3}$ 


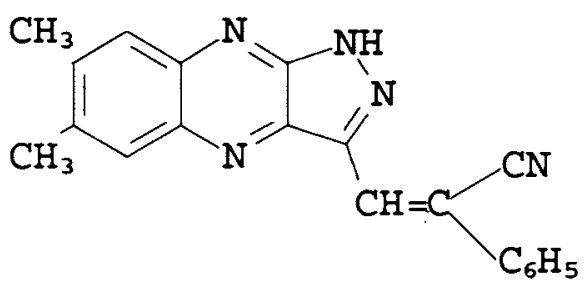

48<smiles>Cc1ccc2nc3[nH]nc(C=CC(=O)O)c3nc2c1</smiles>

49<smiles>Cc1ccc2nc3[nH]nc(C(N)=O)c3nc2c1</smiles>

50

\subsubsection{Substitution reactions}

Compounds containing the pyrazoloquinoxaline ring system undergo substitution reactions at various positions. Acylation reactions take place very easily in the pyrazoloquinoxalines if position 1 is unsubstituted. 1-Acetylpyrazoloquinoxaline-3carboxylic acid was obtained from pyrazoloquinoxaline-3-carboxylic acid on treatment with acetic anhydride and pyridine ${ }^{48}$. De-acetylation takes place under mild conditions at position 1. 1-Acetyl-pyrazoloquinoxaline-3-carbonylchloride (51) on treatment with methanolic ammonia gave pyrazoloquinoxaline-3-carboxamide $(52)^{48}$. 
<smiles>CC(=O)n1nc(C(=O)Cl)c2nc3ccccc3nc21</smiles>

51<smiles>CC(=O)n1nc(C(N)=O)c2nc3ccccc3nc21</smiles>

52

Sulphonation of pyrazoloquinoxaline with pyridine-sulphur trioxide at $170^{\circ} \mathrm{C}$ followed by treatment of the pyridinium salt with $\mathrm{NaOH}$ and subsequent liberation of free acid by ion exchange gave pyrazoloquinoxaline-3-sulphonic acid $(53)^{49}$. 1Phenyl-3-methylpyrazoloquinoxaline (54) with chlorosulphonic acid underwent sulphonation at para position of the phenyl group and gave a single product $\mathbf{5 5}$ which was subsequently converted into sulphonic acid $\mathbf{5 6}$ and sulphonamide 57.

Pyrazoloquinoxalines on nitration gave an isomeric mixture of mono nitro derivatives. The exact position of the nitro group was not determined ${ }^{50}$. An unusual phenylation reaction of phenyl pyrazoloquinoxalines have been reported by P.M. Pillai and P.Ramabhadran ${ }^{40}$. When 1-phenyl-pyrazoloquinoxaline was treated with air oxidised phenylhydrazine, 1,3-diphenylpyrazoloquinoxaline (58) was obtained. Bromination of 1-phenylpyrazoloquinoxaline gave 1-p-bromophenylpyrazoloquinoxaline (59). Similarly 1,3-diphenylpyrazoloquinoxaline gave 1-pbromophenyl-3-phenylpyrazoloquinoxaline (60) on bromination ${ }^{51}$. 

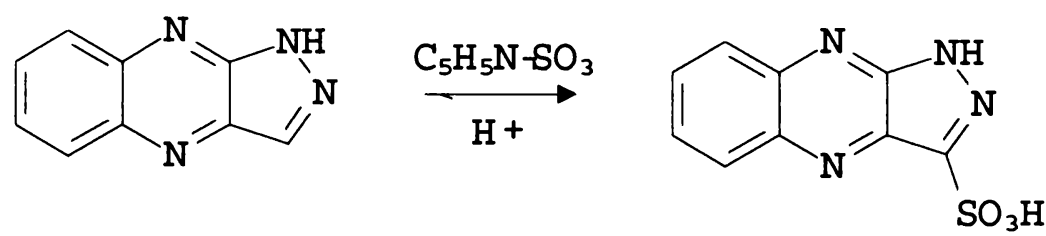

53

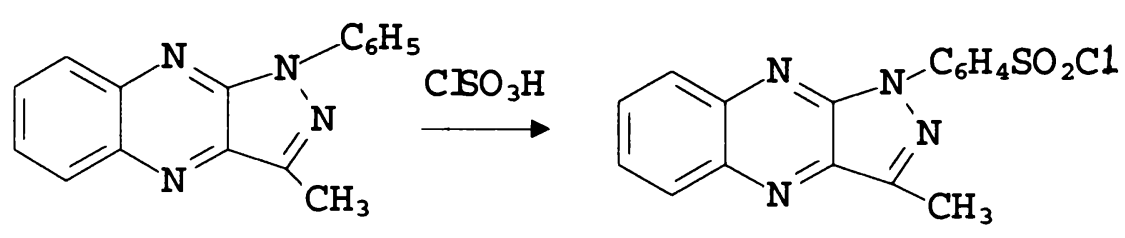

54

55

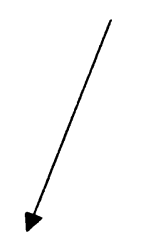

(c)

56

57 
<smiles>c1ccc(-c2nn(-c3ccccc3)c3nc4ccccc4nc23)cc1</smiles>

58<smiles>Brc1ccc(-n2ncc3nc4ccccc4nc32)cc1</smiles>

59<smiles>Brc1ccc(-n2nc(-c3ccccc3)c3nc4ccccc4nc32)cc1</smiles>

60

\subsubsection{Oxidation reactions}

Oxidation of pyrazoloquinoxaline with aqueous $\mathrm{KMnO}_{4}$ gave pyrazolo[3,4-b]pyrazine-5,6-dicarboxylic acid $(61)^{52}$. 1-Phenylpyrazoloquinoxaline with neutral potassium permanganate gave 1-phenylpyrazolopyrazine-5,6-dicarboxylic acid which was characterised as its dimethyl ester (62) ${ }^{51}$.

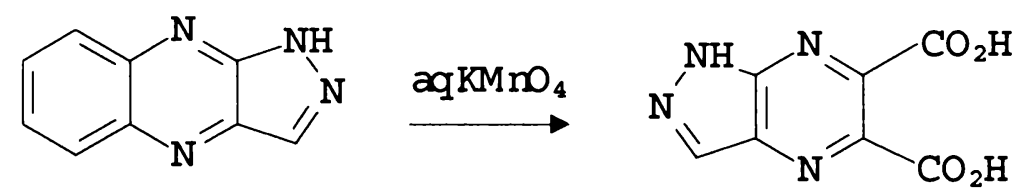




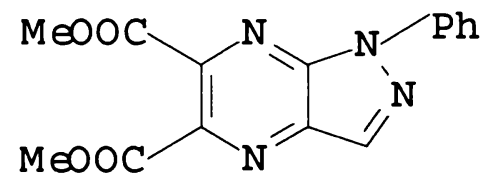

62

\subsubsection{Ring opening reaction}

Attempts to reduce 1-phenylpyrazoloquinoxaline using $\mathrm{NaBH}_{4}$ in methanol and $\mathrm{LiAlH}_{4}$ in ether was unsuccessful. However, with $\mathrm{NaBH}_{4}$ in isopropanol 1-phenyl flavazole gave 2-anilino-quinoxaline-3-carboxamide (63) and 2-anilinoquinoxaline-3carboxylic acid (64) by ring opening.

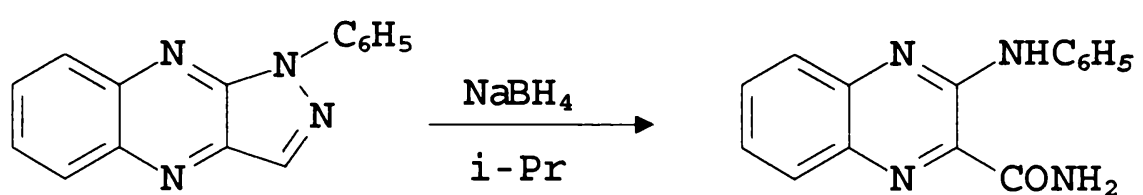

63<smiles>O=C(O)c1cc2ccccc2cc1Nc1ccccc1</smiles>

64 


\subsubsection{Miscellaneous reactions}

Hydrazine in presence of Raney nickel reduced the nitro group in $\mathbf{3 1}$ and gave the amino derivative 65 .

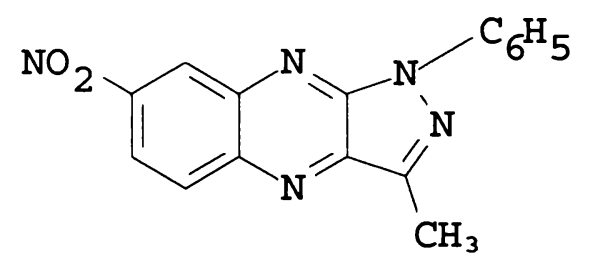

31

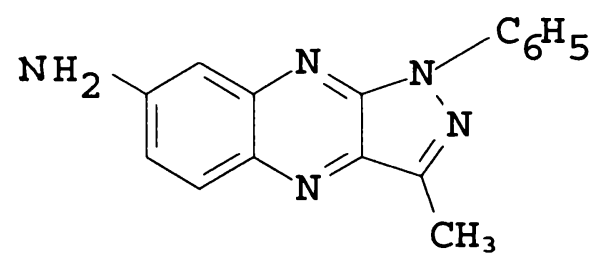

65

The sugar residue of 3-(D-erythro-trihydroxypropyl)pyrazoloquinoxaline (66) was oxidised using lead tetraacetate or periodic acid to give the carboxaldehyde 67. The aldehyde 67 underwent the cannizaro reaction with hot conc. alkali and gave a mixture of primary alcohol 68 and carboxylic acid 69. 
<smiles>OCC(O)c1n[nH]c2nc3ccccc3nc12</smiles>

66<smiles>OCc1n[nH]c2nc3ccccc3nc12</smiles>

68<smiles>O=Cc1n[nH]c2nc3ccccc3nc12</smiles>

67

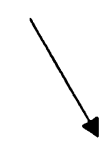<smiles>O=C(O)c1n[nH]c2cc3ccccc3cc12</smiles>

69

It was found that pyrazoloquinoxaline with free 1-position form metal salts which had orange to yellow colours due to the flavazole anion which has a number of resonance forms as shown below.

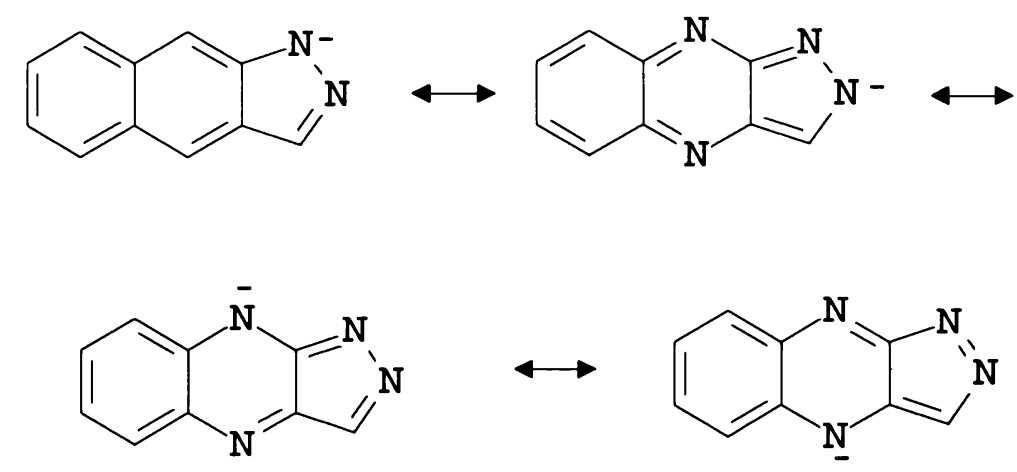




\subsubsection{Biological studies}

In order to study the biological activity, water soluble derivatives of pyrazoloquinoxalines were prepared. For this two methods were used (a) by increasing the hydroxyl group in the heterocyclic system ${ }^{53}$, and (b) by introducing poly hydrogen sulphate salts on the hydroxyl groups of the sugar residue ${ }^{54,55}$. Various derivatives of 1-phenylpyrazoloquinoxalines were subjected to screening for the inhibition of multiplication of Staphylococcus $k$ phage. The growth rate of stapylococcus aureus was inhibited $5-10 \%$ when pyrazoloquinoxalines were added to the growth cultures at concentrations necessary to double the lysis time ${ }^{56}$. 1Phenylpyrazoloquinoxalines was found to be active against clostridium septicum infections in mice ${ }^{57}$.

Buu-Hoi and co-workers ${ }^{43}$ studied the antibacterial, antiinflammatory and analgesic properties of pyrazoloquinoxalines 70-73. The tuberculostatic activity of the hydrazone 74 and semicarbazone 75 were reported by the same authors ${ }^{47}$.<smiles>[R]c1n[nH]c2nc3ccc(C)cc3nc12</smiles>

70. $\mathrm{R}=\mathrm{CHO} ; 71 . \mathrm{R}=\mathrm{CHNOH} ; 72 . \mathrm{R}=\mathrm{CN} ; 73 . \mathrm{R}=\mathrm{COOH}$ 
<smiles>[R]c1cc2nc3[nH]nc(C=NN)c3nc2cc1[R]</smiles>

$\mathrm{R}=\mathrm{H}, \mathrm{CH} 3$<smiles>NC(=O)NCc1n[nH]c2nc3ccccc3nc12</smiles>

75

Sallam and co-workers ${ }^{58,59}$ have shown that C-nucleoside 76 exhibited invitro cytotoxic activity against $\mathrm{KB}$ cells (a human epidermoid carcinoma of the nasopharynx) where as 77 was inactive.<smiles>CCCCCCCCCn1nc(C2CC(O)C(O)O2)c2nc3ccccc3nc21</smiles>

76

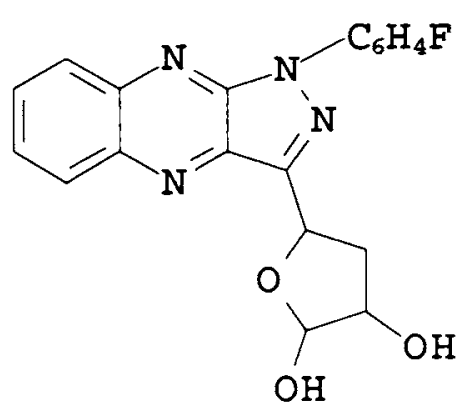

77

1-Phenylpyrazoloquinoxaline of isomaltohexose coupled to chicken gamma globullin induced $\mathrm{T}$ cells dependent anti-(1-6) dextron specific IgM and $\operatorname{IgG}$ responses in CBA, BALB/C and A strain mice ${ }^{60}$. Tichmann and co-workers ${ }^{61}$ prepared $1(m-$ nitrophenyl)-pyrazoloquinoxalines from oligosaccharides of maltose, isomaltose and cellobiose series and were used as model compounds for immunochemical studies. $m$ Aminophenyl derivatives had similar properties as that of nitro derivatives, and are useful for the manufacture of immunogen, antigen models and immunoabsorbants with 
oligosaccharide determinant group ${ }^{62}$. The 1-(m-nitrophenyl)pyrazoloquinoxaline of isomaltose oligosaccharides were used to study their interaction with human antidextran by the qualitative hepten inhibition and fluorescence quenching technique ${ }^{63}$. Cellulose- $m$-aminobenzyloxy methyl ether and $p$-aminobenzyl cellulose were diazotised and coupled with 1-(m-hydroxyphenyl)pyrazoloquinoxaline and 1-( $m$ aminophenylpyrazoloquinoxaline of sugars of maltose and isomaltose series to obtain sugar specific immuno adsorbants for isolation of anti oligosaccharide antibodies from antiserums ${ }^{64}$. 


\subsection{MUCOBROMIC ACID AND ITS REACTIONS}

Hill $^{65}$ and Simonis ${ }^{66}$ carried out investigations on mucobromic acid and found that it was a $\gamma$-aldehydic acid which can exist in tautomeric forms ie. 3,4-dihalogeno-5hydroxy crotonolactone (78) or $\alpha, \beta$-dihalogeno- $\beta$-formyl acrylic acid (79).<smiles>[X]C1=C([X])C(O)OC1=O</smiles>

78<smiles>[X]C(C=O)=C([X])C(=O)O</smiles>

79

The reactions of alcohols with mucohalic acids gave a mixture of normal and pseudo esters ${ }^{67,68}$. The normal ester (80) was assumed to be unstable and it was recently shown that normal esters are thermolabile and rearrange to the respective pseudo-esters $(82)^{69}$. Hill suggested that the ester derivatives have a cyclic or pseudo structure. Mowry and others confirmed this by examining the UV absorption spectrum $^{70,71}$. In the spectrum no absorption maximum in the $260-280 \mathrm{~nm}$ was present which indicated the absence of chromophores containing both carbonyl and carboxyl group in conjugation with a double bond. The conversion of normal ester to pseudoester was by rearrangement, ie a transannular shift of methyl cation after the formation of the cyclic salt. 
<smiles></smiles>

80<smiles>[X]C1=C([X])C(C)(OC)OC1=O</smiles>

81<smiles>[X]C1=C([X])C(OC)OC1=O</smiles>

82

Furthermore, it was shown that mucohalic acids esterified by methanol in presence of acid catalyst gave 3,4-dihalogeno-5-methoxy-5H-furan-2-one (82), while esterification with diazomethane gave normal ester $(80)^{69}$ Mucohalic acids gave Michael addition product 83 with nucleophile followed by the displacement of one of the halogens and this reaction involved a more favoured transition state stabilised by the strongly electron attracting aldehyde group ${ }^{72,73}$.<smiles>O=CC(Br)=C(Br)C(=O)O[Na]</smiles><smiles>[Y]Oc1ccccc1</smiles><smiles>CCCCCCOC(=O)C(Br)=CC(=O)O</smiles>

83

In 1954, Wasserman and Precopio showed that 3,4-dichloro-5methoxycrotonolactone (84) with aniline in cold alcohol gave 4-anilino-5methoxycrotonolactone (86) by the replacement of halogen $\beta$ to the carbonyl ${ }^{72}$. This preferential attack involved a favorable transition state $(85 \mathrm{a}, \mathrm{b})$ stabilized by electron interaction with the lactone carbonyl group. 
<smiles>CO[C@H]1OC(=O)C(Cl)=C1Cl</smiles>

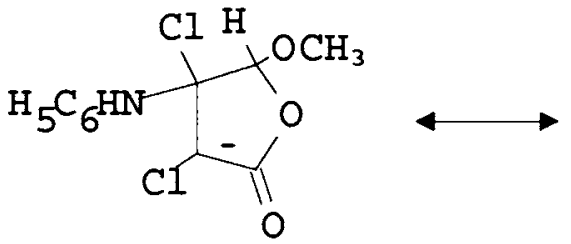

$85 \mathbf{a}$<smiles>CCCCNC1(Cl)C(Cl)=C([O-])O[C@@H]1OC</smiles>

$85 b$<smiles>CO[C@H]1OC(=O)C(Cl)=C1Nc1ccccc1</smiles>

86

Later Semonsky and co-workers reported the preferential attack at the $\alpha$ position ${ }^{74}$. They reported that 5-methyl-3,4-dibromocrotonolactone with aniline in cold ethanol solution gave 5-methyl-4-bromo-3-anilinocrotonolactone by displacement of bromine at the $\alpha$ position. They assigned the structures based on the work of Vinogradova and Semjakin $^{75}$. But the preferential attack at the $\alpha$ position was found to be in error and it was indirectly verified by Hachihama ${ }^{76}$. In order to tag the $\alpha$ and $\beta$ positions of the ester molecule, we have prepared the two chlorobromo esters 88 and 89 from the corresponding acid $87 \mathbf{a}$ and $87 \mathrm{~b}$ respectively. These esters on treatment with aniline gave two different products 90 and 91 by the replacement of the $\beta$ halogen which corresponds to the anilino derivatives derivable from the esters of mucobromic acid and mucochloric acid respectively. These transformations clearly disclose the nature of the halogen replacement reactions in the pseudo ester series of the mucohalic acids and 
also provide a basis for formulating products of uncertain structures derived in analogous replacement reactions.<smiles>O=C1OC(O)C(Cl)=C1Br</smiles>

$87 \mathbf{a}$<smiles>COC1OC(=O)C(Br)=C1Cl</smiles>

$\mathbf{8 8}$<smiles>COC1OC(=O)C(Br)=C1Nc1ccccc1</smiles>

90<smiles>COC1OC(=O)C(Br)=C1Br</smiles>

92<smiles>O=C1OC(O)[C@H](Br)C1Cl</smiles>

87b<smiles>COC1OC(=O)C(Cl)=C1[18CH2]O</smiles>

89

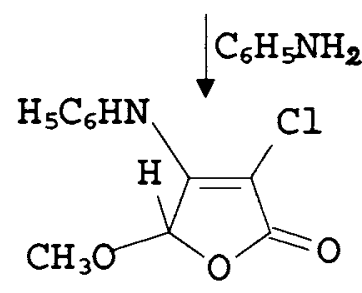

91<smiles>CO[C@H]1OC(=O)C(Cl)=C1Cl</smiles>

84 
Semonsky studied the reactions of mucochloric acid with methyl, n-propyl, n-butyl n-dodecyl and cyclohexyl amine. Reaction of 92 with methyl amine was carried out in ethanol at $-5^{\circ} \mathrm{C}$ using excess of methyl amine.

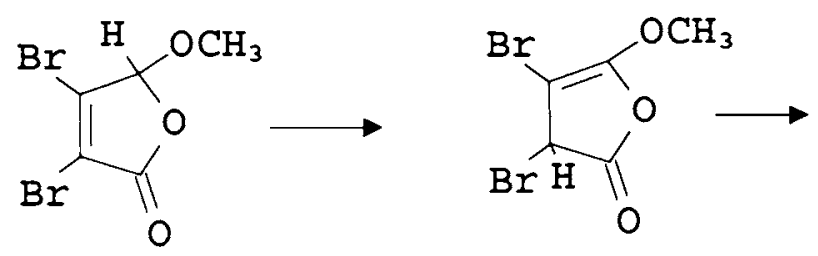

92

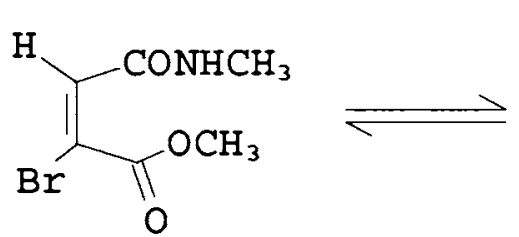

93<smiles>CO[C@H]1C=C(Br)C(=O)N1C</smiles>

94

With the exception of aniline all other amines given above lead to the formation of the corresponding substituted amide (93) or to the formation of the cyclic form, $\mathrm{N}$ substituted 5-hydroxy-5-methyl-4-bromo-crotonolactam $(94)^{74}$.

The aminolysis of the lactone 92 , the double bond was first shifted from the $\alpha, \beta$ to $\beta, \gamma$ position where the enol-lactone reacted by the opening of the lactone ring and splitting of $\mathrm{HBr}$ to give 93 , which cyclises to give structure $94^{77}$. The reactions of mucochloric acid derivatives with secondary and primary amines were investigated by Winterfeld and Nelke ${ }^{78}$. One mmole of normal ester 95 of mucohalic acid treated with 3 mmoles of pyrrolidine gave 3-chloro-4,5-dipyrrolidinocrotonolactone $96 a$ and the reaction was by initial attack on the aldehyde group giving dichlorolactone, which was 
followed by a Michael addition reaction with displacement of chlorine atom $\beta$ to the carbonyl group. But the same normal ester with primary amine in cold alcoholic solution gave a complex inseparable mixture.<smiles>COC(=O)/C(Cl)=C(/Cl)C=O</smiles>

95

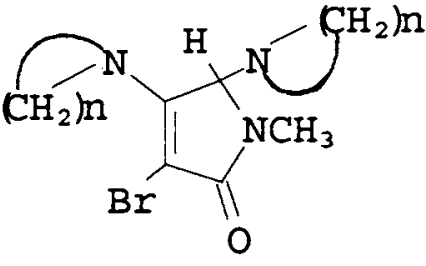

a. $\mathrm{n}=4 ; \mathrm{b} n=5$

Winterfeld prepared 3,4,5-trichlorocrotonolactone (97) in good yield by heating the acid with thionyl chloride and catalytic amount of DMF for $5 \mathrm{~h}$. Two moles of 97 with 4 moles of pyrrolidine or piperidine in a solution of dioxan at room temperature gave 3-chloro-1,2-dipyrrolidino-3-formylacrylamide (98a) and 3-chloro-1,2-dipiperidino-3formylacrylamide (98b), but no product of structure 96 was formed.<smiles>O=C1OC(Cl)C(Cl)=C1Cl</smiles>

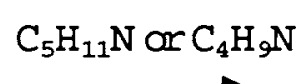

a.. $\mathrm{R}=\mathrm{C}_{4} \mathrm{H}_{9} \mathrm{~N}$, b. $\mathrm{R}=\mathrm{C}_{5} \mathrm{H}_{10} \mathrm{~N}$<smiles>[R]C(=O)/C([R])=C(/Cl)C=O</smiles> 
The product formation was by the attack of secondary amine at the carbonyl carbon to give the intermediate 99 which gave 100 . Then carbon atom $\beta$ to the aldehyde is attacked followed by the displacement of chlorine to give the compound 98.

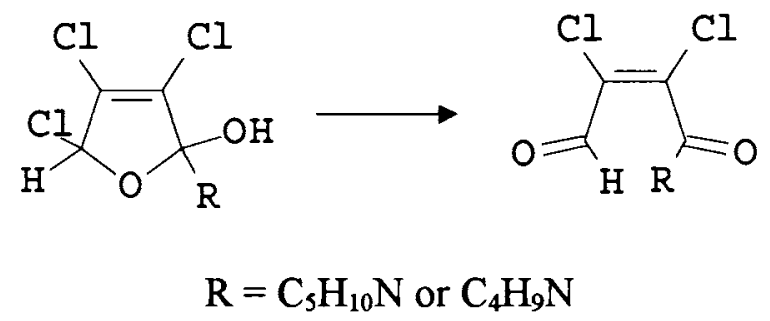

When 2 moles of 3,4,5-trichlorocrotonolactone (97) reacted with 2 moles of ethylenimine (101) the unstable 5-aziridino-3,4-dichlorocrotonolactone (102) was obtained.

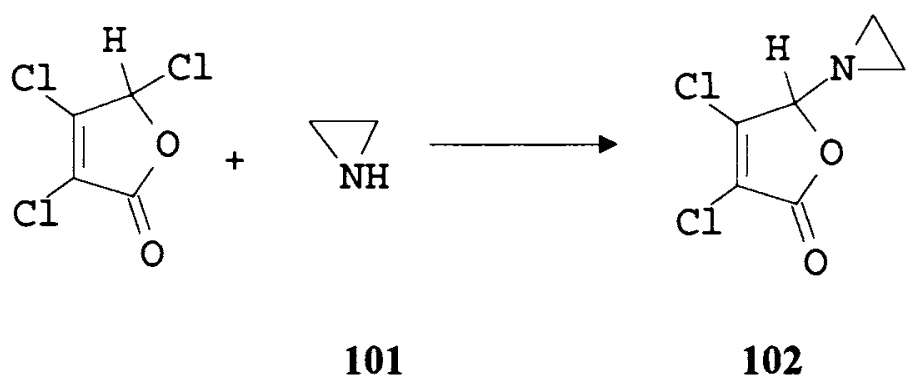

Reaction of 97 with primary amine gave stable amide acetals. One mole of 97 with 2 moles of cyclohexyl amine in absolute dioxan at room temperature gave $\mathrm{N}$ cyclohexyl-3,4-dichloro-5-hydroxycrotonolactam (103). 
<smiles>O=C1OC(Cl)C(Cl)=C1Cl</smiles><smiles>O=C1C(Cl)=C(Cl)C(O)N1C1CCCCC1</smiles>

103

Tryptylamine gave amide acetal 104 with 3,4,5-trichlorocrotonolactone.<smiles>O=C1C(Cl)=C(Cl)C(O)N1Cc1c[nH]c2ccccc12</smiles>

\section{4}

To verify the preferential position of attack of the nucleophile ie. whether the $\alpha$ or $\beta$ halogen is replaced, Jones and young carried out certain reactions with aqueous $\mathrm{CH}_{3} \mathrm{NH}_{2}$ and 4-methyl-pent-2-enoic acid lactone (105) the Michael addition product 106 was obtained .<smiles>CC1C=CC(=O)O1</smiles>

But aniline with 105 gave no product which may be due to its less basic nature ${ }^{79}$. Benzyl amine however, gave stable Michael addition product 107. 


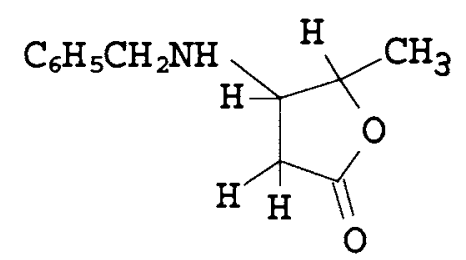

107

Under anhydrous conditions and in presence of $\mathrm{K}_{2} \mathrm{CO}_{3} 105$ reacted with 1-cysteine or $\alpha$-toluenethiol to give the Michael addition products 108 and 109 respectively. Second mole of thiol was not added.

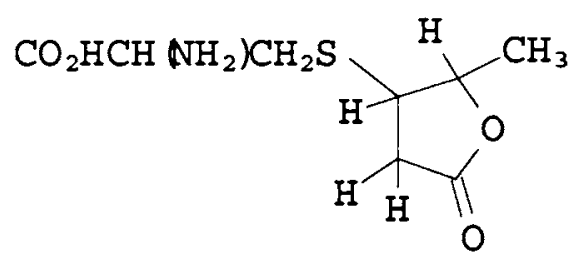

108

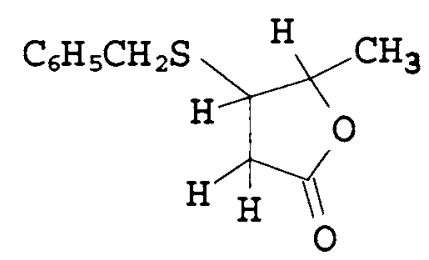

109

Synthesis of optically active 5-(1-menthyloxy)-3,4-dibromo-2-(5H)-furanone (110) was carried out by the reaction of furfural with bromine, followed by the tautomerisation and etherification with $(-)$ menthol. Compound 110 was treated with thiols and amines to give the Michael addition-elimination product $111^{80}$. 


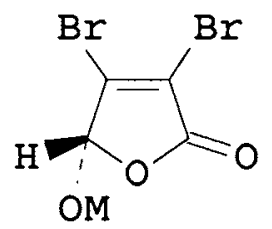

$\mathbf{M}=$ menthol

110<smiles>[R5]C1=C(Br)C(=O)O[C@@H]1[R4]</smiles>

$\mathrm{R}=\mathrm{Ph}, \mathrm{PhCH}_{2}$, furfuryl and $\mathrm{n}-\mathrm{C}_{5} \mathrm{H}_{11}$

In general mucohalic acid undergoes preferential attack at the $\alpha$ position, while the pseudoester react preferentially at the $\beta$ position. The 5-alkyldihalogenocrotonolactones, however reacted to give either the $\beta$-substituted product by the displacement of $\beta$ halogen or 5-hydroxy-5-alkyl-4-halogenocrotonolactam by opening the ring and splitting of $\mathrm{HBr}$. It was found that the reaction product of primary and secondary amines with pseudoester and 5-alkyl derivatives can be isolated, but the reaction of primary and secondary amines with normal ester of mucohalic acid gave a complex mixture.

Furanones are found to exhibit biological activities and it was found that $2(3 \mathrm{H})$ furanone has stronger activity than $2(5 \mathrm{H})$ furanones. The result was obtained by the comparison of HOMO ionisation potential ${ }^{81}$. 3-Chloro-4-(dichloromethyl)-5-hydroxy$2(5 \mathrm{H})$-furanone is one of the potent mutagen present in river and lake water ${ }^{82}$. The reaction product of unsaturated $\gamma$-lactone with primary amine were tested of their carcinogenity by Jones and Young ${ }^{83}$. 
With the exception of 3,4-dibromo-5-methylcrotonolactone, little information is available to explain the overall reactions of the various 5-substituted mucohalic acid derivatives. The reaction of 5-chloro and 5-alkoxy derivatives with primary amines have not yet been demonstrated. 


\section{RESULTS AND DISCUSSION}

\subsection{Synthesis and reactions of 2-phenylpyrazolo[3,4-b]quinoxalines}

The preparation of 1-phenylpyrazolo[3,4-b]quinoxalines or 1-phenylflavazoles (2), by the oxidative cyclisation of quinoxaline-2-carboxaldehyde phenylhydrazone (1) using phenylhydrazine in acetic acid has been reported previously ${ }^{84,85}$.

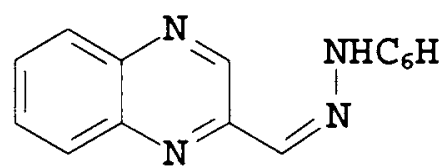

1

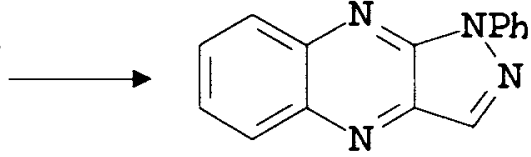

2

Conversion of hydrazone to flavazole can take place by a mechanism similar to osazone formation ${ }^{85}$. But here the net mechanism is an oxidation involving the removal of two hydrogen atoms 3 so mild oxidising agents ${ }^{86,87}$ must be capable of bringing about this conversion. Later it was reported that azobenzene converted the phenylhydrazone to 1 -phenylflavazole in $93 \%$ yield. The mechanism involves the formation of a cyclic tautomer 3 formed from 1 . 
<smiles>C=C=CCCCNc1ccccc1</smiles><smiles>CCCCCCCCCCN1c2ccccc2N=C2C=NN(c3ccccc3)C21</smiles>

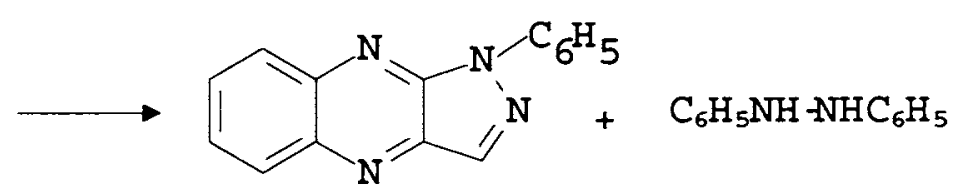

2

Another method by which oxidative cyclisation of 1 to 2 brought about was by heating the hydrazone to a temperature above its melting point in an open atmosphere. Here the oxygen in the atmosphere acts as the oxidising agent. This method was of interest because no other reagents or solvents are required for this conversion. Dahn and coworkers have reported that cyclisation of quinoxalines takes place even if groups such as $\mathrm{COOH}, \mathrm{Cl}, \mathrm{CN}, \mathrm{CONH}_{2}, \mathrm{OH}, \mathrm{COC}_{6} \mathrm{H}_{5}$ and $\mathrm{CH}_{2} \mathrm{C}_{6} \mathrm{H}_{5}$ are present at position 2 of the ring ${ }^{88,89}$. These groups get eliminated during the cyclisation process and it was specifically mentioned that groups such as $\mathrm{CH}_{3}, \mathrm{C}_{6} \mathrm{H}_{5}$ do not depart and flavazole formation does not take place if these groups are present. It was later proved that stable flavazole systems will be formed even by the elimination of phenyl 
group, if the stating material is heated to sufficiently high temperature or in presence of suitable reagents. ${ }^{89}$

We now report a method for the synthesis of 2-phenylpyrazolo[3,4-b]quinoxaline starting from ethyl 2-hydroxyquinoxaline-3-carboxylate (4). This key starting material can be prepared by the condensation of ethyl mesoxalate and $o$ phenylenediamine in $93 \%$ yield ${ }^{90}$. Ethyl mesoxalate was prepared by the oxidation of diethyl malonate with $\mathrm{SeO}_{2}$ at $120-130{ }^{\circ} \mathrm{C}$ in $32 \%$ yield ${ }^{91}$. Compound 4 was also prepared by another route starting from diethyl malonate.

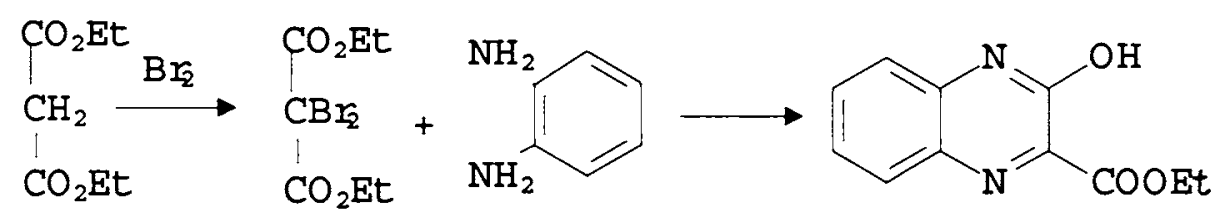

Bromination of diethyl malonate gave the dibromo derivative $5^{92}$ which on condensation with $o$-phenylenediamine gave ethyl 2-hydroxyquinoxaline-3-carboxylate (4) in $40 \%$ yield. The yield was increased to $60 \%$ by adding $\mathrm{NaHCO}_{3}$ at intervals so as to keep the medium basic. Ethyl 2-chloroquinoxaline-3-carboxylate (6) was prepared from 4 by treatment with $\mathrm{POCl}_{3}{ }^{93}$. Compound 6 with phenylhydrazine at room temperature or $100^{\circ} \mathrm{C}$ gave two major products, which were separated by column chromatography over a silica column to give ethyl 2-phenylhydrazinoquinoxaline-3- 
carboxylate (7) and 2-chloroquinoxaline-3-carbonylphenylhydrazide (8) along with trace amount of 2-phenyl-3-oxopyrazolino[3,4-b]quinoxaline (9).<smiles>CCOC(=O)c1nc2ccccc2nc1Cl</smiles>

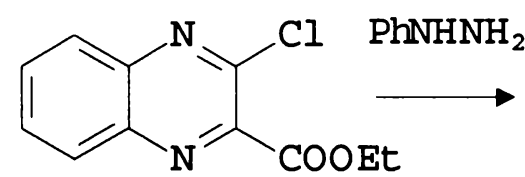<smiles>CCOC(=O)c1nc2ccccc2nc1NNc1ccccc1</smiles><smiles>O=C(Nc1ccccc1)c1nc2ccccc2nc1Cl</smiles>

8

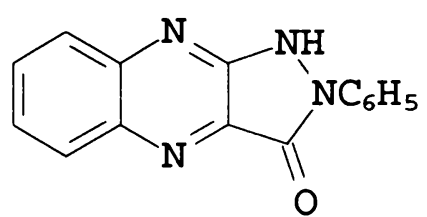

9

Ethyl 2-phenylhydrazinoquinoxaline-3-carboxylate on heating at a temperature of $190{ }^{\circ} \mathrm{C}$ for half an hour gave the same product 9 in $50 \%$ yield. IR spectrum of 9 showed carbonyl group at $1675 \mathrm{~cm}^{-1}$ and the mass spectrum showed characteristic peaks at $262(\mathrm{M}+), 234(\mathrm{M}-\mathrm{CO})$ and $77\left(\mathrm{C}_{6} \mathrm{H}_{5}\right)$. 
<smiles>CCOC(=O)c1nc2ccccc2nc1NNc1ccccc1</smiles>

7

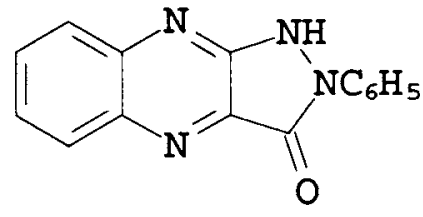

9

The colour change observed when 9 was treated with base is of particular interest. The keto form 9 is yellow in neutral or acidic medium, but with $\mathrm{NaOH}$ it changes to violet. The colour change may be due to the formation of the anion $9 \mathbf{a}$ which may exist in several resonance forms as shown below. As the colour change is pH dependent, compound 9 may be used as an acid base indicator.<smiles>C[N+]1c2nc3ccccc3nc2C(=O)[N+]1c1ccccc1</smiles>

$9 \mathbf{a}$<smiles>[13CH3]</smiles><smiles>O=c1c2nc3ccccc3[n-]c-2nn1[18OH]</smiles>

0<smiles></smiles>

3-Oxo-2-phenylpyrazolino[3,4-b]quinoxaline (9) on treatment with $\mathrm{POCl}_{3}$ gave 3-chloro-2-phenylpyrazoloquinoxaline (10) which was characterised by the following evidence. Mass spectra gave peaks at $\mathrm{m} / \mathrm{z} 280$ and 282 corresponding to the $M$ and $\mathrm{M}+2$ ions and NMR showed two sets of aromatic protons. The signal in the region $\delta$ 
7.9-8.1 corresponds to the quinoxaline protons and the multiplet in the region $\delta$ 7.47.7 correspond to the $\mathrm{N}$-phenyl protons.

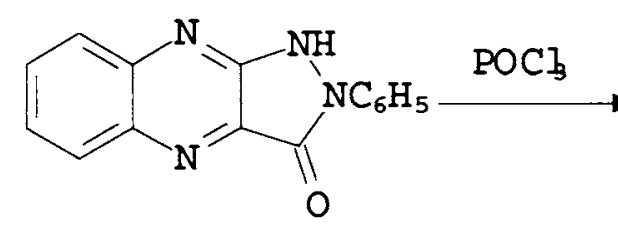

9<smiles>CCCCCCCn1nc2nc3ccccc3nc2c1Cl</smiles>

10

A number of 3-substituted 2-phenylpyrazoloquinoxalines were prepared starting from this chloro derivative. It was reported that introducing $\mathrm{OH}, \mathrm{Cl}, \mathrm{NH}_{2}$ and $\mathrm{OCH}_{3}$ groups are expected to increase the biological activity parent compound. ${ }^{54}$.

Compound 10 was heated with urea at about $130{ }^{\circ} \mathrm{C}$ for 6 hours. The product was extracted with chloroform to give 3-amino-2-phenylpyrazolo[3,4-b]quinoxaline (11). The IR of the compound gave peaks at 3146 and $3500 \mathrm{~cm}^{-1}$ corresponding to $\mathrm{NH}_{2}$ and the NMR showed in addition to the two sets of aromatic protons, one peak at $\delta 2.08$ for the $\mathrm{NH}_{2}$ group. Reaction of $\mathbf{1 0}$ with ammonia and methanol gave two products which were separated by chromatography over a silica column. The first component gave a molecular ion peak at 276 and the NMR showed a singlet at $\delta 4.7$ corresponding to the three methyl protons. The compound was identified as 3methoxy-2-phenylpyrazolo[3,4-b]quinoxaline (12) and the second component was found to be identical to 11 . 


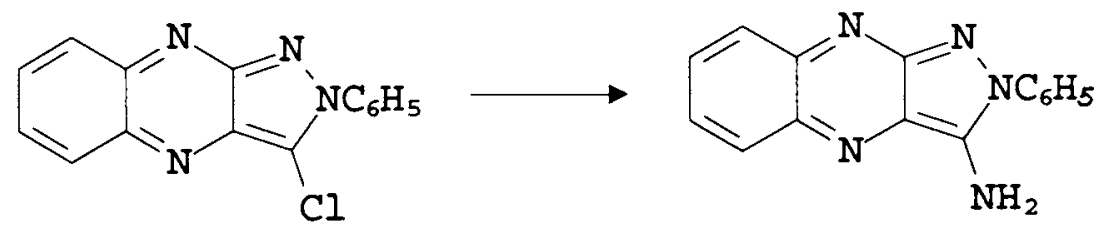

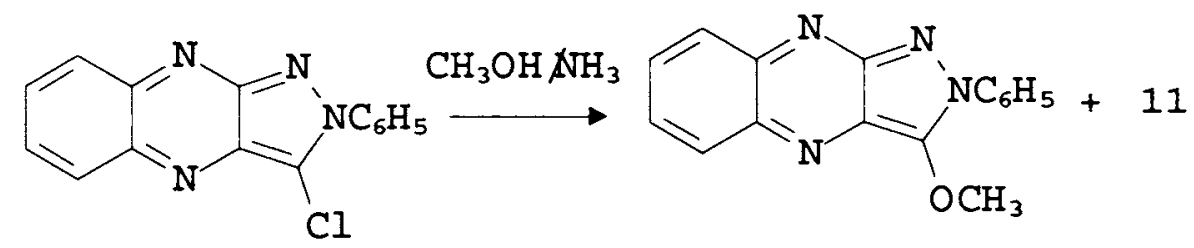

12

On refluxing 10 with absolute alcohol in the presence of potassium carbonate, the product obtained was 3-ethoxy-2-phenylpyrazolo[3,4-b]quinoxaline (13) which was confirmed by the spectral and analytical data.

10<smiles>CCCCCCCCn1nc2nc3ccccc3nc2c1OCC</smiles>

13

Substitution reaction of $\mathbf{1 0}$ with various secondary amines like morpholine, pyrrolidine, piperidine were carried out and the products were obtained in good yield. With morpholine a violet coloured solid was obtained which gave a peak at $\mathrm{m} / \mathrm{z} 331$ in its mass spectrum. The NMR showed peaks at $\delta 3.5$ and 3.75 and the two sets of 
aromatic protons and the compound was assigned to be 3-morpholino-2phenylpyrazolo[3,4-b]quinoxaline (14). With pyrrolidine and piperidine the corresponding 3-substituted products 15 and 16 respectively were obtained, which were characterised by their spectral data.<smiles>CCCN1CCCCC1c1c2nc3ccccc3nc2nn1C1CCOCC1</smiles>

14

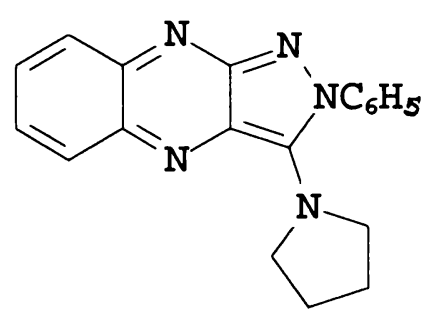

15

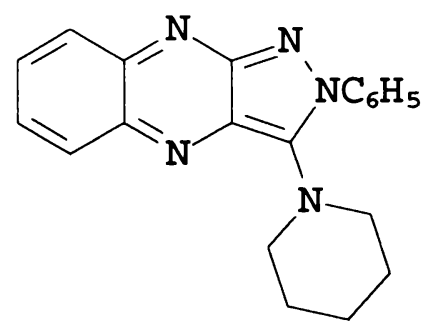

16

Reaction of 10 with sodium borohydride in isopropanol gave the parent heterocycle, 2-phenylpyrazolo[3,4-b]quinoxaline (17). Mass spectrum of this compound gave the molecular ion at m/z 246 and the NMR showed an additional aromatic proton at $\delta 9.95$. 


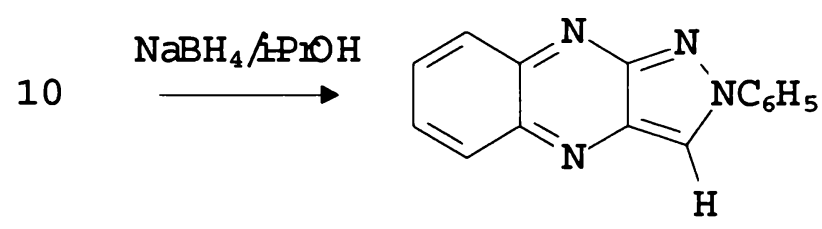

17

In addition to all these reactions the chloro compound was subjected to oxidation using $\mathrm{KMnO}_{4}$ to give 3-chloro-2-phenylpyrazolo[3,4-b]pyrazine dicarboxylic acid (18). IR of this compound shows peaks at $1778(\mathrm{C}=0)$ and $3250 \mathrm{~cm}^{-1}(\mathrm{OH})$. Pyrazolopyrazine derivatives were reported to be effective in treatment of cancer $^{94 a}$, certain bone diseases ${ }^{94 b}$ and also used in skin conditioners and $\operatorname{cosmetics~}^{94 c}$.<smiles>CCCCCCCCCn1nc2nc3ccccc3nc2c1Cl</smiles><smiles></smiles>

18 


\subsection{REACTIONS OF MUCOBROMIC ACID}

Mucobromic acid (19) was prepared from furanoic acid by treatment with bromine in $60-70 \%$ yield $^{95}$ or It may also be prepared from furfural ${ }^{96}$. Mucobromic acid in crystalline state was reported to exist as furanone derivative (19) and reacts in this form under conditions which do not favour tautomerism. It can also exist as $\alpha, \beta-$ dibromo- $\beta$-formylacrylic acid (20), which can react only under suitable conditions in the presence of catalysts ${ }^{97}$.

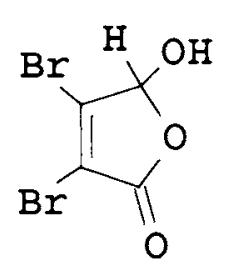

19

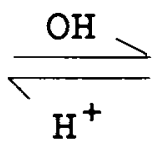

20

The UV spectrum of mucobromic acid in ethanol shows two strong absorptions, one at $242 \mathrm{~nm}$ corresponding to structure 19 and the other at $275 \mathrm{~nm}$ corresponding to structure 20 . In $0.1 \mathrm{~N}$ alkali, the absorption at $242 \mathrm{~nm}$ disappeared while a single intense peak remained at $275 \mathrm{~nm}$. This observation correlated the structure of mucobromic acid with penicillic acid which showed a maximum at $225 \mathrm{~nm}$ in aqueous solution due to the pseudo acid form 21(b) and shifted to a new maximum at $295 \mathrm{~nm}$ in $0.1 \mathrm{~N}$ alkali corresponding to the anion of $21(\mathrm{a})^{98}$. 
<smiles>C=C(C)C(=O)C(=C=O)OC</smiles>

21(a)<smiles>C=C(C)C1(O)OC(=O)C=C1OC</smiles>

21(b)

Mucobromic acid on reduction with $\mathrm{NaBH}_{4}$ in water at $0{ }^{\circ} \mathrm{C}$ gave 3,4dibromocrotonolactone (22), UV spectrum showed an absorption at $237 \mathrm{~nm}$, NMR gave a single peak at $\delta 4.92$ and MS gave a peak at 240 corresponding to the molecular ion along with the $M+2$ and $M+4$ peaks as expected ${ }^{99}$.<smiles>O=C1OC(O)C(Br)=C1Br</smiles>

19<smiles>[2H]C1OC(=O)C(Br)=C1Br</smiles>

22

Refluxing mucobromic acid with absolute ethanol in the presence of conc. $\mathrm{H}_{2} \mathrm{SO}_{4}$ for 8 hours gave the pseudo ester, 3,4-dibromo-5-ethoxycrotonolactone ${ }^{100}$ (23). The UV spectrum of this compound shows a peak at $243 \mathrm{~nm}$ characteristic of the 
pseudo form. It was found that if the spectrum is taken in alkali the lactone ring would eventually open to the acyclic form and show an absorption maximum at $275 \mathrm{~nm}$.

19

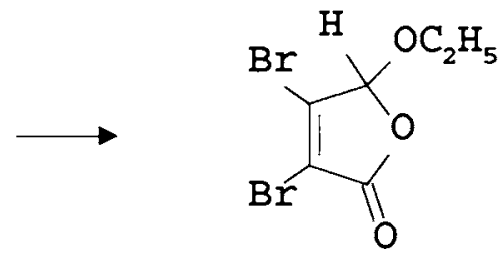

23

TABLE I

UV data of mucobromic acid and its derivatives<smiles>[X]C1=C(Br)C(=O)OC1[R]</smiles>

\begin{tabular}{|c|c|c|c|}
\hline 1 & $\mathrm{R}=\mathrm{OH}, \mathrm{X}=\mathrm{Br}$ & $\begin{array}{l}95 \% \text { ethanol } \\
0.1 \mathrm{~N} \mathrm{NaHCO} \\
0.1 \mathrm{~N} \mathrm{Na}_{2} \mathrm{CO}_{3}\end{array}$ & $\begin{array}{c}242 \mathrm{~nm}(\varepsilon 7950), 275 \mathrm{~nm}(\varepsilon 1410) \\
275 \mathrm{~nm}(\varepsilon 8350) \\
276 \mathrm{~nm}(\varepsilon 8470)\end{array}$ \\
\hline 2 & $\mathrm{R}=\mathrm{OEt}, \mathrm{X}=\mathrm{Br}$ & $\begin{array}{l}95 \% \text { ethanol } \\
0.1 \mathrm{~N} \mathrm{NaHCO} \\
0.1 \mathrm{~N} \mathrm{Na}_{2} \mathrm{CO}_{3}\end{array}$ & $\begin{array}{c}243 \mathrm{~nm}(\varepsilon 8730) \\
247 \mathrm{~nm}(\varepsilon 6790), 276 \mathrm{~nm}(\varepsilon 6410) \\
\text { 1h later: } 276 \mathrm{~nm}(\varepsilon 8330) \\
276 \mathrm{~nm}(\varepsilon 8230)\end{array}$ \\
\hline 3 & $\mathrm{R}=\mathrm{OH}, \mathrm{X}=\mathrm{N}_{3}$ & $\begin{array}{c}95 \% \text { ethanol } \\
0.1 \mathrm{~N} \mathrm{NaHCO} \\
\end{array}$ & $\begin{array}{l}274 \mathrm{~nm}(\varepsilon 18500) \\
297 \mathrm{~nm}(\varepsilon 10120)\end{array}$ \\
\hline 4 & $\mathrm{R}=\mathrm{OEt}, \mathrm{X}=\mathrm{N}_{3}$ & $\begin{array}{l}95 \% \text { ethanol } \\
0.1 \mathrm{~N} \mathrm{NaHCO} \\
\end{array}$ & $\begin{array}{l}274 \mathrm{~nm}(\varepsilon 22750) \\
277 \mathrm{~nm}(\varepsilon 19200)\end{array}$ \\
\hline
\end{tabular}

NMR data of mucobromic acid in various solvents have been reported and the NMR spectra of 3,4-dichloro-5-methoxycrotonolactone and its tautomeric acyclic 
form gave a basis for comparison ${ }^{101}$. Since UV data showed that mucobromic acid existed in the pseudo acid form, the peaks at $\delta 6.26$ in water, $\delta 5.7$ in $\mathrm{CD}_{3} \mathrm{CN}$ and $\delta$ 5.82 in acetone was attributed to the proton on furanone ring. The singlet could be due to a rapid equilibrium between the predominate pseudo-ester and the minor component, the acyclic acid. The equilibrium could be at such a rate that the two proton absorptions were detected as a singlet ${ }^{102}$. This was confirmed by taking NMR in different base concentrations.

As the equivalent amount of base added was increased, a continuos down field shift for the chemical shift of the proton from $\delta 6.95$ to 7.95 was observed. This may be due to the increasing concentration of the formyl proton $\mathrm{H}_{B}$ in rapid equilibrium with the decreasing concentration of furanone ring proton $\mathrm{H}_{\mathrm{A}}$. The acyclic structure contained a singlet due to the formyl proton at $\delta 9.35$. A spectrum of mucobromic acid was in agreement with the earlier results ${ }^{103}$.

The reaction of mucohalic acid and their esters were first studied by Hill ${ }^{104}$. Simonis in a detailed study found that with one mole of aniline, mucobromic acid was converted to the schiff base 24 and with two moles of aniline a dianilino derivative 25 was formed in which the halogen $\alpha$ to the carboxyl group had been replaced ${ }^{105}$. It is well established that reactions of mucohalic acids involving replacement of halogen takes place preferentially at the position $\alpha$ to the carboxyl group ${ }^{106,107}$. 
<smiles>CCCCCCCCCC(=O)C(Br)=C(Br)C(=O)O</smiles>

24

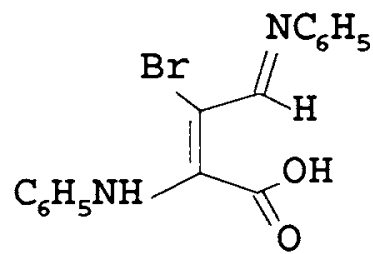

25

We have seen that in the acid series, there exist an equilibrium between the open (acid-aldehyde) form and the cyclic (hemiacetal-lactone) form. Displacement of halogen in the acid by the nucleophiles preferentially takes place in the $\alpha$ position since this involves a more favoured transition state stabilised by the strongly electron attracting aldehyde group $(26,27)$.<smiles>O=CC(=CC(Br)C(Br)Br)C(=O)O</smiles>

26

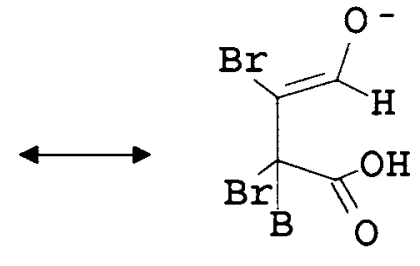

27

To study the reactivity of the system towards nucleophiles, the first series of reactions were reportedly carried out with hydrazine and its derivatives and it was found that pyridazone derivatives were the products ${ }^{108}$. 


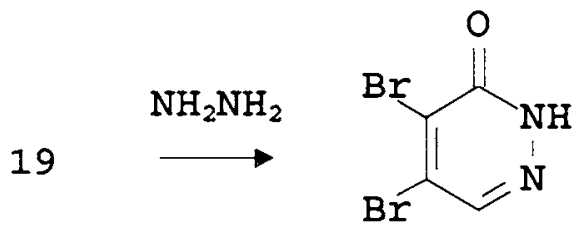

28

Treatment of mucobromic acid with hydrazine at $70{ }^{\circ} \mathrm{C}$ gave 4,5 -dibromo-6pyridazone (28) in 55\% yield, which on treatment with $\mathrm{POCl}_{3}$ gave 6-chloro-4,5dibromopyridazine (29) in 50\% yield. Proton NMR showed a singlet at $\delta 9.1$ and mass spectra gave the molecular ion peak at 270. Attempts were made to condense this compound with $o$-phenylenediamine, ethylenediamine etc. but no reaction took place as the halogens attached to the heterocyclic nucleus was apparently unreactive towards nucleophiles.

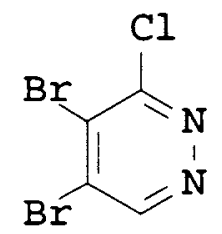

29

Refluxing mucobromic acid with urea in methanol gave a white solid, $\mathrm{m}$ p 170 ${ }^{\circ} \mathrm{C}$. This compound showed $\mathrm{IR}$ bands at 1614,1700 and $1750 \mathrm{~cm}^{-1}$ corresponding to $\mathrm{C}=\mathrm{C}$, amide carbonyl and lactone carbonyl respectively along with the bands at 3250 , 
3372 , and $3470 \mathrm{~cm}^{-1}$ corresponding to $\mathrm{NH}_{2}$ and $\mathrm{OH} .{ }^{1} \mathrm{H}$ NMR showed three set of protons and in mass spectra the molecular ion was apparently absent but the peak corresponding to $\mathrm{M}-\mathrm{CONH}_{2}$ was observed at $254 \mathrm{~nm}$. Spectral data along with the elemental analysis showed the structure as 1-carboxamido-3,4-dibromo-5-hydroxy-3pyrrolin-2-one (30).

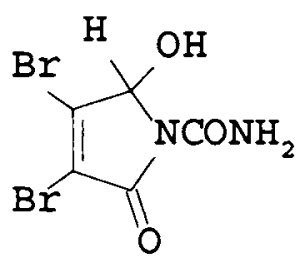

30

In order to study the reactivity of the unsaturated lactones to nucleophilic addition across the unsaturated double bond the first reaction was carried out with iodine azide ${ }^{109}$. Fowler and collaborators ${ }^{110}$ have shown that iodine azide can be readily prepared in situ by the reaction of $\mathrm{NaN}_{3}$ and iodine monochloride in acetonitrile and that would add not only in good yield, but in a highly specific manner to a variety of unsaturated systems. The reaction gave a solid product $\mathrm{m} \mathrm{p} 77-78{ }^{\circ} \mathrm{C}$ having an IR band at $2120 \mathrm{~cm}^{-1}$. The expected product was 2-azido-3-formyl-3-iodo-1,3dibromopropanoic acid, but the chemical analysis and IR spect rum indicated the presence of azide group with no iodine present and a position of unsaturation.

Reaction of mucobromic acid and $\mathrm{NaN}_{3}$ in acetonitrile at room temperature, also gave a the same solid product with $\mathrm{m} \mathrm{p} 77^{\circ} \mathrm{C}$. It showed unsaturation at 1625 
$\mathrm{cm}^{-1}$ and lactone carbonyl at $1760 \mathrm{~cm}^{-1}$ along with a strong azide band at $2120 \mathrm{~cm}^{-1}$, indicating that azide substitution has taken place in the molecule. Two mechanistic pathway are possible for this reaction, attack of the azide on the acyclic form of mucobromic acid (20) giving rise to an intermediate (31), which consequently loses bromine at the same position to give 32 .<smiles>O=CC(=O)C(Br)=C(Br)Br</smiles>

20<smiles>C=CC(=O)C(O)=CC(=O)O</smiles>

$31 \mathbf{a}$<smiles>N#C/C(=C/C=O)C(=O)O</smiles>

$31 b$<smiles>C=C=C1C(=N)C(=O)OC1(Br)Br</smiles>

32

The alternative pathway was the nucleophilic attack on pseudo-acid form (19) at the $\beta$ positon giving intermediate (33) which can give away bromine at the $\beta$-carbon to give 34 .<smiles>CC(C)C1OC(=O)C(Br)=C1Br</smiles><smiles>COC1=C(Br)C([18Br])C(O)OC1[18Br]</smiles>

33<smiles>[R18]C1=C([Y3])C(O)(O)OC1=O</smiles>

34 
To determine the position of attack of the azide, the reaction was repeated with the ester 23. The ester could give only one product obtained by the attack at the $\beta$ position $^{97}$. 5-Ethoxy-3,4-dibromocrotonolactone (23) with sodium azide gave a solid with low melting point and characteristic azide absorption at $2120 \mathrm{~cm}^{-1}$ in addition to unsaturation and carbonyl peaks. The product was identified as 4-azido-3-bromo-5ethoxycrotonolactone (36) by the following method.<smiles>CCOC1OC(=O)C(Br)=C1Br</smiles>

19

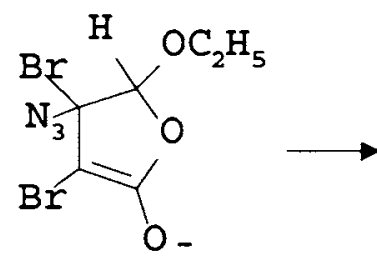

The UV spectra of 36 showed an intense absorption at $274 \mathrm{~nm}$. The azide group in $\beta$-position could extend the conjugation and would shift from $243 \mathrm{~nm}$ to 274 nm $(37 a, b)$.<smiles>[N-]=[N+]=NC1=C(Br)C(=O)OC1O</smiles>

$37 \mathbf{a}$
36<smiles>CCOC1OC(=O)C(C(=O)Br)=C1[N]</smiles>

6 
due to extended conjugation which is present in $\mathbf{3 4}$ and not present in $\mathbf{3 2}$. Thus the reaction of mucobromic acid and sodium azide in acetonitrile solvent, the halogen $\beta$ to the carbonyl group is replaced. This is due to the fact that in acetonitrile the acid predominantly exist in the furanone form which is verified by the NMR data, and hence $\beta$ attack is more favourable.

As another method for confirming the position of azide group we have prepared the azide of 3,4-dibromocrotonolactone (22) in the same manner and the product obtained was needle shaped solid of m. p. $60{ }^{\circ} \mathrm{C}$. The mass spectrum of the compound showed peaks corresponding to $\mathrm{M}+$ and $\mathrm{M}+2$ at 203 and 205 respectively. NMR shows singlet at $\delta 5.19$ corresponding to two hydrogens. UV showed a $\lambda_{\max }$ at $268 \mathrm{~nm}$ which again confirms that the azide group is on the carbon $\beta$ to the carbonyl and the red shift is due to the extended conjugation. IR gave the strong azide absorption at $2131 \mathrm{~cm}^{-1}$ and the product was identified as 4-azido-3bromocrotonolactone (38).<smiles>O=C1OC(Br)C(Br)=C1Br</smiles>

22

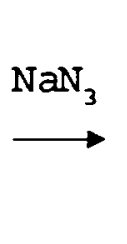<smiles>[N]C1=C(Br)C(=O)OC1</smiles>

38 
Mucobromic acid and benzoyl chloride on refluxing gave a solid with $m$. $p$.

$155{ }^{\circ} \mathrm{C}$. The procedure used for the synthesis of pseudo esters were adopted from Mowry and David ${ }^{111}$ who synthesised pseudoesters of mucochloric acid. The pseudoester obtained from mucobromic acid and benzoyl chloride was characterised by spectral and analytical methods and it was shown as 3,4-dibromo-5benzoyloxycrotonolactone (39).

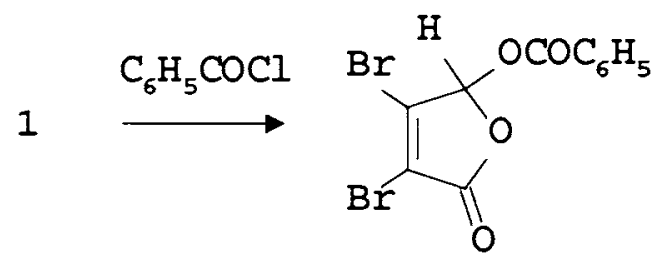

39

The reaction of compound 39 with sodium azide did not give the expected Michael addition product, but gave a sweet smelling clear liquid which was identified as benzoyl azide, by comparing the spectral data with an authentic compound prepared from sodium azide and benzoyl chloride ${ }^{112}$.

A mixture of sodium azide and benzoyloxy derivative (39) was refluxed in the same solvent acetonitrile. The resulting dark solution was diluted with water and extracted with ether to give a light yellow solid with an IR absorption at 3140,3225 $\mathrm{cm}^{-1}$ characteristic of primary amines, along with two carbonyl absorptions at 1775 and $1730 \mathrm{~cm}^{-1}$, corresponding to lactone and ester carbonyl groups respectively. Elemental 
analysis and NMR data helped to identify the product as 4-amino-3-bromo-5benzoyloxycrotonolactone (40) in $46 \%$ yield. Although the product isolated at room temperature was benzoyl azide but on refluxing, a bromine atom was displaced by the azide group which was converted to the amine probably through a nitrene intermediate.

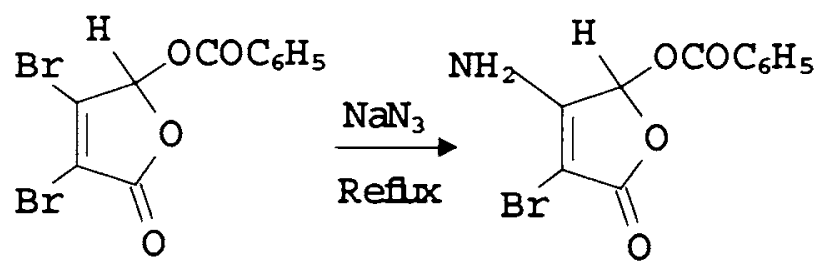

40

It was previously reported that vinyl azides were photolysed to azirines and reduced to aziridines using $\mathrm{LiAlH}_{4}{ }^{113,114}$. It was expected that the photolytic or thermal reactions of azides of mucobromic acid derivatives should give an aziridino- $\gamma-$ lactone 41 a compound of pharmaceutical interest, since it had both physiologically active lactone and the biologically active aziridine moieties in the basic skeleton. Photolysis and thermal reactions of these azides were carried out but no product could be isolated.

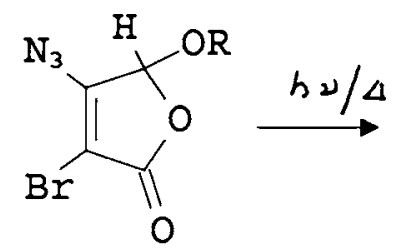

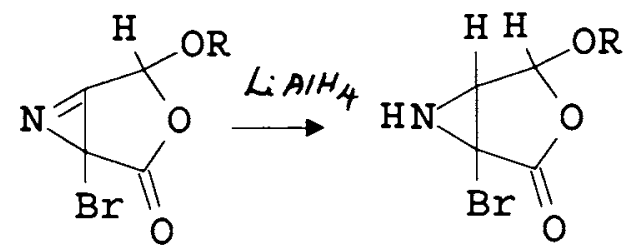


Reaction of mucobromic acid with o-phenylenediamine was carried out in alcohol at low temperature. The reaction gave a number of products which were difficult to be separated. To mucobromic acid in ether, a very dilute solution of $a$ phenylenediamine in ether was added with stirring. A white solid of $\mathrm{m} \mathrm{p} 45{ }^{\circ} \mathrm{C}$ was isolated from the reaction mixture which decomposed to give a blue coloured solid very soon. So the characterisation of the product was not possible. The reaction was repeated by changing the solvents to $\mathrm{THF}, \mathrm{DMF}$, water etc., but in all cases a mixture of inseparable products were obtained.

Following the work of Winterfeld, who used a derivative 3,4,5trichlorocrotonolactone (42) for reactions with primary amine ${ }^{115}$, the chloro derivative was prepared from mucobromic acid by heating with thionyl chloride with a catalytic amount of DMF for 5 hours at $50{ }^{\circ} \mathrm{C}$. Excess thionyl chloride was removed and the residue crystallised from alcohol to give $52 \%$ of 5 -chloro-3,4-dibromocrotonolactone (43). Compound 43 gave UV absorption at $247 \mathrm{~nm}$, IR absorption at $1780 \mathrm{~cm}^{-1}$ of the carbonyl and a singlet at $\delta 6.6$ in the ${ }^{1} \mathrm{H}$ NMR spectrum.<smiles>O=C1OC(Cl)C(Cl)=C1Cl</smiles> 

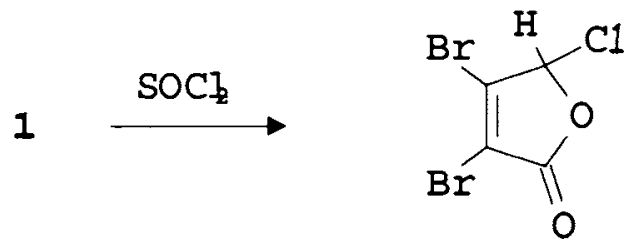

43

\subsection{REACTIONS OF 5-CHLORO-3,4-DIBROMOCROTONOLACTONE}

It was established that in case of pseudoesters the attack of nucleophiles take place at the $\beta$ position $^{97}$, since displacement at this site should involve a more stable transition state stabilized by the electronic interactions with the lactone carbonyl group (44a, b) and no comparable stabilisation arises from attack at the $\alpha$ position.

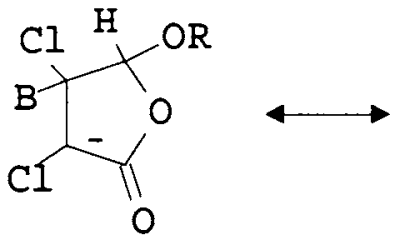

$44 \mathbf{a}$

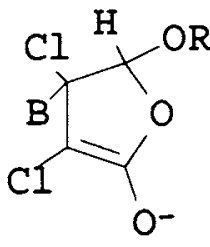

$44 b$

Nelke and Winterfeld had reported that the reactions of 42 with 2 moles of cyclohexylamine gave 1-cyclohexyl-3,4-dichloro-5-hydroxy-3-pyrrolin-2-one (45) in $64 \%$ yield, $\mathrm{m} \mathrm{p} 156{ }^{\circ} \mathrm{C}$. The compound showed UV absorption at $210 \mathrm{~nm}$ and $\mathrm{IR}$ showed both carbonyl and unsaturated functions at 1705 and $1640 \mathrm{~cm}^{-1}$ respectively. 


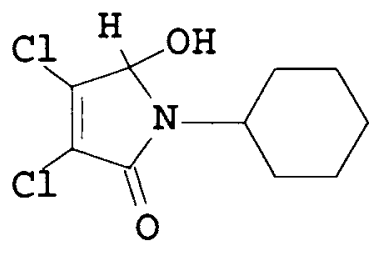

45

Reaction of 5-chloro-3,4-dibromocrotonolactone (43) with methylamine in the ratio 1:2 gave a white solid crystallised from chloroform having a melting point 158 ${ }^{0} \mathrm{C}$. IR indicated a hydroxyl group at $3280 \mathrm{~cm}^{-1}$ and a carbonyl at $1670 \mathrm{~cm}^{-1}$ along with a position of unsaturation at $1640 \mathrm{~cm}^{-1}$. The UV spectrum showed a maximum at 223 nm, while ${ }^{1} \mathrm{H}$ NMR showed methyl group in addition to the doublets at $\delta 5.24$ and $\delta$ 6.76. As Winterfeld had reported the two doublets at $\delta 5.45$ and $\delta 6.87$ were for the C-5 and hydroxyl protons respectively for 1-cyclohexyl-3,4-dichloro-5-hydroxy-3pyrrolin-2-one (45), a similar reaction can be assumed and the product was assigned the structure 3,4-dibromo-5-hydroxy-1-methyl-3-pyrrolin-2-one (46), which was also supported by elemental analysis.<smiles>O=C1OC(Cl)C(Br)=C1Br</smiles><smiles>CNCCN</smiles><smiles>CN1C(=O)C(Br)=C(Br)C1O</smiles> 
A similar result was also obtained when 1 mole of 5-chlorocompound 43 was stirred with 3-aminopropanol in dioxan for 15 hours. The product was identified as 3,4-dibromo-1-(3-hydroxypropyl)-5-hydroxy-3-pyrroline-2-one (47), which gave UV absorption characteristic of $\gamma$-lactams at $224 \mathrm{~nm}$ in addition to the doublets at $\delta 5.48$ and $\delta 6.98$.

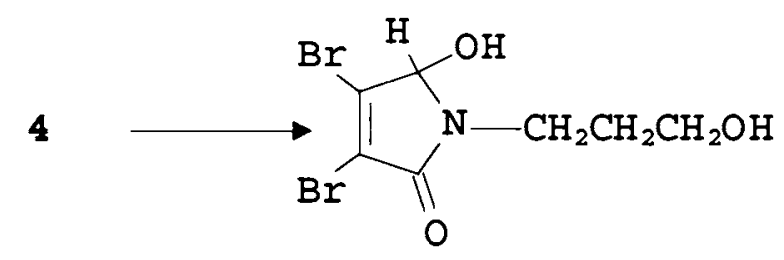

47

With 2 moles of ethanolamine, the 5-chloro derivative 43 gave the corresponding N-substituted 3,4-dibromo-5-hydroxy-3-pyrrolin-2-one (48). Analysis of the mass spectrum showed the molecular ion peak at 299 along with $M+2$ and $M+4$ peaks. IR showed unsaturation along with lactam carbonyl at $1650 \mathrm{~cm}^{-1}$ and two $\mathrm{OH}$ bands at 3366 and $3128 \mathrm{~cm}^{-1}$.

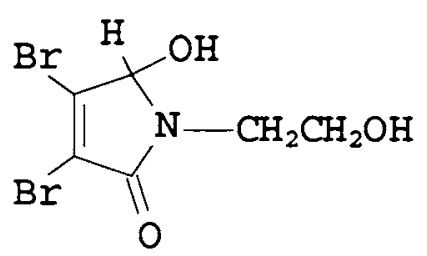


5-Chloro-3,4-dibromocrotonolactone (43) on treatment with two moles of hydrazine gave 4,5-dibromo-6-pyridazone (28), $\mathrm{m} \mathrm{p} 218^{\circ} \mathrm{C}$ which was formed by the opening of the lactone ring.

Treatment of 43 with aniline in absolute ethanol at $0{ }^{\circ} \mathrm{C}$ gave a product which showed IR band at $1758 \mathrm{~cm}^{-1}$ corresponding to the lactone carbonyl along with unsaturation at 1590 and the NH band at $3198 \mathrm{~cm}^{-1}$, NMR showed a multiplet in the region $\delta$ 7.1-7.8 and a singlet at $\delta 6.8$. The compound was identified as 4-anilino-3bromo-5-chlorocrotonolactone (49).

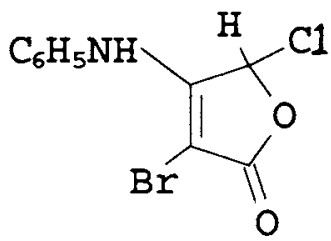

49

Thus with the exception of aniline, all other reactions lead to the formation of 3-pyrroline-2-one derivatives. A probable mechanistic pathway for the reaction is given below. The nucleophile is attacking the carbonyl carbon and results in the opening of the ring followed by the ring closure with the elimination of chloride ion. 

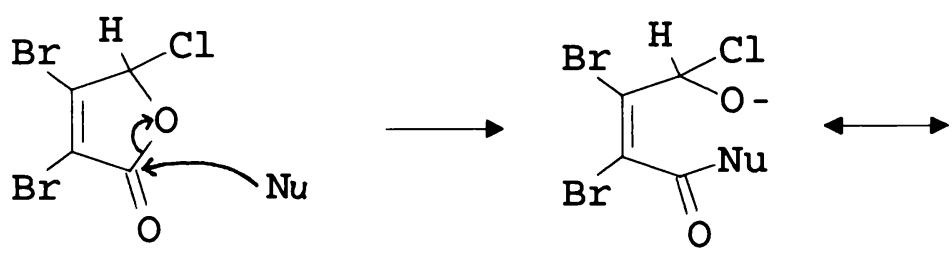

50
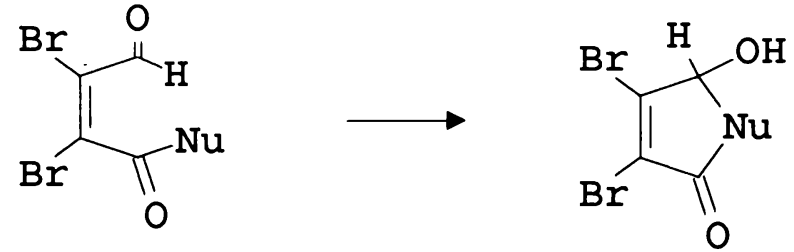

51

\subsection{REACTIONS OF 5-BENZOYLOXY-3,4-DIBROMOCROTONO-}

\section{LACTONE}

After observing the general trend of reaction for the pseudo acid chloride derivative with nucleophile, the same technique and procedure were adopted to a series of reactions with pseudo ester benzoates 39 .

It is known that good leaving groups enhance the rate of ester hydrolysis and poor leaving groups retard the rate $e^{116,117}$. It was expected that reactions of this 
pseudoester involving the attack at carbonyl carbon resulting in the formation of pyrroline-2-one should be more facile since benzoate is a good leaving group.

Treatment of 5-benzoyloxy-3,4-dibromocrotonolactone (39) with ammonia in THF gave a white solid which was identified as ammonium benzoate. From THF filtrate, a light yellow solid was isolated which gave intense absorption at $222 \mathrm{~nm}$, indicating the $\alpha, \beta$-unsaturated $\gamma$-lactam chromophore. It gave a carbonyl absorption at $1750 \mathrm{~cm}^{-1}$ in the IR spectrum. The solid was identified as 3,4-dibromo-5-hydroxy-3pyrroline-2-one $e^{118}(52)$.<smiles>CCOC1OC(=O)C(Br)=C1Br</smiles>

Reaction of methyl amine with 39 in THF under stirring for 15 hours an yellow solution was obtained which on dilution with water followed by extraction with methylene chloride yielded white crystals $\mathrm{m} p 156-158{ }^{\circ} \mathrm{C}$. From the identical spectral data as in the case of 52, the compound was identified as 3,4-dibromo-5-hydroxy-1methyl-3-pyrroline-2-one (46) which was formed in $49 \%$ yield. 


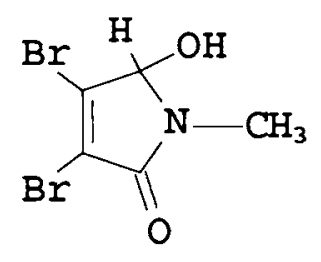

46

The benzoyloxy derivative 39 when stirred with 3-aminopropanol in THF the known 3,4-dibromo-1-(3-hydroxypropyl)-5-hydroxy-3-pyrrolin-2-one (47) was formed in $42 \%$ yield.

When two moles of aniline were added to one mole of benzoyloxy compound (39) in hot ethanol and the yellow solution was cooled for 24 hours at $5{ }^{\circ} \mathrm{C}$, 4-anilino3-bromo-5-benzoyloxycrotonolactone (53) was obtained in $95 \%$ yield. It showed absorption at $232 \mathrm{~nm}$ in its UV spectrum indicating the presence of an unsaturated lactone chromophore.

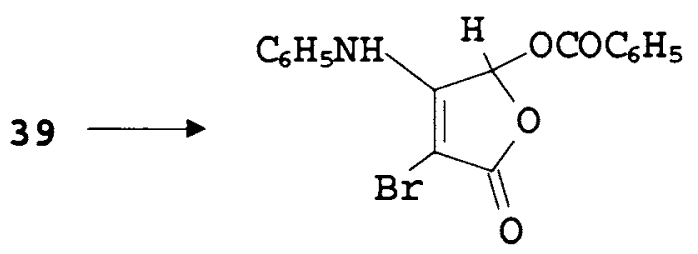

53

The same reaction was repeated with THF as the solvent. After removal of the precipitated aniline benzoate, the mother liquor was concentrated to give a solid which 
gave UV absorption at $227 \mathrm{~nm}$ characteristic of unsaturated lactam chromophore . IR showed carbonyl and unsaturation at 1650 and $1615 \mathrm{~cm}^{-1}$ respectively The compound was identified as 3,4-dibromo-5-hydroxy-1-phenyl-3-pyrrolin-2-one (54).

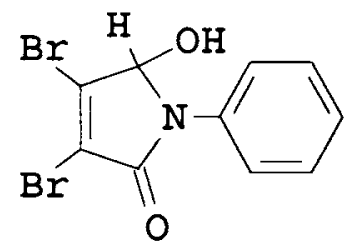

54

The mechanism for the formation of pyrroline-2-one from benzoyloxy derivative will be similar to that proposed for the reactions of 5-chloro-3,4dibromocrotonolactone.

\subsection{REACTIONS OF 3,4-DIBROMOCROTONOLACTONE}

So far we have described the reactions of two pseudo esters and in general they give two types of reactions with nucleophiles (1) replacing the bromine at the $\beta$ position of the carbonyl group and (2) opening of the lactone ring resulting in the formation of 3-pyrrolin-2-one derivatives. 3,4-Dibromocrotonolactone (22) is another derivative of mucobromic acid obtained by the reduction of the acid using $\mathrm{NaBH}_{4}$. The same product was also obtained by the reduction of 5-ethoxy-3,4dibromocrotonolactone with sodium borohydride. 
<smiles>CCOC1OC(=O)C(Br)=C1Br</smiles>

23

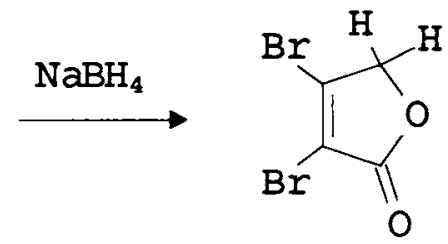

22

Reaction of aniline and 22 in absolute alcohol gave an off white solid, $\mathrm{m} \mathrm{p}$ $81{ }^{\circ} \mathrm{C}$ in $65 \%$ yield. IR of the compound gave bands corresponding to the lactone carbonyl at $1790 \mathrm{~cm}^{-1}$, unsaturation at $1600 \mathrm{~cm}^{-1}$. The mass spectrum showed the molecular ion at 253 along with an $M+2$ peak. Elemental analysis and NMR confirms the structure as 4-anilino-3-bromocrotonolactone (55).<smiles>O=C1OC(CBr)C(Br)=C1Br</smiles>

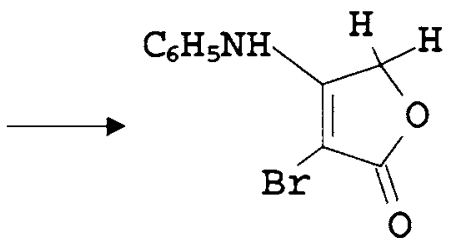

55

Secondary amines like morpholine, pyrrolidine and piperidine were reacted with the lactone and the products were isolated. But the products obtained from morpholine and piperidine decomposed on keeping. The product obtained with pyrrolidine gave a molecular ion peak at 233 along with an $\mathrm{M}+2$ peak. IR shows unsaturation and the lactone carbonyl group. Additional information from NMR and 
elemental analysis confirmed the structure as 4-pyrrolidino-3-bromocrotonolactone (56).

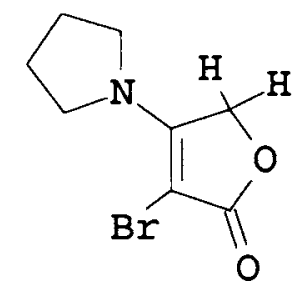

56

With $o$-phenylenediamine in DMF lactone (22) gave an off white solid of melting point $145^{\circ} \mathrm{C}$. IR showed characteristic peaks corresponding to $\mathrm{NH}_{2}, \mathrm{NH}$, carbonyl and unsaturation. NMR shows four set of protons, in the region $\delta 6.45-7.1$ gives a multiplet of the aromatic protons, $\delta 5.2$ gives a broad $\mathrm{NH}_{2}$ and at $\delta 4.67$ the $\mathrm{CH}_{2}$ protons and along with these at $\delta 9$ we are having the singlet for the $\mathrm{NH}$ proton. Mass spectra gives $M+$ and $M+2$ peaks at 268 and 270 of equal intensity.

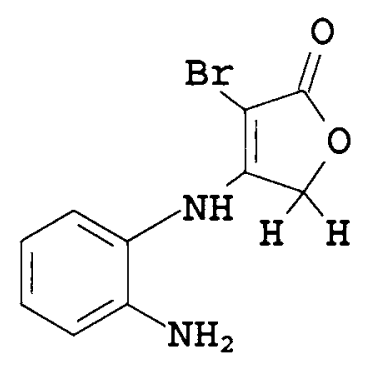


From these evidences and also supported by elemental analysis the compound was identified as 4-(2-amino)anilino-3-bromocrotonolactone (57). The compound contains a free $\mathrm{NH}_{2}$ groups and a bromine, so attempts were made to make an internal cyclisation which can give rise to a quinoxaline derivative. Some of the methods used for cyclisation was refluxing in DMF, keeping the reaction mixture in UV radiation and refluxing the reactants in methanol in presence of pyridine. In all these attempts the compound 57 remained unchanged. Compound 57 was kept under UV radiation in solvents like methanol, tertiary butanol etc. but no change was observed.

Reaction of lactone with $\mathrm{NaN}_{3}$ gave 4-azido-3-bromocrotonolactone which was given earlier. On refluxing the same mixture for 3 hours gave a light yellow solid which gave IR bands characteristic of $\mathrm{NH}_{2}$ at 3300 and $3456 \mathrm{~cm}^{-1}$, unsaturation at $1593 \mathrm{~cm}^{-1}$ and lactone carbonyl at $1750 \mathrm{~cm}^{-1}$. Mass spectrum showed molecular ion peak at 177 and $M+2$ peak at 179 . NMR gave two sets of protons and the compound was identified as 4-amino-3-bromocrotonolactone (58).

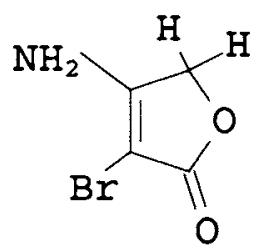


3,4-Dibromocrotonolactone (22) refluxed with $o$-aminophenol in methanol in presence of pyridine gave a solid and the yield was $45 \%$ and the analytical and spectral data confirmed the product as 3-bromo-4-(2-hydroxy)anilinocrotonolactone (59).

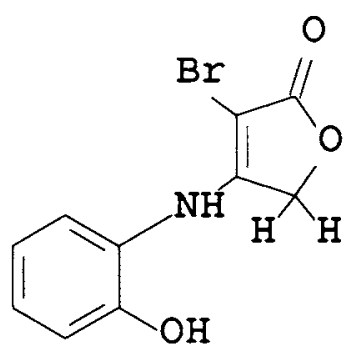

59

Finally the lactone was treated with hydrazine hydrate in methanol and gave a solid, $\mathrm{m} \mathrm{p} 150{ }^{\circ} \mathrm{C}$ in $50 \%$ yield. NMR showed 2 set of protons at $\delta 5.29$ and $\delta 8.5$ in the ratio 2:1. Mass spectrum did not give the molecular ion peak, but the peak corresponding to $\mathrm{M}-\mathrm{H}_{2} \mathrm{O}$ was present as the base peak at 334. NMR and elemental analysis confirmed the structure as 4-bis(3-bromocrotonolactonyl) hydrazine (60).

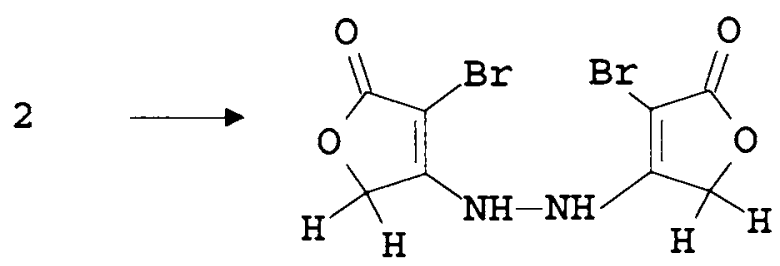


In the above reactions we come across only one type of product, which is formed by the replacement of the halogen in the $\beta$ position and the possible mechanism is given below.
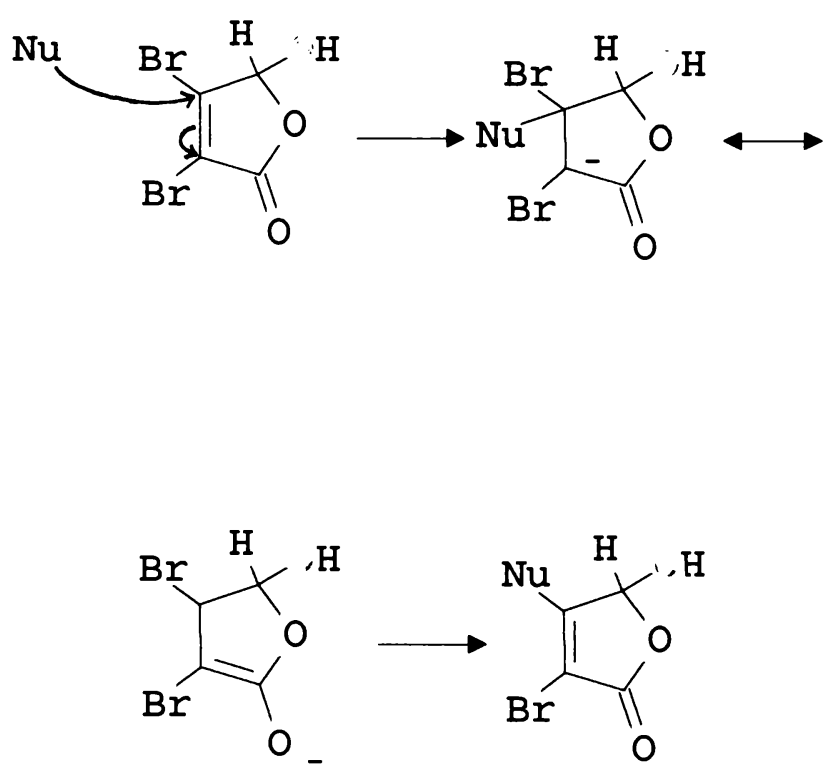


\subsection{DISCUSSION OF THE SPECTRAL DATA}

The $\lambda \max$ values of 3,4-dibromo-5-benzoyloxycrotonolactone (39) and 5ethoxy derivative 23 were calculated from simple Woodward rules for systems containing the $\alpha, \beta$-unsaturated ketone chromophore ${ }^{119,120}$. The calculated absorption was at $240 \mathrm{~nm}$ and the observed absorption were at $240 \mathrm{~nm}$ and $243 \mathrm{~nm}$ respectively.

The IR, UV, and NMR data of lactams and lactones are presented in Table II and III. It was clear that presence of groups which could extend conjugation will shift the $\lambda \max$ to higher wave length. In the case of azides, the azide group at the $\beta$ position would extend conjugation of the lactone, shifting the $\lambda \max$ to $274 \mathrm{~nm}$ from $232 \mathrm{~nm}$.

In the case of unsaturated lactams the calculated $\lambda \max$ was $222 \mathrm{~nm}$. The experimental values are showing absorption between $218-228 \mathrm{~nm}$. So by having the UV data one can easily predict whether the product is having a lactone ring or lactam ring without going into detailed analysis.

IR spectra for the carbonyl groups in $\alpha, \beta$-unsaturated- $\gamma$-lactone were expected to be between $1740-1790 \mathrm{~cm}^{-1}$, while cyclic lactams were expected to absorb around $1700 \mathrm{~cm}^{-1} 121$. The experimental values obtained in the case of unsaturated lactones 
show bands between $1740-1800 \mathrm{~cm}^{-1}$ and unsaturated lactams between 1625 and $1700 \mathrm{~cm}^{-1}$. Furthermore, in the lactam there will be additional band between 3200 and $3400 \mathrm{~cm}^{-1}$ showing the presence of $\mathrm{OH}$ group.

Mass spectra and a detailed fragmentation pattern of 4-anilino-3bromocrotonolactone, 4-azido-3-bromocrotonolactone and 3,4-dibromo-5-hydroxy-3pyrrolin-2-one are given.

\section{TABLE II}

UV, IR and NMR data of 3,4-Dibromo-5-hydroxy-3-pyrrolin-2-one

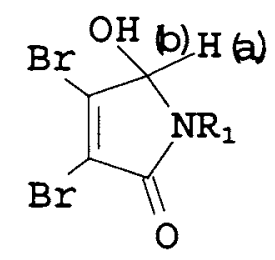

\begin{tabular}{|c|c|c|c|c|c|c|}
\hline $\mathrm{R}_{1}$ & $\mathrm{Ha}$ & $\mathrm{Hb}$ & $\lambda \max (\varepsilon)$ & $\mathrm{C}=\mathrm{C}$ & $\mathrm{C}=\mathrm{O}$ & $\mathrm{OH}$ \\
\hline $\mathrm{CH}_{3}$ & 5.24 & 7.30 & $223(11500)$ & 1640 & 1670 & 3280 \\
\hline$\left(\mathrm{CH}_{2}\right)_{3} \mathrm{OH}$ & 5.48 & 6.98 & $224(10300)$ & 1600 & 1680 & 3150 \\
& & & & & & 3360 \\
\hline$\left(\mathrm{CH}_{2}\right)_{2} \mathrm{OH}$ & 5.48 & 6.97 & & 1610 & 1650 & 3128 \\
& & & & & & 3326 \\
\hline $\mathrm{H}$ & & & $222(10650)$ & 1600 & 1700 & 3380 \\
\hline $\mathrm{C}_{6} \mathrm{H}_{5}$ & & & $228(12430)$ & 1615 & 1680 & 3440 \\
\hline
\end{tabular}


TABLE III

UV, IR and NMR data of substituted crotonolactones<smiles>[R]C1=C(Br)C(=O)OC1([R])[2H]</smiles>

\begin{tabular}{|c|c|c|c|c|c|}
\hline R1 & R2 & $\mathrm{H}$ & $\lambda \max (\varepsilon)$ & $\mathrm{C}=\mathrm{O}$ & $\mathrm{C}=\mathrm{C}$ \\
\hline $\mathrm{Br}$ & $-\mathrm{OC}_{2} \mathrm{H}_{5}$ & 5.82 & $243(8700)$ & 1790 & 1610 \\
\hline $\mathrm{Br}$ & $-\mathrm{OCOC}_{6} \mathrm{H}_{5}$ & 7.28 & $\begin{array}{c}240(20170) \\
279(1300)\end{array}$ & 1800 & 1610 \\
\hline $\mathrm{NHC}_{6} \mathrm{H}_{5}$ & $-\mathrm{OCOC}_{6} \mathrm{H}_{5}$ & 7.82 & $\begin{array}{l}232(16800) \\
290(19000)\end{array}$ & 1765 & 1580 \\
\hline $\mathrm{Br}$ & $\mathrm{Cl}$ & 6.66 & $247(9750)$ & 1780 & 1600 \\
\hline $\mathrm{N}_{3}$ & $-\mathrm{OC}_{2} \mathrm{H}_{5}$ & 5.88 & $274(22275)$ & 1790 & 1640 \\
\hline $\mathrm{N}_{3}$ & $\mathrm{OH}$ & 4.53 & $274(18500)$ & 1760 & 1625 \\
\hline $\mathrm{Br}$ & $\mathrm{H}$ & 4.92 & $237(7000)$ & 1790 & 1610 \\
\hline $\mathrm{N}_{3}$ & $\bar{H}$ & 5.19 & $268(11500)$ & 1750 & 1625 \\
\hline $\mathrm{NH}_{2}$ & $\mathrm{H}$ & 4.73 & $258(19560)$ & 1750 & 1593 \\
\hline $\mathrm{NHC}_{6} \mathrm{H}_{5}$ & $\mathrm{H}$ & 5.12 & $284(29000)$ & 1790 & 1600 \\
\hline $\mathrm{C}_{4} \mathrm{H}_{8} \mathrm{~N}$ & $\mathrm{H}$ & 4.7 & $277(12360)$ & 1732 & 1650 \\
\hline & $\mathrm{H}$ & 5.2 & $\begin{array}{l}240(13320) \\
267(14870)\end{array}$ & 1736 & 1640 \\
\hline & $\mathrm{H}$ & 4.81 & $280(23000)$ & 1716 & 1626 \\
\hline NH & $\mathrm{H}$ & 5.29 & $\begin{array}{l}276(22390) \\
320(23460)\end{array}$ & 1749 & 1626 \\
\hline
\end{tabular}




\subsection{BIOLOGICAL ACTIVITY STUDIES}

The following three compounds were screened for their activity against enteric pathogens: 1. ethyl-2-phenylhydrazinoquinoxaline-3-carboxylate (7) 2. 3-morpholino2-phenylpyrazolo[3,4-b]quinoxaline (14) and 3-amino-2-phenylpyrazolo[3,4-b]quinoxaline (11). The enteric pathogens on which the activity checked were $V$. cholerae inaba, V.cholerae ogawa, V. cholerae-0139, S. tybhi, klebsilla, Shigella dysenteria, Shigella flexneri, shigella sonni etc and fơnd that 3-amino-2phenylpyrazolo[3,4-b]quinoxaline was showing activity against $V$. cholerae ogawa, $V$. cholerae inaba and V. cholerae 0139 at concentrations of $200 \mu \mathrm{g} / \mathrm{mL}$.

Attempts were also made to check the anticancer activity of some pyrazoloquinoxalines. Unfortunately these compounds were insoluble in water and the phosphate buffer in which the in vitro testing was carried out. 


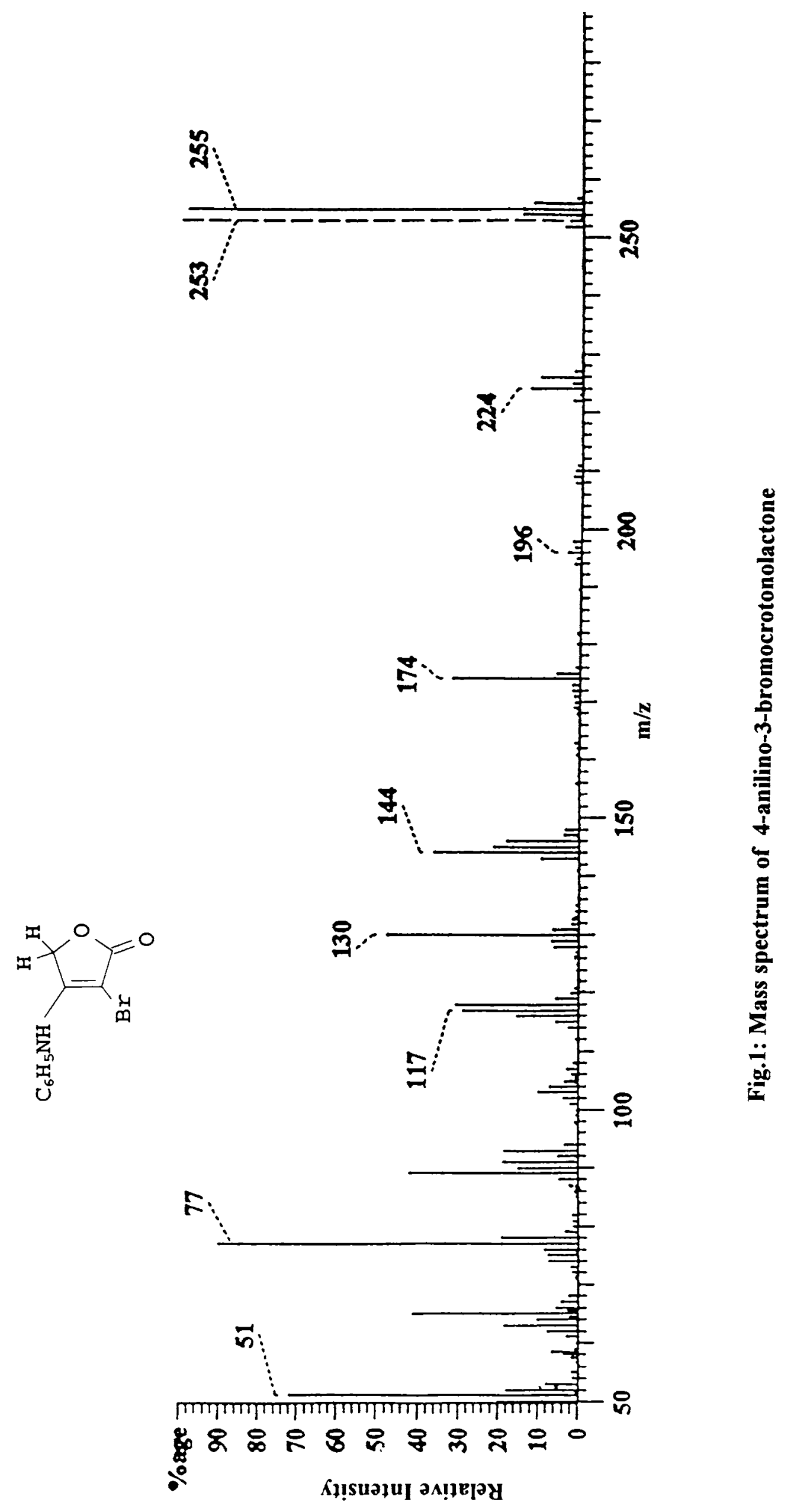


3.8 FRAGMENTATION PATTERN OF 4-ANILINO-3-

BROMOCROTONOLACTONE

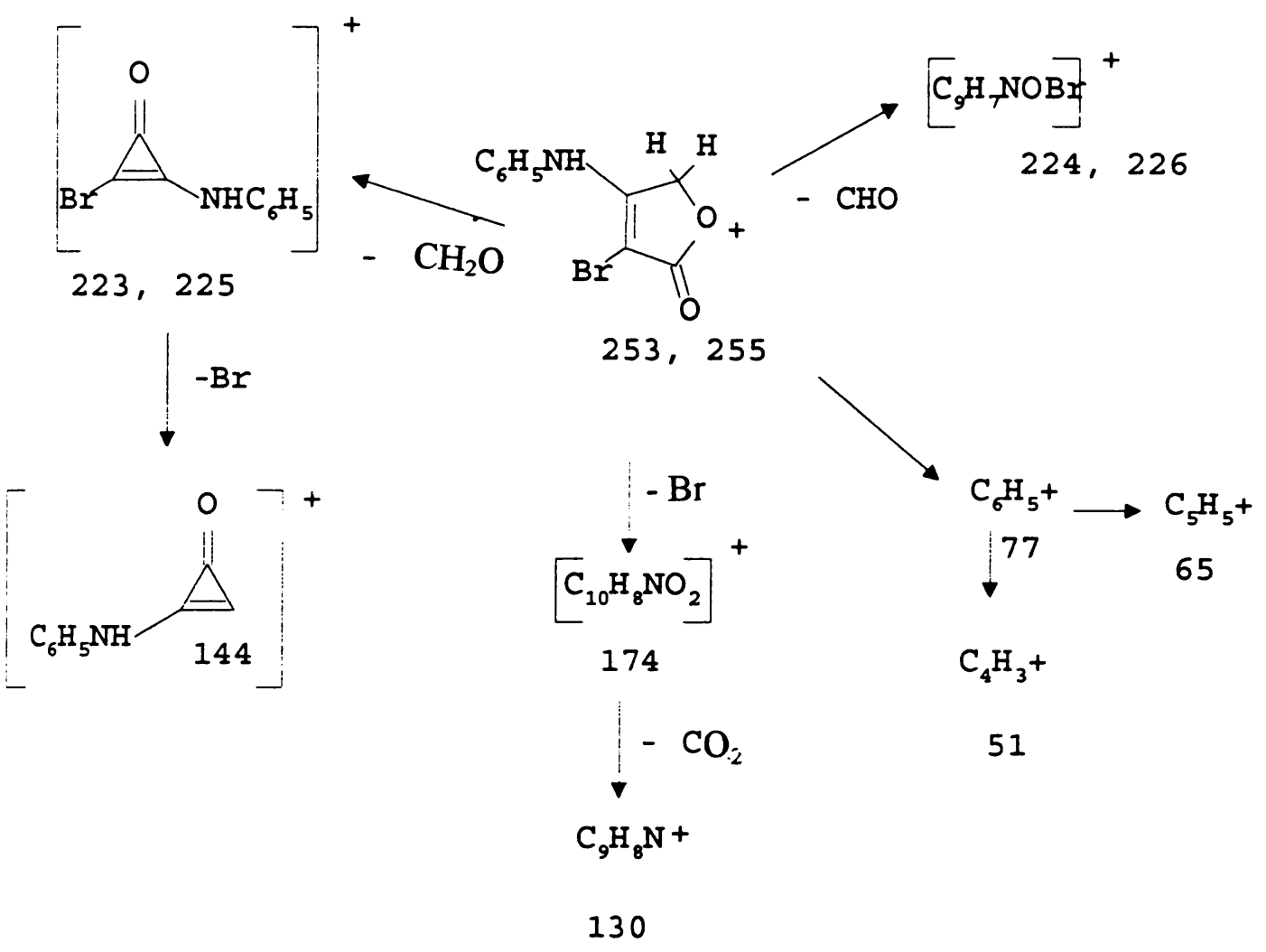




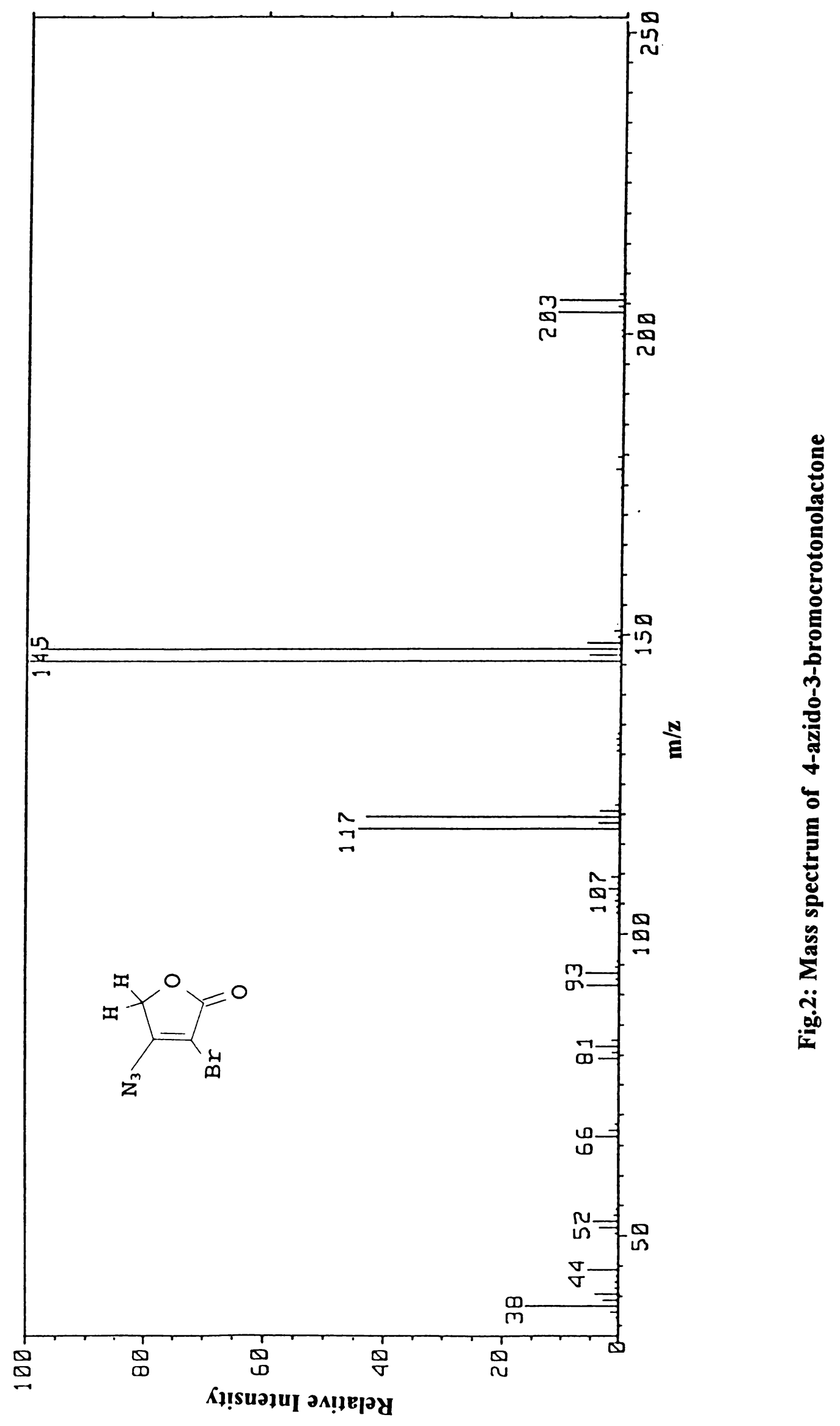


3.9 FRAGMENTATION PATTERN OF 4-AZIDO-3-

BROMOCROTONOLACTONE

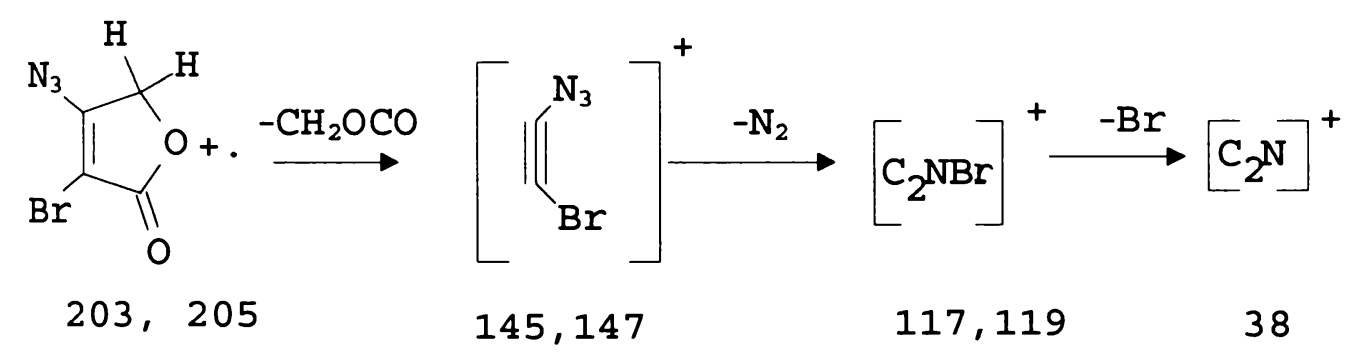




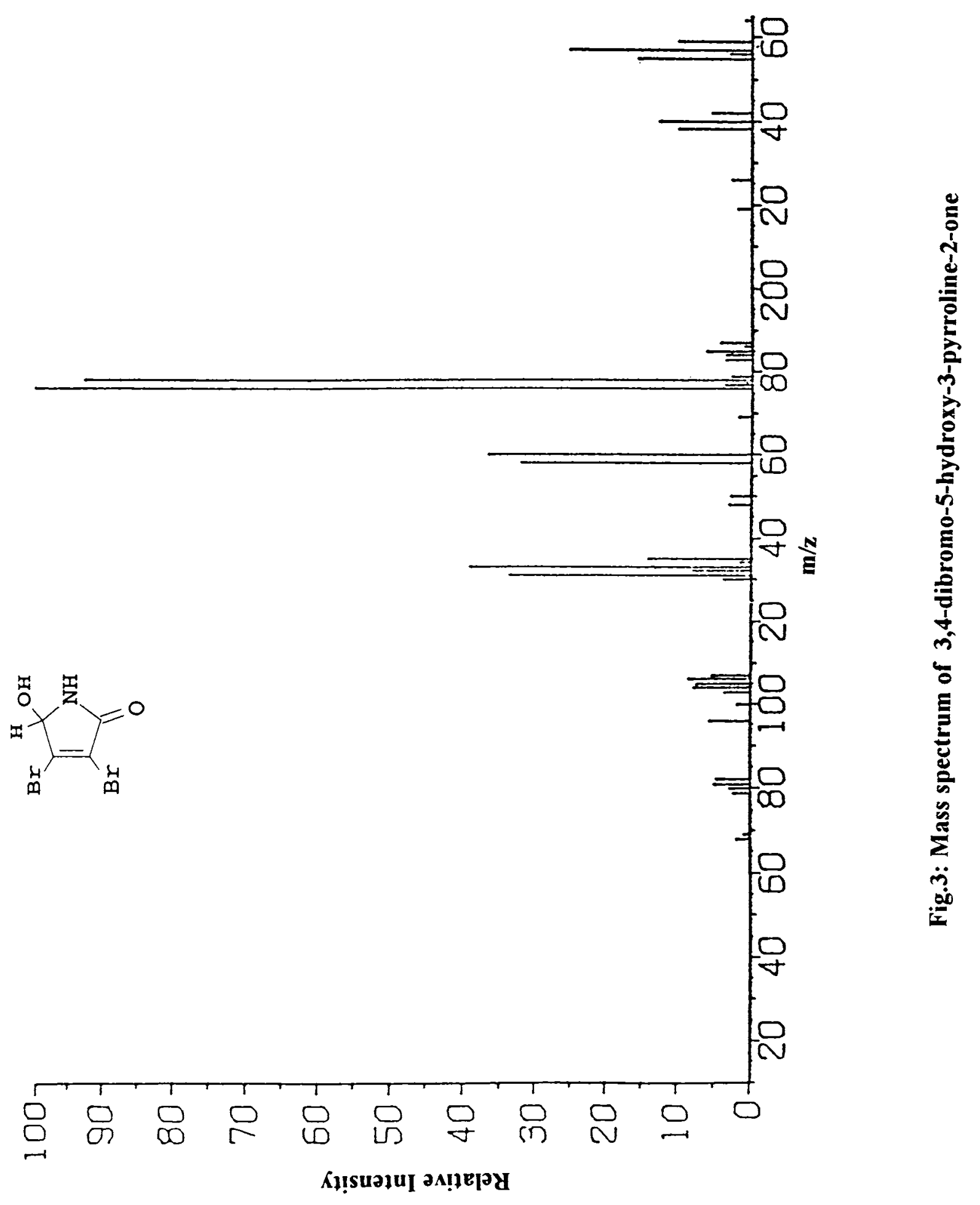


3.10 FRAGMENTATION PATTERN OF 3,4-DIBROMO-5-HYDROXY-

3-PYRROLINE-2-ONE

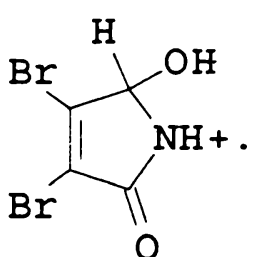

$255,257,259$
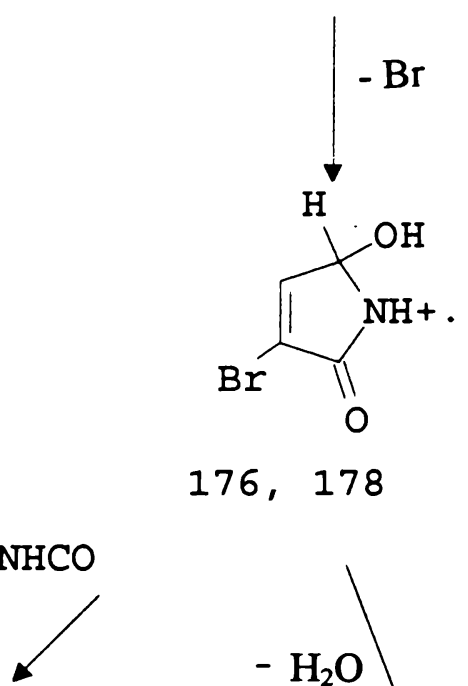

$\left[\mathrm{C}_{3} \mathrm{H}_{2} \mathrm{OBr}\right]^{+}$ 133,135

176,178

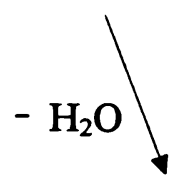

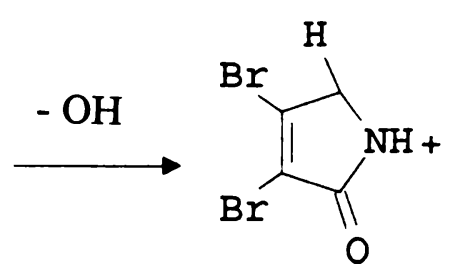

$238,240,242$

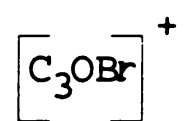

131,133

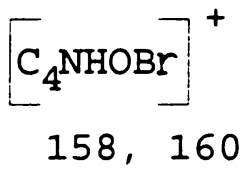




\section{EXPERIMENTAL PROCEDURES}

All melting points were taken on a Neolab capillary melting point apparatus and are uncorrected. UV spectra were obtained with a Shimadzu 160-A spectrophotometer. IR spectra were recorded on a Schimadzu DR 8001 FT-IR. Proton magnetic resonance (PMR) spectra were recorded at $400 \mathrm{MHz}$ on a Jeol GSX 400 NB FT-NMR. Mass spectra were recorded on a Finnigan Mat 8230 Mass spectrometer. Elemental analysis were carried out on a Carlo Erba-model 1106 analyser. The photochemical reactions were carried out using a high pressure mercury lamp (250w). All reactions were monitored by thin layer chromatography and TLC plates were made using silica gel G. The products were separated by column chromatography on silica gel of 60-120 mesh size. All reagents were of high quality and were further purified by distillation or recrystallisation. Solvents were purified by the general methods.

\subsection{Ethyl 2-Hydroxyquinoxaline-3-carboxylate (4)}

To a solution of dibromodiethyl malonate $(10.0 \mathrm{~g}, 0.03 \mathrm{~mol})$ in methanol (20 $\mathrm{mL}$ ) was added $o$-phenylenediamine $(3.5 \mathrm{~g}, 0.03 \mathrm{~mol})$ with stirring and the reaction mixture was kept alkaline by adding $\mathrm{NaHCO}_{3}$ at intervals. The stirring was continued for $12 \mathrm{~h}$ and the reaction mixture poured into crushed ice. The yellow precipitate was 
filtered, washed with water, dried and recrystallised from methanol to yield $5.0 \mathrm{~g}$ (50\%) of ethyl 2-hydroxyquinoxaline-3-carboxylate (4); m p $175^{\circ} \mathrm{C}\left(\mathrm{Lit}{ }^{90} \mathrm{~m} \mathrm{p} 176{ }^{\circ} \mathrm{C}\right)$

\subsection{Ethyl 2-Chloroquinoxaline-3-carboxylate (6)}

A mixture of ethyl 2-hydroxyquinoxaline-3-carboxylate (4) (4.36 g, $0.02 \mathrm{~mol})$ and freshly distilled $\mathrm{POCl}_{3}(50 \mathrm{~mL})$ was refluxed on a water bath for $3 \mathrm{~h}$ under a calcium chloride guard tube. The mixture was cooled and poured into crushed ice with stirring. The precipitate was filtered, washed with water, dried and recrystallised from hexane to give $3.25 \mathrm{~g}(75 \%)$ of $6, \mathrm{~m} \mathrm{p} 42{ }^{\circ} \mathrm{C}\left(\mathrm{Lit}^{93} \mathrm{~m} \mathrm{p} 42{ }^{\circ} \mathrm{C}\right)$

\subsection{Ethyl 2-Phenylhydrazinoquinoxaline-3-carboxylate (7)}

A mixture of ethyl 2-chloroquinoxaline-3-carboxylate (6) (2.0 g, $0.01 \mathrm{~mol})$ and freshly distilled phenylhyrazine $(0.9 \mathrm{~g}, 0.02 \mathrm{~mol})$ was heated on a steam bath for $2 \mathrm{~h}$. The mixture was cooled, dissolved in chloroform, washed with $2 \mathrm{~N} \mathrm{HCl}$ and concentrated. On examination by TLC (chloroform) it showed two components which were separated by chromatography on an silica column. Elution with chloroform gave the first and the major component which was recrystallised from hexane to yield $1.6 \mathrm{~g}$

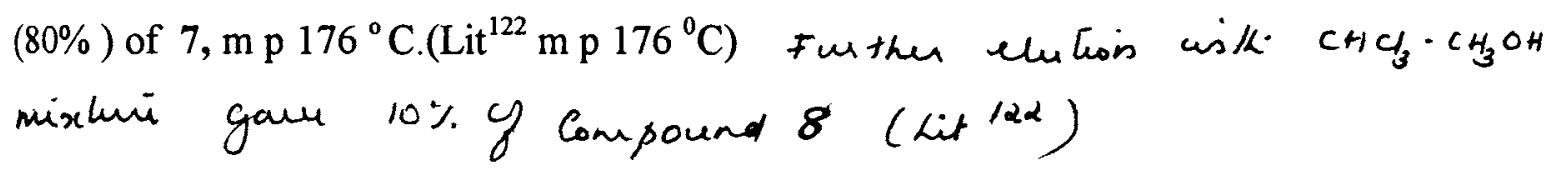

\subsection{3-Oxo-2-phenylpyrazolino[3,4-b]quinoxaline (9)}

Ethyl 2-phenylhydrazinoquinoxaline-3-carboxylate (7) $(1.0 \mathrm{~g}, 0.003 \mathrm{~mol})$ was heated at $190^{\circ} \mathrm{C}$ for about 30 minutes in an oil bath. After cooling the flask, $\mathrm{CHCl}_{3}$ 
$(10 \mathrm{~mL})$ was added and boiled for 2 minutes. The undissolved product was washed with $\mathrm{CHCl}_{3}$ and then with methanol. The residue was recrystallised from methanol to give $500 \mathrm{mg}(50 \%)$ of the product ; $\mathrm{m} \mathrm{p}>280{ }^{\circ} \mathrm{C}$.

$\mathrm{UV}\left(\mathrm{CH}_{3} \mathrm{OH}\right): \lambda_{\max } 204 \mathrm{~nm}\left(\varepsilon 7.8 \times 10^{3}\right), 285 \mathrm{~nm}\left(\varepsilon 1.2 \times 10^{4}\right) ; \mathrm{IR}$ (nujol): 1675 $(\mathrm{C}=0), 3300 \mathrm{~cm}^{-1}(\mathrm{NH}) ; \mathrm{MS}: \mathrm{m} / \mathrm{z}, 77,234,262(\mathrm{M}+)$.

\subsection{3-Chloro-2-phenylpyrazolo[3,4-b]quinoxaline (10)}

3-Oxo-2-phenylpyrazolino[3,4-b]quinoxaline (9) $(500 \mathrm{mg}, 0.0019 \mathrm{~mol})$ was refluxed with $\mathrm{POCl}_{3}(5 \mathrm{~mL})$ for $3 \mathrm{~h}$, cooled and diluted with ice cold water. The solid was filtered and dried and recrystallised from hexane to yield $250 \mathrm{mg}(50 \%)$ of 10 as a white solid; $\mathrm{m} \mathrm{p} 153{ }^{\circ} \mathrm{C}$.

Anal: Calculated for $\mathrm{C}_{15} \mathrm{H}_{9} \mathrm{~N}_{4} \mathrm{Cl}$ : C, 64.28; H, 3.24; N, 20.10. Found: C, 64.05; H, $3.20 ; \mathrm{N}, 19.96$.

UV $\left(\mathrm{CH}_{3} \mathrm{OH}\right): \lambda_{\max } 335 \mathrm{~nm}\left(\varepsilon 2.2 \times 10^{4}\right), 239 \mathrm{~nm}\left(\varepsilon 5.1 \times 10^{4}\right) ; \mathrm{PMR}$ (DMSO): $\delta$ 7.4-7.7 (m, 5H), $\delta$ 7.9-8.1 (m, 4H); MS: m/z, 245, $280(\mathrm{M}+), 282(\mathrm{M}+2)$.

\subsection{3-Amino-2-phenylpyrazolo[3,4-b]quinoxaline (11)}

A mixture of $10(200 \mathrm{mg}, 0.007 \mathrm{~mol})$ and urea $(1.0 \mathrm{~g})$ was heated on an oil bath at $130^{\circ} \mathrm{C}$ for $6 \mathrm{~h}$. Water $(25 \mathrm{~mL})$ was added and boiled again. The solution was extracted with chloroform and the product purified by column chromatography on a 
silica column using $\mathrm{CHCl}_{3}-\mathrm{CH}_{3} \mathrm{OH}(99: 1)$ mixture as the eluent to yield $620 \mathrm{mg}(62 \%)$ of $11 ; \mathrm{m} \mathrm{p} 210^{\circ} \mathrm{C}$

Anal: Calculated for $\mathrm{C}_{15} \mathrm{H}_{11} \mathrm{~N}_{5}: \mathrm{C}, 68.96 ; \mathrm{H}, 4.24 ; \mathrm{N}, 26.81$. Found: $\mathrm{C}, 68.76 ; \mathrm{H}, 4.35$; $\mathrm{N}, 26.62$.

UV $\left(\mathrm{CH}_{3} \mathrm{OH}\right): \lambda_{\max } 348 \mathrm{~nm}\left(\varepsilon 1.9 \times 10^{4}\right), 265 \mathrm{~nm}\left(\varepsilon 3.8 \times 10^{4}\right) ; \mathrm{IR}$ (nujol): 1268, 1330, 1560, 3146 and $3500 \mathrm{~cm}^{-1}$; PMR (DMSO): $\delta 2.08(\mathrm{~s}, 2 \mathrm{H}), \delta 7.6-7.8(\mathrm{~m}, 5 \mathrm{H}), \delta$ 7.9-8.2 (M, 4H); MS: m/z 261(M+).

\subsection{3-Methoxy-2-phenylpyrazolo[3,4-b]quinoxaline (12)}

A mixture of compound $10(200 \mathrm{mg}, 0.0007 \mathrm{~mol})$, methanol $(40 \mathrm{~mL})$ and liquor ammonia $(15 \mathrm{~mL})$ was stirred at room temperature for $24 \mathrm{~h}$. It showed 2 products on TLC $\left(99: 1 \mathrm{CHCl}_{3}-\mathrm{CH}_{3} \mathrm{OH}\right)$ which were separated and purified by column chromatography on a silica column using a mixture of $\mathrm{CHCl}_{3}: \mathrm{CH}_{3} \mathrm{OH}(99: 1)$ as the eluent. The first fraction on evaporation gave $50 \mathrm{mg}(25 \%)$ of 3-methoxy-2phenylpyrazolo[3,4-b]quinoxaline; $\mathrm{m} \mathrm{p} 175^{\circ} \mathrm{C}$.

Anal: Calculated for $\mathrm{C}_{16} \mathrm{H}_{12} \mathrm{~N}_{4} \mathrm{O} ; \mathrm{C}, 69.50 ; \mathrm{H}, 4.38 ; \mathrm{N}, 20.28$. Found: $\mathrm{C}, 69.58 ; \mathrm{H}$, $4.25 ; \mathrm{N}, 20.10$.

UV ( $\left.\mathrm{CH}_{3} \mathrm{OH}\right): \lambda_{\max } 349 \mathrm{~nm}\left(\varepsilon 7.17 \times 10^{4}\right), 243 \mathrm{~nm}\left(\varepsilon 1.31 \times 10^{4}\right)$; IR (nujol): 1098, 1158, $1244 \mathrm{~cm}^{-1}$; PMR (DMSO): $\delta 4.7(\mathrm{~s}, 3 \mathrm{H}), \delta$ 7.2-7.8 (m, 5H), $\delta$ 7.9-8.4 (m, 4H); MS: m/z $276(M+)$. 
The second component on elution from the column was shown to be identical to 3amino-2-phenylpyrazolo[3,4-b]quinoxaline, $\mathrm{m} \mathrm{p} .210^{\circ} \mathrm{C}$.

\subsection{3-Ethoxy-2-phenylpyrazolo[3,4-b]quinoxaline (13)}

A mixture of $10(280 \mathrm{mg}, 0.0009 \mathrm{~mol})$, absolute ethanol $(50 \mathrm{~mL})$ and potassium carbonate $(1.0 \mathrm{~g})$ was refluxed on a boiling waterbath for $3 \mathrm{~h}$. The reaction mixture was diluted with water and extracted with chloroform, the chloroform layer was dried and evaporated. The residue was recrystallised from $\mathrm{CHCl}_{3}$-hexane to .yield $168 \mathrm{mg}(60 \%)$ of $13 ; \mathrm{m} \mathrm{p} 156{ }^{\circ} \mathrm{C}$.

Anal: Calculated for $\mathrm{C}_{17} \mathrm{H}_{14} \mathrm{~N}_{4} \mathrm{O}: \mathrm{C}, 70.34 ; \mathrm{H}, 4.86 ; \mathrm{N}, 20.28$. Found: C, 70.12; H, $4.73 ; \mathrm{N}, 20.26$.

UV ( $\left.\mathrm{CH}_{3} \mathrm{OH}\right): \lambda_{\max } 357 \mathrm{~nm}\left(\varepsilon 2.1 \times 10^{4}\right), 243 \mathrm{~nm}\left(\varepsilon 4.2 \times 10^{4}\right)$; IR (nujol): 1020, $1142,1244 \mathrm{~cm}^{-1}$; PMR (DMSO): $\delta 1.6(\mathrm{t}, 3 \mathrm{H}), \delta 5.3(\mathrm{q}, 2 \mathrm{H}) \delta 7.5-7.8(\mathrm{~m}, 5 \mathrm{H}), \delta 7.9-$ $8.2(\mathrm{~m}, 4 \mathrm{H}) ; \mathrm{MS}: \mathrm{m} / \mathrm{z} 290(\mathrm{M}+)$

\subsection{3-Morpholino-2-phenylpyrazolo[3,4-b]quinoxaline (14)}

Compound $10(200 \mathrm{mg}, 0.0007 \mathrm{~mol})$ and morpholine $(5 \mathrm{~mL})$ were heated for 2 h on a water bath. The mixture was diluted with cold water and the solid was filtered and purified by column chromatography using silica gel and $\mathrm{CHCl}_{3}-\mathrm{CH}_{3} \mathrm{OH}(99: 1)$ mixture as eluent to give $150 \mathrm{mg}(75 \%)$ of $14 ; \mathrm{m} \mathrm{p} 182{ }^{\circ} \mathrm{C}$. 
Anal: Calculated for $\mathrm{C}_{19} \mathrm{H}_{17} \mathrm{~N}_{5} \mathrm{O}: \mathrm{C}, 68.88 ; \mathrm{H}, 5.17 ; \mathrm{N}, 21.14$. Found: $\mathrm{C}, 68.76 ; \mathrm{H}$, $5.03 ; \mathrm{N}, 21.24$.

$\mathrm{UV}\left(\mathrm{CH}_{3} \mathrm{OH}\right): \lambda_{\max } 354 \mathrm{~nm}\left(\varepsilon 2.53 \times 10^{4}\right), 241 \mathrm{~nm}\left(\varepsilon 2.37 \times 10^{4}\right)$; IR (nujol): 1028, $1145,1238 \mathrm{~cm}^{-1}:$ PMR (DMSO): $\delta 3.5(\mathrm{t}, 4 \mathrm{H}), \delta 3.75(\mathrm{t}, 4 \mathrm{H}), \delta 7.5-7.8(\mathrm{~m}, 5 \mathrm{H}), \delta 7.9-$ $8.05(\mathrm{~m}, 4 \mathrm{H}) ; \mathrm{MS}: \mathrm{m} / \mathrm{z} 331(\mathrm{M}+)$.

\subsection{3-Pyrrolidino-2-phenylpyrazolo[3,4-b]quinoxaline (15)}

Compound $10(200 \mathrm{mg}, 0.0007 \mathrm{~mol})$ and pyrrolidine $(5 \mathrm{~mL})$ were heated for 2 $\mathrm{h}$ on a water bath. The mixture was diluted with cold water and the solid was filtered and purified by column chromatography using silica gel and $\mathrm{CHCl}_{3}-\mathrm{CH}_{3} \mathrm{OH}(99: 1)$ mixture as eluent to give $150 \mathrm{mg}(75 \%)$ of $15 ; \mathrm{m} \mathrm{p} 162{ }^{\circ} \mathrm{C}$.

Anal: Calculated for $\mathrm{C}_{19} \mathrm{H}_{17} \mathrm{~N}_{5}: \mathrm{C}, 72.38 ; \mathrm{H}, 5.44 ; \mathrm{N}, 22.12$. Found: $\mathrm{C}, 72.28 ; \mathrm{H}, 5.24$; $\mathrm{N}, 22.22$.

UV $\left(\mathrm{CH}_{3} \mathrm{OH}\right): \lambda_{\max } 272 \mathrm{~nm}\left(\varepsilon 3.18 \times 10^{4}\right), 349 \mathrm{~nm}\left(\varepsilon 1.89 \times 10^{4}\right) ;$ PMR (DMSO): $\delta$ $1.9(\mathrm{~m}, 4 \mathrm{H}), \delta 3.7(\mathrm{~m}, 4 \mathrm{H}), \delta$ 7.5-7.8 (m, 5H), $\delta$ 7.9-8.1 (m, 4H); MS: m/z $315(\mathrm{M}+)$.

\subsection{3-Piperidino-2-phenylpyrazolo[3,4-b]quinoxaline (16)}

Compound $10(200 \mathrm{mg}, 0.0007 \mathrm{~mol})$ and piperidine $(5 \mathrm{~mL})$ were heated for $2 \mathrm{~h}$ on a water bath. The mixture was diluted with cold water and the solid was filtered and purified by column chromatography using silica gel and $\mathrm{CHCl}_{3}-\mathrm{CH}_{3} \mathrm{OH}(99: 1)$ mixture as eluent to give $180 \mathrm{mg}(80 \%)$ of $16 ; \mathrm{m} \mathrm{p} 195^{\circ} \mathrm{C}$. 
Anal: Calculated for $\mathrm{C}_{20} \mathrm{H}_{19} \mathrm{~N}_{5}: \mathrm{C}, 72.94 ; \mathrm{H}, 5.82 ; \mathrm{N}, 21.27$. Found: $\mathrm{C}, 72.74 ; \mathrm{H}, 5.80$; $\mathrm{N}, 21.16$.

$\mathrm{UV}\left(\mathrm{CH}_{3} \mathrm{OH}\right): \lambda_{\max } 349 \mathrm{~nm}\left(\varepsilon 2.2 \times 10^{4}\right), 262 \mathrm{~nm}\left(\varepsilon 5.2 \times 10^{4}\right)$; PMR (DMSO): $\delta 2.5$ $(\mathrm{m}, 6 \mathrm{H}), \delta 3.49(\mathrm{~m}, 4 \mathrm{H}), \delta$ 7.5-7.8 (m, 4H), $\delta 7.9-8.1(\mathrm{~m}, 4 \mathrm{H}) ; \mathrm{MS}: \mathrm{m} / \mathrm{z} 329(\mathrm{M}+)$

\subsection{2-Phenylpyrazolo[3,4-b]quinoxaline (17)}

3-Chloro-2-phenylpyrazolo[3,4-b]quinoxaline (10) $(200 \mathrm{mg}, 0007 \mathrm{~mol})$ in isopropanol $(5 \mathrm{~mL})$ was mixed with powdered $\mathrm{NaBH}_{4}(400 \mathrm{mg}, 0.01 \mathrm{~mol})$ and refluxed for $6 \mathrm{~h}$. The unreacted $\mathrm{NaBH}_{4}$ was decomposed with water, isopropanol was removed under reduced pressure and the product was extracted with $\mathrm{CHCl}_{3}$. The chloroform layer was dried and removed under reduced pressure and the residue was recrystallised from ethyl acetate-hexane to yield $100 \mathrm{mg} \mathrm{(50 \% )} \mathrm{of} 17 ; \mathrm{m} \mathrm{p} 200^{\circ} \mathrm{C}$.

Anal: Calculated for $\mathrm{C}_{15} \mathrm{H}_{10} \mathrm{~N}_{4}$ : $\mathrm{C}, 73.17 ; \mathrm{H}, 4.09 ; \mathrm{N}, 22.76$. Found: $\mathrm{C}, 73,15 ; \mathrm{H}, 4.10$; N 22.76 .

UV $\left(\mathrm{CH}_{3} \mathrm{OH}\right): \lambda_{\max } 365 \mathrm{~nm}\left(\varepsilon 3.3 \times 10^{4}\right) ; 235 \mathrm{~nm}\left(\varepsilon 5.5 \times 10^{4}\right) ;$ PMR (DMSO): $\delta$ 7.6-7.9 (m, 5H) $\delta 8.1-8.4(\mathrm{~m}, 4 \mathrm{H}), \delta 9.95(\mathrm{~s}, 1 \mathrm{H}) ; \mathrm{MS}: \mathrm{m} / \mathrm{z} 246(\mathrm{M}+)$.

\subsection{3-Chloro-2-phenylpyrazolo[3,4-b]pyrazine dicarboxylic acid (18)}

A mixture of $10(500 \mathrm{mg}, 0.0017 \mathrm{~mol})$ and $4 \% \mathrm{KMnO}_{4}(50 \mathrm{~mL})$ was boiled under reflux for $5 \mathrm{~h}$ with vigorous stirring. The mixture was filtered and the residue was made into a slurry in boiling water and filtered. The filtrates were combined and 
concentrated under reduced pressure, cooled and acidified. The solution was further cooled and the solid separated was filtered, dried and recrystallised from boiling water to give $250 \mathrm{mg}(50 \%)$ of $18 ; \mathrm{m} \mathrm{p}>230^{\circ} \mathrm{C}$

Anal: Calculated for $\mathrm{C}_{13} \mathrm{H}_{7} \mathrm{~N}_{4} \mathrm{O}_{4} \mathrm{Cl}$ : C, 48.75; $\mathrm{H}, 2.82 ; \mathrm{N}, 17.30$. Found: $\mathrm{C}, 48.05 ; \mathrm{H}$, $2.82 ; \mathrm{N}, 17.30$.

$\mathrm{UV}\left(\mathrm{CH}_{3} \mathrm{OH}\right): \lambda_{\max } 210 \mathrm{~nm}\left(\varepsilon 1.4 \times 10^{4}\right), 271 \mathrm{~nm}\left(\varepsilon 5.4 \times 10^{3}\right) ; \mathrm{IR}$ (nujol): 1778,3250 $\mathrm{cm}^{-1 ;} \mathrm{MS}: \mathrm{m} / \mathrm{z} 276,302,318(\mathrm{M}+), 320(\mathrm{M}+2)$.

\subsection{Mucobromic acid (2,3-Dibromo-3-formylacrylic acid) (19)}

A mixture of freshly distilled furfural $(50.0 \mathrm{~g}, 0.052 \mathrm{~mol})$ and water $(500 \mathrm{~mL})$ was stirred vigorously. The flask was immersed in an ice bath and bromine (144 mL, $2.81 \mathrm{~mol}$ ) was added slowly using a dropping funnel with occasional shaking. During the addition of bromine the temperature was kept below $5^{\circ} \mathrm{C}$. After addition the mixture was refluxed for 30 minutes, and the excess bromine was removed by distillation. The reaction mixture was evaporated under reduced pressure and the solid obtained was washed with sodium bisulphite and then with water. The solid was recrystallised from hot water to yield $37.5 \mathrm{~g}(75 \%)$ of mucobromic acid; $\mathrm{m} \mathrm{p} 124{ }^{\circ} \mathrm{C}$ $\left(\right.$ lit $\left.^{96} \mathrm{mp} 126^{0} \mathrm{C}\right)$.

UV (EtOH): $\lambda_{\max } 242 \mathrm{~nm}(\varepsilon 7900), 275 \mathrm{~nm}(\varepsilon$ 1400); IR (KBr): 1220, 1270 (C-O), $1610(\mathrm{C}=\mathrm{C}), 1765(\mathrm{C}=\mathrm{O}), 3310 \mathrm{~cm}^{-1}(\mathrm{OH}) ; \operatorname{PMR}\left(\mathrm{CDCl}_{3}\right): \delta 4.57(\mathrm{~s}, 1 \mathrm{H}), \delta 6.26 \quad(\mathrm{~s}$, $1 \mathrm{H})$. 


\subsection{3,4-Dibromocrotonolactone (22)}

To a mixture of mucobromic acid (19) $(1.0 \mathrm{~g}, 0.0039 \mathrm{~mol})$ in water $(10 \mathrm{~mL})$ was added $\mathrm{NaBH}_{4}(0.15 \mathrm{~g}, 0.0018 \mathrm{~mol})$ with stirring. The mixture frothed and turned light yellow. After stirring for $1 \mathrm{~h}$ at room temperature, the mixture was diluted with 2 $\mathrm{N} \mathrm{HCl}$ and cooled. The solid separated was collected, dried and recrystallised from hexane to give $650 \mathrm{mg}(65 \%)$ of $22 ; \mathrm{m} \mathrm{p} 90{ }^{\circ} \mathrm{C}\left(\right.$ lit $\left.^{99} \mathrm{~m} \mathrm{p} 89{ }^{\circ} \mathrm{C}\right)$ $\mathrm{UV}\left(\mathrm{CH}_{3} \mathrm{OH}\right): \lambda_{\max } 237\left(\varepsilon\right.$ 7000); IR (KBr): $1215(\mathrm{C}-\mathrm{O}), 1610(\mathrm{C}=\mathrm{C}), 1790 \mathrm{~cm}^{-1}$ $(\mathrm{C}=0) ; \mathrm{PMR}\left(\mathrm{CDCl}_{3}\right): \delta 4.92(\mathrm{~s}, 2 \mathrm{H}) ; \mathrm{MS}: \mathrm{m} / \mathrm{z} 240(\mathrm{M}+)$

\subsection{3,4-Dibromo-5-ethoxycrotonolactone (23)}

Mucobromic acid (19) $(20.0 \mathrm{~g}, 0.076 \mathrm{~mol})$ and absolute ethanol $(50 \mathrm{~mL})$ were refluxed for $8 \mathrm{~h}$ in presence of conc. sulphuric acid $(0.2 \mathrm{~mL})$ on a water bath. Excess solvent was removed by distillation and the residue was diluted with water $(50 \mathrm{~mL})$ and extracted with ether $(250 \mathrm{~mL})$. The ether layer was washed with saturated $\mathrm{NaHCO}_{3}$ solution and dried using sodium sulphate. The solvent was removed under vacuum to give a light brown oil which solidified on cooling to give $16 \mathrm{~g}(80 \%)$ of 23 as a lachrymatric solid; $\mathrm{m} \mathrm{p} 50{ }^{\circ} \mathrm{C}$.(lit ${ }^{100} \mathrm{~m} \mathrm{p} \mathrm{51)}$.

UV (EtOH): $\lambda_{\max } 243 \mathrm{~nm}\left(\varepsilon\right.$ 8700); IR (KBr): $1210(\mathrm{C}-\mathrm{O}), 1610(\mathrm{C}=\mathrm{C}), 1780 \mathrm{~cm}^{-1}$ $(\mathrm{C}=0)$; PMR (DMSO): $\delta 1.25(\mathrm{t}, 3 \mathrm{H}), \delta 3.8(\mathrm{q}, 2 \mathrm{H}), \delta 5.82(\mathrm{~s}, 1 \mathrm{H})$ 


\subsection{4,5-Dibromo-6-pyridazone (28)}

To a hot solution of mucobromic acid (19) $(2.0 \mathrm{~g}, 0.007 \mathrm{~mol})$ in alcohol was added hydrazine hydrate $(0.7 \mathrm{~mL}, 0.014 \mathrm{~mol})$ with stirring. The mixture was stirred for an additional $1 \mathrm{~h}$ at room temperature when a solid started separating. The solid was filtered, dried and recrystallised from alcohol to yield $1.2 \mathrm{~g}(60 \%)$ of $28 ; \mathrm{m} \mathrm{p} 218$ ${ }^{0} \mathrm{C}\left(\right.$ lit ${ }^{108} \mathrm{~m} \mathrm{p} 218{ }^{\circ} \mathrm{C}$ )

\subsection{4,5-Dibromo-6-chloropyridazine (29)}

4,5-Dibromo-6-pyridazone (28) (400 mg, $0.0015 \mathrm{~mol})$ was refluxed on a water bath with excess $\mathrm{POCl}_{3}(6 \mathrm{~mL})$ for $4 \mathrm{~h}$ in presence of DMF as catalyst. The mixture was cooled and poured into crushed ice, the separated solid was filtered, dried and recystallised from hexane to yield $200 \mathrm{mg}(50 \%)$ of $29 ; \mathrm{m} \mathrm{p} 84{ }^{\circ} \mathrm{C}$.

Anal: Calculated for $\mathrm{C}_{4} \mathrm{HN}_{2} \mathrm{ClBr}_{2}$ : C, 17.74; $\mathrm{H}, 0.03 ; \mathrm{N}, 10.35$. Found: $\mathrm{C}, 18.05 ; \mathrm{H}$, $0.00 ; \mathrm{N}, 11.7$

UV $\left(\mathrm{CH}_{3} \mathrm{OH}\right): \lambda_{\max } 208 \mathrm{~nm}\left(\varepsilon\right.$ 32432); PMR $\left(\mathrm{CDCl}_{3}\right): \delta 9.1(\mathrm{~s}, 1 \mathrm{H}) ; \mathrm{MS}: \mathrm{m} / \mathrm{z} 270$ $(\mathrm{M}+)$.

\subsection{1-Carboxamido-3,4-dibromo-5-hydroxy-3-pyrrolin-2-one (30)}

Mucobromic acid (19) (100 mg, $0.0003 \mathrm{~mol})$ was refluxed with urea $(200 \mathrm{mg}$, $0.003 \mathrm{~mol}$ ) for $3 \mathrm{~h}$ in methanol on a water bath. Excess solvent was removed by distillation, the residue was diluted with water $(20 \mathrm{~mL})$ and extracted with methylene 
chloride $(50 \mathrm{~mL})$. The organic layer was dried and evaporated and the residue was purified by chromatography on a silica column using $\mathrm{CHCl}_{3}-\mathrm{CH}_{3} \mathrm{OH}(99: 1)$ as eluent to give $65 \mathrm{mg}(65 \%)$ of $30 ; \mathrm{m} \mathrm{p} 170{ }^{\circ} \mathrm{C}$.

Anal: Calculated for $\mathrm{C}_{5} \mathrm{H}_{4} \mathrm{O}_{3} \mathrm{~N}_{2} \mathrm{Br}_{2}: \mathrm{C}, 20.13 ; \mathrm{H}, 1.34 ; \mathrm{N}, 8.34$. Found: $\mathrm{C}, 19.09, \mathrm{H}$, $1.00 ; \mathrm{N}, 8.34$.

$\mathrm{UV}\left(\mathrm{CH}_{3} \mathrm{OH}\right): \lambda_{\max } 240 \mathrm{~nm}(\varepsilon 15150), 203 \mathrm{~nm}(\varepsilon$ 9090); IR (KBr): $1614(\mathrm{C}=\mathrm{C}), 1650$ $(\mathrm{NH}), 1750(\mathrm{C}=\mathrm{O}), 1700 \mathrm{C}=0), 3250,3372,3470 \mathrm{~cm}^{-1}\left(\mathrm{NH}_{2}, \mathrm{OH}\right) ; \mathrm{PMR}$ (DMSO): $\delta$ $6.2(\mathrm{~s}, 2 \mathrm{H}), \delta 6.5(\mathrm{~d}, 1 \mathrm{H}), \delta 7.5(\mathrm{~d}, 1 \mathrm{H})$.

\subsection{4-Azido-3-bromo-5-hyroxycrotonolactone (34)}

A mixture of sodium azide $(6.5 \mathrm{~g}, 0.108 \mathrm{~mol})$ and acetonitrile $(40 \mathrm{~mL})$ was stirred and cooled to $0{ }^{\circ} \mathrm{C}$. To this was added mucobromic acid (19) (14.0 g, 0.054 mol) in acetonitrile $(20 \mathrm{~mL})$ and the reaction mixture was stirred for additional $24 \mathrm{~h}$ at room temperature. The deep red mixture was diluted with water $(100 \mathrm{~mL})$, extracted with ether $(250 \mathrm{~mL})$. The ether extract was washed with $5 \%$ sodium thiosulphate, followed by saturated $\mathrm{NaCl}$ solution, decolourised with carbon and evaporated under reduced pressure to give $4.68 \mathrm{~g}(72 \%)$ of 34 as white crystals; $\mathrm{m} \mathrm{p} 70{ }^{\circ} \mathrm{C}$.

UV $\left(\mathrm{CH}_{3} \mathrm{OH}\right): \lambda_{\max } 274 \mathrm{~nm}(\varepsilon$ 18500); IR (KBr): $1220(\mathrm{C}-\mathrm{O}), 1625(\mathrm{C}=\mathrm{C}), 1760$ $(\mathrm{C}=0), 2120\left(\mathrm{~N}_{3}\right), 3250 \mathrm{~cm}^{-1}(\mathrm{OH}) ; \operatorname{PMR}\left(\mathrm{CDCl}_{3}\right): \delta 4.53(\mathrm{~s}, 1 \mathrm{H}), \delta 6.67(\mathrm{~s}, 1 \mathrm{H})$. 


\subsection{4-Azido-3-bromocrotonolactone (38)}

To an ice cold solution of sodium azide $(100 \mathrm{mg}, 0.0016 \mathrm{~mol})$ in acetonitrile $(10 \mathrm{~mL})$ was added 3,4-dibromocrotonolactone (22) $(200 \mathrm{mg}, 0.0008 \mathrm{~mol})$ in acetonitrile $(2 \mathrm{~mL})$ and stirred overnight at room temperature. It was diluted with water $(10 \mathrm{~mL})$ and extracted with ether $(50 \mathrm{~mL})$. The ether layer was washed with $5 \%$ sodium thiosulphate, and then with water. The ether layer was dried and evaporated to give needle shaped crystals, which was purified by crystallisation from hexane to yield $50 \mathrm{mg}(50 \%)$ of the product; $\mathrm{m} \mathrm{p} 60{ }^{\circ} \mathrm{C}$

$\mathrm{UV}\left(\mathrm{CH}_{3} \mathrm{OH}\right): \lambda_{\max } 268 \mathrm{~nm}(\varepsilon$ 11500); IR (KBr): $1230(\mathrm{C}-\mathrm{O}), 1625(\mathrm{C}=\mathrm{C}), 1750$ $(\mathrm{C}=0), 2131 \mathrm{~cm}^{-1}\left(\mathrm{~N}_{3}\right)$; PMR (DMSO): $\delta 5.19(\mathrm{~s}, 2 \mathrm{H}) ; \mathrm{MS}: \mathrm{m} / \mathrm{z} 117,119,145,147$, $203,205$.

\subsection{5-Benzoyloxy-3,4-dibromocrotonolactone (39)}

A $100 \mathrm{~mL}$ flask was charged with mucobromic acid (19) $(25.8 \mathrm{~g}, 0.1 \mathrm{~mol})$ and benzoyl chloride $(14.1 \mathrm{~g}, 0.1 \mathrm{~mol})$. The flask was fitted with a reflux condenser which was attached with a tube which was dipped into $2 \mathrm{~N} \mathrm{NaOH}$ solution and the mixture was heated on a steam bath until the evolution of $\mathrm{HCl}$ ceased. The resulting solid was washed with hexane and recrystallised from ethyl acetate-hexane to give $23.2 \mathrm{~g}(90 \%)$ of a white solid; $\mathrm{m} \mathrm{p} 153{ }^{\circ} \mathrm{C}$. 
UV (EtOH): $\lambda_{\max } 240 \mathrm{~nm}(\varepsilon$ 20170), $279 \mathrm{~nm}(\varepsilon$ 1300); IR (KBr): 1240, 1260 (C-O), $1610(\mathrm{C}=\mathrm{C}), 1750($ ester $\mathrm{C}=0), 1800 \mathrm{~cm}^{-1}(\mathrm{C}=0)$; PMR $\left(\mathrm{CDCl}_{3}\right): \delta 7.28(\mathrm{~s}, 1 \mathrm{H}), \delta$ 7.64-8.16 (m, 5H).

\subsection{3,4-Dibromo-5-chlorocrotonolactone (43)}

A mixture of mucobromic acid (19) (17.7 g, $0.006 \mathrm{~mol})$, thionyl chloride (50 $\mathrm{mL}$ ) and 2 drops of DMF was heated to $50^{\circ} \mathrm{C}$ for $5 \mathrm{~h}$ on a water bath. Excess thionyl chloride was removed under vacuum, and the remaining solid was washed with ice cold water. The solid was filtered, dried and dissolved in alcohol and water was added to initiate crystallisation. The mixture was cooled, and the solid separated was filtered to give $9.2 \mathrm{~g}(52 \%)$ of 43 as a white lachrymal solid; $\mathrm{m} \mathrm{p} 49{ }^{\circ} \mathrm{C}$

UV (EtOH): $\lambda_{\max } 247 \mathrm{~nm}\left(\varepsilon\right.$ 9700); IR (KBr): $1200(\mathrm{C}-\mathrm{O}), 1600(\mathrm{C}=\mathrm{C}), 1780 \mathrm{~cm}^{-1}$ $(\mathrm{C}=0) ; \operatorname{PMR}\left(\mathrm{CDCl}_{3}\right): \delta 6.6(\mathrm{~s}, 1 \mathrm{H})$.

\subsection{3,4-Dibromo-5-hydroxy-1-methyl-3-pyrrolin-2-one (46)}

Method A: A solution of 5-chloro-3,4-dibromocrotonolactone (43) (891 mg, 0.003 mol) in dioxan was slowly mixed with stirring to an ice cold solution of methylamine $(0.8 \mathrm{~mL}, 0.006 \mathrm{~mol})$ in dioxan $(7 \mathrm{~mL})$, followed by additional stirring at room temperature for $15 \mathrm{~h}$. The solution was diluted with water $25 \mathrm{~mL}$ ) and then extracted with methylene chloride $(100 \mathrm{~mL})$. The organic layer was washed with $1 \mathrm{~N} \mathrm{HCl}(50$ $\mathrm{mL}$ ) followed by saturated $\mathrm{NaCl}$ solution and then decolourised with charcoal. The 
solvent was dried and evaporated and hexane was added to the residue to initiate crystallisation. It was further recystallised from chloroform to give $640 \mathrm{mg}(72 \%)$ of 46 as a white solid; $\mathrm{m} \mathrm{p} 157^{\circ} \mathrm{C}$.

Anal: Calculated for $\mathrm{C}_{5} \mathrm{H}_{5} \mathrm{NO}_{2} \mathrm{Br}_{2}: \mathrm{C}, 22.16 ; \mathrm{H}, 1.86 ; \mathrm{N}, 5.17$. Found: $\mathrm{C}, 22.29 ; \mathrm{H}$, $1.97 ; \mathrm{N}, 5.10$.

$\mathrm{UV}\left(\mathrm{CH}_{3} \mathrm{OH}\right): \lambda_{\max } 223 \mathrm{~nm}(\varepsilon 11500), 225 \mathrm{~nm}(\varepsilon 2700), 228 \mathrm{~nm}(\varepsilon 10,800) ; \mathrm{R}(\mathrm{KBr}):$ $1250(\mathrm{C}-\mathrm{O}), 1640(\mathrm{C}=\mathrm{C}), 1670(\mathrm{C}=\mathrm{O}), 3280 \mathrm{~cm}^{-1}(\mathrm{OH})$; PMR (DMSO): $\delta 2.98$ (s, $3 \mathrm{H}), \delta 5.24(\mathrm{~d}, 1 \mathrm{H}), \delta 7.3(\mathrm{~d}, 1 \mathrm{H})$

Method B: A THF solution of methyl amine $(186 \mathrm{mg}, 0.006 \mathrm{~mol})$ was slowly added to a stirred ice cold solution of 5-benzoyloxy-3,4-dibromocrotonolactone (39) (1.0 g, $0.003 \mathrm{~mol})$ in THF $(8 \mathrm{~mL})$. After stirring the yellow solution for $16 \mathrm{~h}$ at room temperature, it was diluted with water $(10 \mathrm{~mL})$ and extracted with methylene chloride $(100 \mathrm{~mL})$. The organic layer was washed with water, dried and concentrated to give a yellow oil which solidified on cooling. The solid was further purified by crystallisation from chloroform to give 46 with $\mathrm{mp} 157^{\circ} \mathrm{C}$. It was identical to the 3,4-dibromo-5hydroxy-1-methyl-3-pyrrolin-2-one prepared by Method A. 


\subsection{3,4-Dibromo-1-(3-hydroxypropyl)-5-hydroxy-3-pyrrolin-2-one (47)}

Method A: A solution of 5-chloro-3,4-dibromocrotonolactone (43) (891 mg, 0.003 mol) in dioxan $(3 \mathrm{~mL})$ was slowly mixed with a cold solution of 3-aminopropanol ( $450 \mathrm{mg}, 0.006 \mathrm{~mol})$ in dioxan $(7 \mathrm{~mL})$ followed by stirring at room temperature for 15 h.

The solution was diluted with water and extracted with $\mathrm{CH}_{2} \mathrm{Cl}_{2}$. The methylene chloride layer was washed with $1 \mathrm{~N} \mathrm{HCl}(50 \mathrm{~mL})$ and saturated $\mathrm{NaCl}$ solution and was decolourised with charcoal. The solution was concentrated and hexane was added to initiate crystallisation. The solution was cooled overnight to give $350 \mathrm{mg}(40 \%)$ of 47 as white crystals; $\mathrm{m} \mathrm{p} 129^{\circ} \mathrm{C}$.

Anal: Calculated for $\mathrm{C}_{7} \mathrm{H}_{9} \mathrm{NO}_{3} \mathrm{Br}_{2}: \mathrm{C}, 26.83 ; \mathrm{H}, 2.89 ; \mathrm{N}, 4.47$. Found: $\mathrm{C}, 26.68 ; \mathrm{H}$, $2.98 ; \mathrm{N}, 4.36$.

UV (EtOH): $\lambda_{\max } 224 \mathrm{~nm}(\varepsilon$ 10,300); IR (KBr): $1600(\mathrm{C}=\mathrm{C}), 1680(\mathrm{C}=\mathrm{O}), 3150,3360$ $\mathrm{cm}^{-1}(\mathrm{OH}) ;$ PMR (DMSO): $\delta 1.78(\mathrm{t}, 2 \mathrm{H}), \delta 3.50(\mathrm{~m}, 4 \mathrm{H}), \delta 4.48(\mathrm{~m}, 1 \mathrm{H}), \delta 5.48(\mathrm{~d}$, $1 \mathrm{H}), \delta 6.98(\mathrm{~d}, 1 \mathrm{H})$.

Method B: To an ice cold solution of 3,4-dibromo-5-benzoyloxycrotonolactone (39) $(1.0 \mathrm{~g}, 0.003 \mathrm{~mol})$ in THF $(5 \mathrm{~mL})$ was added 3-aminopropanol $(608 \mathrm{mg}, 0.006$ $\mathrm{mol})$ in THF $(5 \mathrm{~mL})$. The reaction mixture was stirred for $15 \mathrm{~h}$ at room temperature. It was diluted with water $(25 \mathrm{~mL})$ and extracted with methylene chloride $(200 \mathrm{~mL})$. The organic layer was washed with $2 \mathrm{~N} \mathrm{HCl}$ and then with water and finally 
decolourised using charcoal. The solution was cooled overnight to give crystals which gave spectral data identical to the compound prepared by method A m p $129{ }^{\circ} \mathrm{C}$

\subsection{3,4-Dibromo-1-(2-hydroxyethyl)-5-hydroxy-3-pyrrolin-2-one (48)}

5-Chloro-3,4-dibromocrotonolactone (43) (250 $\mathrm{mg}, 0.0009 \mathrm{~mol})$ was added to an ice cold solution of ethanolamine $(0.1 \mathrm{~mL}, 0.0018 \mathrm{~mol})$ in THF $(5 \mathrm{~mL})$ and stirred for $15 \mathrm{~h}$ at room temperature. During stirring a thick mass was formed at the bottom of the flask. The mixture was diluted with water $(25 \mathrm{~mL})$ and extracted with ether $(100 \mathrm{~mL})$. The ether layer was washed with dil $\mathrm{HCl}$ followed by water and dried. The solvent was evaporated to give a thick mass which solidified on cooling overnight. It was recrystallised from ethyl acetate-hexane to yield $100 \mathrm{mg}(40 \%)$ of $48 ; \mathrm{m} \mathrm{p}-105{ }^{\circ} \mathrm{C}$ Anal: Calculated for $\mathrm{C}_{6} \mathrm{H}_{7} \mathrm{NO}_{3} \mathrm{Br}_{2}$ : C, 24.08; $\mathrm{H}, 2.34 ; \mathrm{N}, 4.68$. Found: C, 23.99; $\mathrm{H}$, $2.17 ; \mathrm{N}, 5.18$.

IR (KBr): $1610(\mathrm{C}=\mathrm{C}), 1650(\mathrm{C}=\mathrm{O}), 3366(\mathrm{OH})$; PMR (DMSO): $\delta 3.59(\mathrm{~m}, 4 \mathrm{H}), \delta$ $4.79(\mathrm{~m}, 1 \mathrm{H}) \delta 5.48(\mathrm{~d}, 1 \mathrm{H}), 6.97(\mathrm{~d}, 1 \mathrm{H}) ; \mathrm{MS}: \mathrm{m} / \mathrm{z} 133,220,299(\mathrm{M}+), 301(\mathrm{M}+2)$, $303(M+4)$. 


\subsection{3,4-Dibromo-5-hydroxy-3-pyrrolin-2-one (52)}

To a cold solution of 3,4-dibromo-5-benzoyloxycrotonolctone (39) (1.0 g, $0.003 \mathrm{~mol})$ in THF $(30 \mathrm{~mL})$ was added ammonia $(20 \mathrm{~mL})$ and stirred for $4 \mathrm{~h}$. After filtering the precipitated ammonium benzoate, the filtrate was concentrated to give a dark brown solid. This solid was recrystallised from benzene to give $550 \mathrm{mg}(55 \%)$ of 52 as a light yellow solid; $\mathrm{mp} 169^{\circ} \mathrm{C}$.

UV (EtOH): $\lambda_{\max } 222 \mathrm{~nm}(\varepsilon 10,600)$; IR (KBr): $1600(\mathrm{C}=\mathrm{C}), 1700(\mathrm{C}=0), 3250(\mathrm{NH})$, $3380 \mathrm{~cm}^{-1}(\mathrm{OH})$; MS: m/z $255(\mathrm{M}+)$.

\subsection{4-Anilino-3-bromo-5-benzoyloxycrotonolactone(53)}

To a solution of 3,4-dibromo-5-benzoyloxycrotonolactone (39) (1,6 g, 0.0045 mol) in absolute ethanol $(4 \mathrm{~mL})$ was added aniline $(0.8 \mathrm{~g}, 0.009 \mathrm{~mol})$ in absolute ethanol $(6 \mathrm{~mL})$. The mixture was heated on a steam bath to bring about a clear solution. It was cooled overnight, and then water was added to initiate crystallisation. The product recrystallised from alcohol to give $1.26 \mathrm{~g}(79 \%)$ of $53 ; \mathrm{m} \mathrm{p} 177^{\circ} \mathrm{C}$.

Anal: Calculated for $\mathrm{C}_{17} \mathrm{H}_{12} \mathrm{NO}_{4} \mathrm{Br}$ : C, 54.24; H, 3.23; N, 3.74. Found: C, 54.29; $\mathrm{H}$, 3.38; N, 3.78 . 
$\mathrm{UV}\left(\mathrm{CH}_{3} \mathrm{OH}\right): \lambda_{\max } 232 \mathrm{~nm}(\varepsilon 16,800), 290 \mathrm{~nm}(\varepsilon$ 19,000); IR (KBr): 1240, $1255(\mathrm{C}-$ 0), $1580(\mathrm{C}=\mathrm{C}), 1740($ ester $\mathrm{C}=0), 1765 \mathrm{~cm}^{-1}(\mathrm{C}=\mathrm{O})$; PMR $\left(\mathrm{CDCl}_{3}\right): \delta 7.28(\mathrm{~m}, 5 \mathrm{H})$, $\delta 7.54(\mathrm{~m}, 5 \mathrm{H}), \delta 7.82(\mathrm{~d}, 1 \mathrm{H}), \delta 8.20(\mathrm{~d}, 1 \mathrm{H})$

\subsection{3,4-Dibromo-5-hydroxy-1-phenyl-3-pyrrolin-2-one (54)}

A mixture of 3,4-dibromo-5-benzoyloxycrotonolactone (39) (800 mg, 0.0022 $\mathrm{mol})$, aniline $(400 \mathrm{mg}, 0.0045 \mathrm{~mol})$ and THF $(30 \mathrm{~mL})$ were heated to bring about a homogeneous solution and then cooled to $5^{\circ} \mathrm{C}$ for 2 days. The precipitate formed was removed and was identified as aniline hydrobromide. The filtrate was concentrated to give an yellow oil which was again dissolved in ethanol when a precipitate of aniline benzoate was formed. The precipitate was removed and water was added to the filtrate when $336 \mathrm{mg}(42 \%)$ of 54 as a light yellow solid was obtained; $\mathrm{m} \mathrm{p} 175^{\circ} \mathrm{C}$.

Anal: Calculated for $\mathrm{C}_{10} \mathrm{H}_{7} \mathrm{Br}_{2} \mathrm{NO}_{2}$ : C, 36.06; H, 2.12; N, 4.20. Found: C, 36.19; H, $2.43 ;$ N.4.14.

UV (EtOH): $\lambda_{\max } 228 \mathrm{~nm}(\varepsilon$ 12400), $282 \mathrm{~nm}(\varepsilon 2600) ; \mathrm{R}(\mathrm{KBr}): 1615(\mathrm{C}=\mathrm{C}), 1680$ $(\mathrm{C}=0), 3440 \mathrm{~cm}^{-1}(\mathrm{OH}) ; \mathrm{MS}: \mathrm{m} / \mathrm{z} 331(\mathrm{M}+)$.

\subsection{4-Anilino-3-bromocrotonolactone (55)}

To a cold solution of 3,4-dibromocrotonolactone (22) (100 mg, $0.0004 \mathrm{~mol})$ in absolute ethanol $(1 \mathrm{~mL})$ was added aniline $(0.07 \mathrm{~mL}, 0.0008 \mathrm{~mol})$ in alcohol $(1 \mathrm{~mL})$. 
The mixture was cooled overnight when a solid was formed. The solid separated and recrystallised from $\mathrm{CHCl}_{3}$ to yield $65 \mathrm{mg}(65 \%)$ of $55 ; \mathrm{m} \mathrm{p} 81{ }^{\circ} \mathrm{C}$.

Anal: Calculated for $\mathrm{C}_{10} \mathrm{H}_{8} \mathrm{NO}_{2} \mathrm{Br}$ : C, 47.43; $\mathrm{H}, 3.16 ; \mathrm{N}, 5.53$. Found: $\mathrm{C}, 46.92 ; \mathrm{H}$, $3.05 ; \mathrm{N}, 5.63$.

UV $\left(\mathrm{CH}_{3} \mathrm{OH}\right): \lambda_{\max } 284 \mathrm{~nm}(\varepsilon$ 29000); IR (KBr): $1259(\mathrm{C}-\mathrm{O}), 1600(\mathrm{C}=\mathrm{C}), 1790$ $(\mathrm{C}=0), 3300 \mathrm{~cm}^{-1}(\mathrm{OH}) ; \operatorname{PMR}\left(\mathrm{CDCl}_{3}\right): \delta 5.12(\mathrm{~s}, 2 \mathrm{H}), \delta 7.12-7.45(\mathrm{~m}, \mathrm{Ar}), \delta 9.69(\mathrm{~s}$, 1H); MS: m/z 130, 144, 174, 224, $253(\mathrm{M}+), 255(\mathrm{M}+2)$.

\subsection{3-Bromo-4-(N-pyrrolidino)crotonolactone (56)}

To a solution of 3,4-dibromocrotonolactone (22) $(500 \mathrm{mg}, 0.002 \mathrm{~mol})$ in THF $(3 \mathrm{~mL})$ was added pyrrolidine $(0.3 \mathrm{~mL}, 0.0042 \mathrm{~mol})$ in THF $(2 \mathrm{~mL})$. The reaction mixture was stirred until the spot of lactone on TLC (methylene chloride) disappeared. The volume was reduced and diluted with water $(25 \mathrm{~mL})$, extracted with $\mathrm{CHCl}_{3}$ (100 $\mathrm{mL}$ ) The solvent was removed and the component separated by a silica column using chloroform-methanol $(99: 1)$ mixture as the eluent to give $300 \mathrm{mg}(60 \%)$ of $56 ; \mathrm{m} \mathrm{p}$ $135{ }^{\circ} \mathrm{C}$.

Anal: Calculated for $\mathrm{C}_{8} \mathrm{H}_{10} \mathrm{NO}_{2} \mathrm{Br}$ : $\mathrm{C}, 41.55 ; \mathrm{H}, 4.32 ; \mathrm{N}, 6.06$. Found: $\mathrm{C}, 42.38 ; \mathrm{H}$, $4.46 ; \mathrm{N}, 5.59$

UV $\left(\mathrm{CH}_{3} \mathrm{OH}\right): \lambda_{\max } 277 \mathrm{~nm}(\varepsilon$ 12360); IR (KBr): 1228, $1259(\mathrm{C}-\mathrm{O}), 1650(\mathrm{C}=\mathrm{C})$, $1732 \mathrm{~cm}^{-1}(\mathrm{C}=0) ; \mathrm{PMR}\left(\mathrm{CDCl}_{3}\right): \delta 2.1(\mathrm{~m}, 4 \mathrm{H}), \delta 3.3(\mathrm{~m}, 4 \mathrm{H}), \delta 4.7(\mathrm{~s}, 2 \mathrm{H}) ; \mathrm{MS}: \mathrm{m} / \mathrm{z}$ 94, 122, 152, $231(\mathrm{M}+), 233(\mathrm{M}+2)$. 
The same reaction was repeated using dioxan as the solvent and the product obtained was identical with the product obtained above, $\mathrm{m} \mathrm{p} 135^{\circ} \mathrm{C}$

\subsection{4-(2-Amino)anilino-3-bromocrotonolactone (57)}

Method A: To a solution of 3,4-dibromocrotonolactone (22) (200 mg, $0.0008 \mathrm{~mol})$ in DMF (1 mL) was added o-phenylenediamine $(80 \mathrm{mg}, 0.00075 \mathrm{~mol})$ and stirred for 3

h. It was poured into crushed ice and the solid separated was filtered and dried. It was recrystallised from ethylacetate-hexane to yield $100 \mathrm{mg}(50 \%)$ of $57 ; \mathrm{m} \mathrm{p} 145^{\circ} \mathrm{C}$. Anal: Calculated for $\mathrm{C}_{10} \mathrm{H}_{9} \mathrm{~N}_{2} \mathrm{O}_{2} \mathrm{Br}$ : C, 44.77; H, 3.35; N, 10.44. Found: C, 43.25; $\mathrm{H}$, $3.13 ; \mathrm{N}, 10.42$.

UV ( $\left.\mathrm{CH}_{3} \mathrm{OH}\right): \lambda_{\max } 240 \mathrm{~nm}(\varepsilon$ 13320), $267 \mathrm{~nm}(\varepsilon$ 14870); IR (KBr): $1640(\mathrm{C}=\mathrm{C})$, $1736(\mathrm{C}=0), 3312,3366,3447 \mathrm{~cm}^{-1}\left(\mathrm{NH}, \mathrm{NH}_{2}\right)$; PMR (DMSO): $\delta 4.67(\mathrm{~s}, 2 \mathrm{H}), \delta 5.2$ $(\mathrm{s}, 2 \mathrm{H}), \delta 6.45-7.1$ (m. Ar), $\delta 9(\mathrm{~s}, 1 \mathrm{H}) ; \mathrm{MS}: \mathrm{m} / \mathrm{z}, 131,145,189,268(\mathrm{M}+), 270(\mathrm{M}+2)$.

Method B: To 3,4-dibromocrotonolactone (22) $(200 \mathrm{mg}, 0.0008 \mathrm{~mol})$ in alcohol (5 $\mathrm{mL}$ ) was added o-phenylenediamine $(80 \mathrm{mg}, 0.0075 \mathrm{~mol})$ in presence of pyridine and the mixture was refluxed for $8 \mathrm{~h}$ on a water bath The mixture diluted with water ( 25 $\mathrm{mL}$ ) to get a solid, which was purified on a silica column using $\mathrm{CHCl}_{3}$ as the eluent. The spectral data of the product was identical to the product obtained by Method A above, $\mathrm{m} \mathrm{p} 145^{\circ} \mathrm{C}$.

Method C: A mixture of 3,4-dibromocrotonolactone (22) (200 mg, $0.0019 \mathrm{~mol})$ and o-phenylenediamine $(200 \mathrm{mg}, 0.0019 \mathrm{~mol})$ in methanol was kept under UV 
radiation for $6 \mathrm{~h}$. The solvent was removed and the mixture was separated by a silica column using chloroform-methanol (99:1) mixture as the eluent. The first fraction obtained was the unreacted lactone and the second fraction was the product. m p 145 ${ }^{0} \mathrm{C}$. The spectral data were identical to 57 prepared by earlier methods.

\subsection{4-Amino-3-bromocrotonolactone (58)}

A mixture of 3,4-dibromocrotonolactone (22) $(150 \mathrm{mg}, 0.0006 \mathrm{~mol})$ and sodium azide $(80 \mathrm{mg}, 0.0012 \mathrm{~mol})$ in acetonitrile $(10 \mathrm{~mL})$ was refluxed for $4 \mathrm{~h}$ on a water bath. The mixture was diluted with water $(15 \mathrm{~mL})$ and extracted with ether (100 $\mathrm{mL}$ ). Ether layer was washed with water, dried and concentrated under reduced pressure and the residue obtained was recrystallised from ethyl acetate-hexane to give $90 \mathrm{mg}(60 \%)$ of (58); m p $178{ }^{\circ} \mathrm{C}(\mathrm{D})$.

Anal: Calculated for $\mathrm{C}_{4} \mathrm{H}_{4} \mathrm{O}_{2} \mathrm{NBr}$ : C, 28.51; H, 2.06; N, 7.90. Found: C, 27.11; H, $2.23 ; \mathrm{N}, 7.84$

UV ( $\left.\mathrm{CH}_{3} \mathrm{OH}\right): \lambda_{\max } 258 \mathrm{~nm}(\varepsilon$ 19560); IR (KBr): $1593(\mathrm{C}=\mathrm{C}), 1649(\mathrm{NH}), 1750$ (C=O), 3300, $3456 \mathrm{~cm}^{-1}\left(\mathrm{NH}_{2}\right)$; PMR (DMSO): $\delta 4.73(\mathrm{~s}, 2 \mathrm{H}), \delta .4(\mathrm{~s}, 2 \mathrm{H}) ; \mathrm{MS}: \mathrm{m} / \mathrm{z}$, $122,147,149,177(\mathrm{M}+), 179(\mathrm{M}+2)$.

\subsection{3-Bromo-4-(2-hyroxy)anilinocrotonolactone (59)}

To a solution of 3,4-dibromocrotonolactone $(22)(500 \mathrm{mg}, 0.002 \mathrm{~mol})$ in methanol $(5 \mathrm{~mL})$ was added o-aminophenol $(200 \mathrm{mg}, 0.002 \mathrm{~mol})$ and two drops of 
pyridine and the mixture was refluxed for $3 \mathrm{~h}$ on a water bath and poured over crushed ice. The solid separated was filtered and dried, further purification was done by chromatography on a silica column with chloroform-methanol $(99: 1)$ as eluent. The first fraction separated from the column was the unreacted lactone and the second fraction gave $225 \mathrm{mg}(45 \%)$ of the product; $\mathrm{m} \mathrm{p} 171{ }^{\circ} \mathrm{C}$.

Anal: Calculated for $\mathrm{C}_{10} \mathrm{H}_{8} \mathrm{NO}_{3} \mathrm{Br}$ : C, 44.60; $\mathrm{H}, 2.79 ; \mathrm{N}, 5.20$. Found: C, 44.32; H, $2.80 ; \mathrm{N}, 5.40$.

$\mathrm{UV}\left(\mathrm{CH}_{3} \mathrm{OH}\right): \lambda_{\max } 280 \mathrm{~nm}(\varepsilon$ 23000); IR (KBr): $1230(\mathrm{C}-\mathrm{O}), 1626(\mathrm{C}=\mathrm{C}), 1716$ $(\mathrm{C}=0), 3088(\mathrm{OH}), 3341 \mathrm{~cm}^{-1}(\mathrm{NH})$; PMR (DMSO): $\delta 4.81(\mathrm{~s}, 2 \mathrm{H}), \delta 6.8-7.1(\mathrm{~m}, \mathrm{Ar})$, $\delta 8.9(\mathrm{~s}, 1 \mathrm{H}), \delta 10.01(\mathrm{~s}, 1 \mathrm{H}) ; \mathrm{MS}: \mathrm{m} / \mathrm{z} 109,133,190,269(\mathrm{M}+), 271(\mathrm{M}+2)$.

\subsection{N,N'-Bis-(3-bromocrotonolactonyl)hydrazine (60)}

To a solution of hydrazine hydrate $(0.2 \mathrm{~mL}, 0.004 \mathrm{~mol})$ in methanol was added 3,4-dibromocrotonolactone (22) (500 mg, $0.002 \mathrm{~mol})$ and stirred overnight. The reaction mixture was diluted with water $(25 \mathrm{~mL})$ and extracted with $\mathrm{CH}_{2} \mathrm{Cl}_{2}(150 \mathrm{~mL})$. The compound was purified by column chromatography on a silica column with methylene chloride as the eluent and further recrystallised from $\mathrm{CHCl}_{3}-\mathrm{CH}_{3} \mathrm{OH}$ to give $250 \mathrm{mg}(50 \%)$ of $(60) ; \mathrm{m} \mathrm{p} 150^{\circ} \mathrm{C}(\mathrm{D})$. 
Anal: Calculated for $\mathrm{C}_{8} \mathrm{H}_{6} \mathrm{~N}_{2} \mathrm{O}_{4} \mathrm{Br}_{2}: \mathrm{C}, 27.27 ; \mathrm{H}, 1.70 ; \mathrm{N}, 7.95$. Found: C, 27.90; $\mathrm{H}$, $1.65 ; \mathrm{N}, 8.12$.

$\mathrm{UV}\left(\mathrm{CH}_{3} \mathrm{OH}\right): \lambda_{\max } 276 \mathrm{~nm}(\varepsilon$ 22390), $320 \mathrm{~nm}(\varepsilon 23460), \mathrm{IR}$ (KBr): 1219 (C-O), 1626 $(\mathrm{C}=\mathrm{C}), 1749(\mathrm{C}=\mathrm{O}), 3300 \mathrm{~cm}^{-1}(\mathrm{NH})$; PMR (DMSO): $\delta 5.29(\mathrm{~s}, 2 \mathrm{H}), \delta 8.5(\mathrm{~s}, 1 \mathrm{H})$. 


\section{SUMMARY AND CONCLUSIONS}

Pyrazolo[3,4-b]quinoxaline derivatives have been reported to have useful biological activity. So synthesis of a number of substituted pyrazoloquinoxalines were carried out, which are expected to have improved biological properties. Thus ethyl-2hydroxyquinoxaline-3-carboxylate was taken as the key starting material which is prepared by the reaction of $o$-phenylenediamine with dibromodiethyl malonate. The 2hydroxyquinoxaline-3-carboxylate on treatment with $\mathrm{POCl}_{3}$ followed by $\mathrm{PhNHNH}_{2}$ gave 2-phenylhydrazinoquinoxaline-3-carboxylate. On heating this compound above its melting point, 3-oxo-2-phenylpyrazolino[3,4-b]quinoxaline was obtained. This compound was treated with $\mathrm{POCl}_{3}$ to give 3-chloro-2-phenylpyrazoloquinoxaline. The chloro compound was subjected to various reactions like substitution, reduction, oxidation etc. By substitution reactions, using nucleophiles the corresponding 3substituted products were obtained. Reduction with $\mathrm{NaBH}_{4}$ in isopropanol gave the parent heterocycle, 2-phenylpyrazolo[3,4-b]quinoxaline. Oxidation with aq. $\mathrm{KMnO}_{4}$ gave pyrazolopyrazine dicarboxylic acid which is another heterocyclic system used in treatment of cancer and also widely used in cosmetics. A detailed spectral analysis of the above compounds are given along with the elemental analysis.

In the view of synthesising a series of potential physiologically active heterocycles another starting compound mucobromic acid was used, which can be 
readily synthesised from furfural. Four new derivatives of mucobromic acid were prepared 1) 3,4-dibromocrotonolactone 2) 5-chloro-3,4-dibromocrotonolactone 3) 5ethoxy-3,4-dibromocrotonolactone and 4) 5-benzoyloxy-3,4-dibromocrotonolactone.

Reactions of mucobromic acid with hydrazine and its derivatives gave the corresponding pyridazone derivatives. With urea it gave a pyrrolin-2-one derivative obtained by the opening of the lactone ring, while with sodium azide in acetonitrile it gave 4-azido-3-bromocrotonolactone by replacing the halogen with the nucleophile.

Reactions of 5-chloro-3,4-dibromocrotonolactone with methyl amine, 3-aminopropanol and 2-aminoethanol gave the unsaturated lactams ie. 1-Substituted-5hydroxy-3-pyrrolin-2-ones. This was similar to Winterfelds work involving the reactions of cyclohexyl amine and tryptamine with 3,4,5-trichlorocrotonolactone to give the unsaturated lactams. The benzoyloxy derivative also gave the same reaction sequence with the above nucleophiles, and the same reaction can be expected since both contained relatively excellent leaving groups. 5-Benzoyloxycrotonolactone reacted with aniline in THF to give 3,4-dibromo-5-hydroxy-1-phenyl-3-pyrrolin-2-one, while with aniline in alcohol it gave 4-anilino-3-bromo-5-benzoyloxycrotonolactone. 


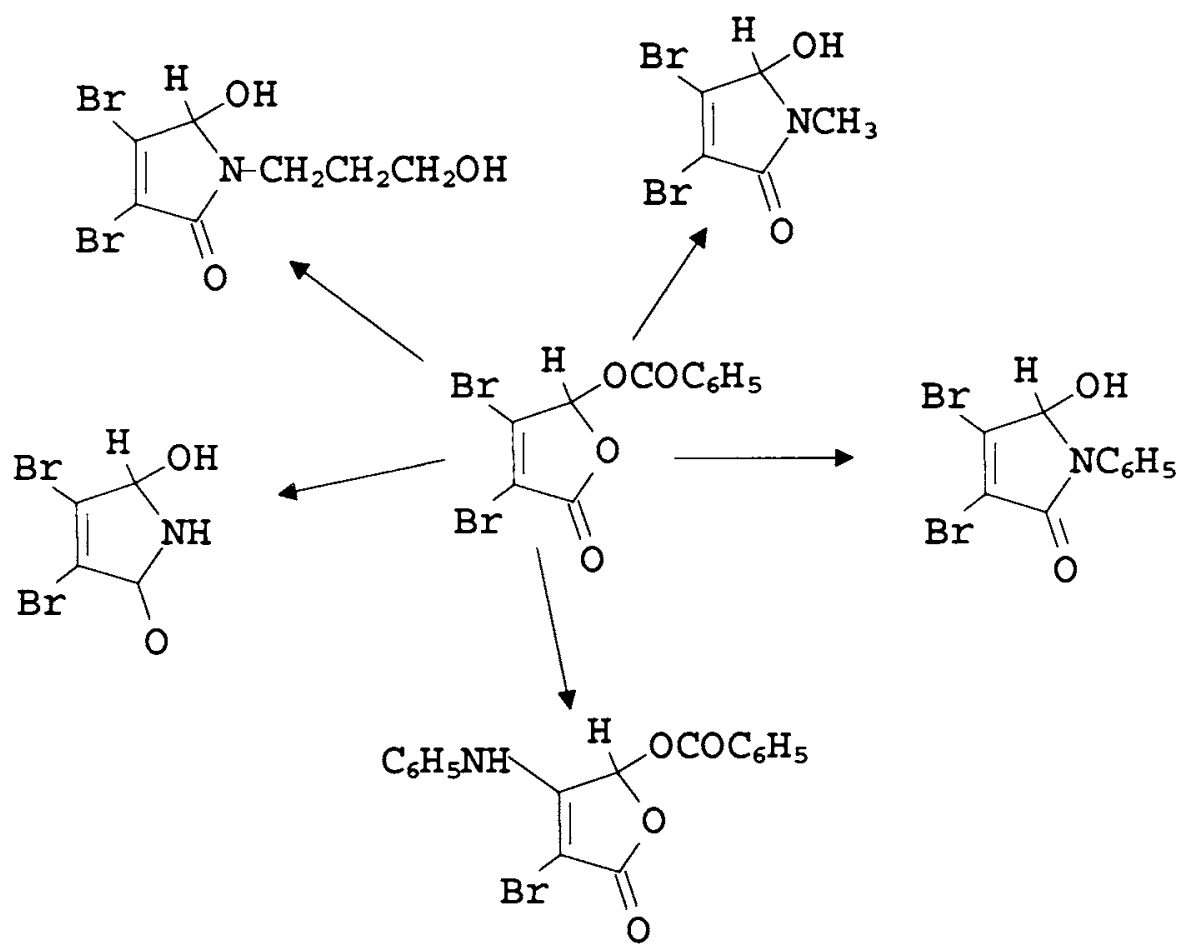

Reactions of 3,4-dibromocrotonolactone with various nucleophiles gave only one type of product which is obtained by the replacement of halogen $\beta$ to that of the carbonyl group. So in general mucobromic acid and its derivatives on reactions with nucleophiles gave either 3-pyrrolin-2-one derivatives or 4-substituted 3bromocrotonolactones, the structure of all these compounds were established by detailed spectral and elemental analysis. Reaction mechanisms have also been proposed for the formation of the above products. 


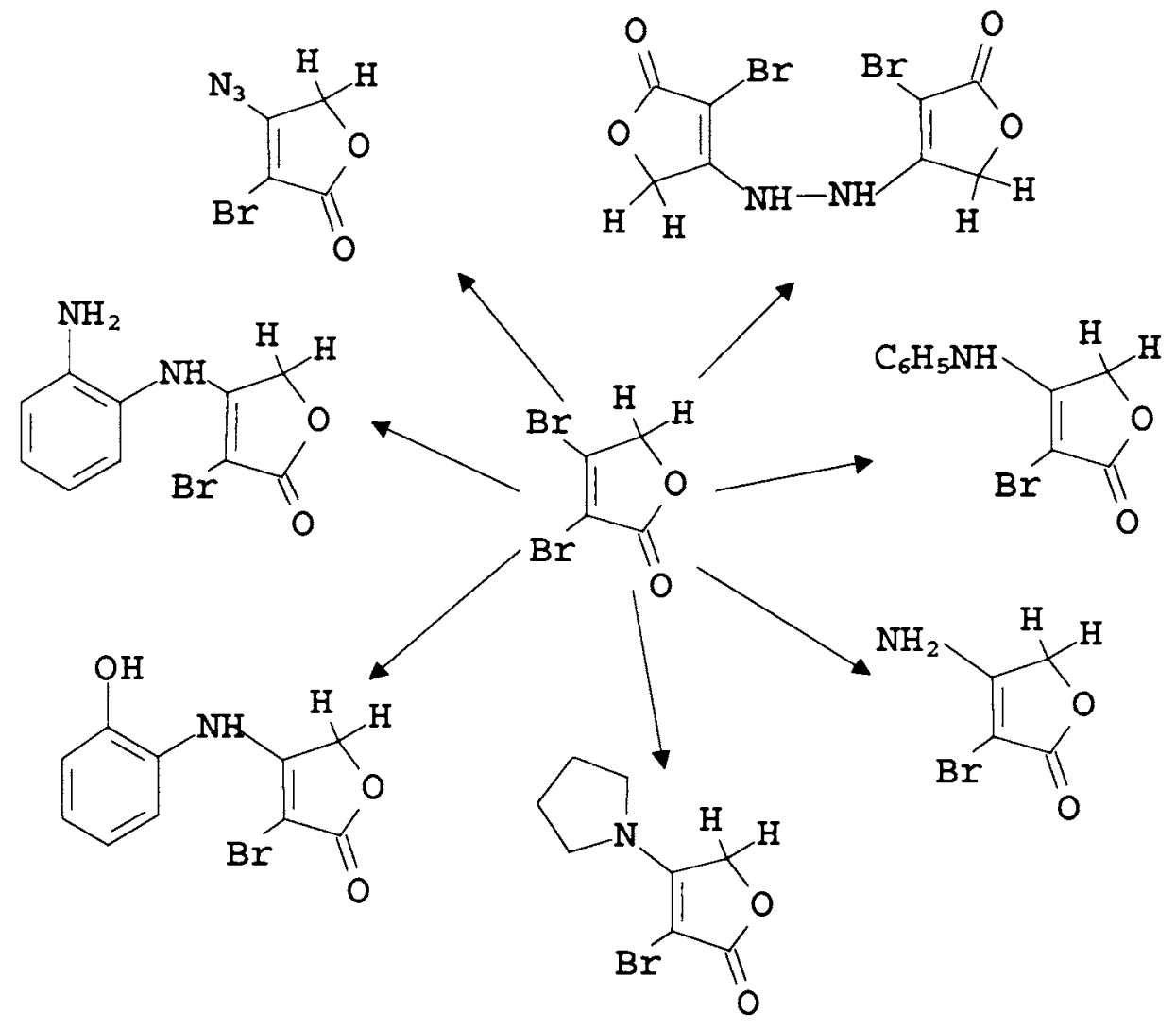

Thus in conclusion a number of new heterocycles expected to have interesting biological activity were synthesised and characterised using spectral and analytical methods. Also mucobromic acid and its derivatives were prepared and reacted with several nucleophiles to give new products. The information gained from these reactions increased the knowledge of the reactions of unsaturated lactones and lead to the formation and characterisation of new potentially active nitrogen heterocycles. 
REFERENCES
19. A.R. Katritsky, A. J. Boultan and J.M. Lagowski. Advances in Heleiocyche
vol. 2. Acadimii Press. New York. P. 204. (1963)

16. A. Zmujdzin, Pol. Patent, 69644 (1974), Chem. Abstr. 81, 77966 (1974).

2. E. C. Taylor and M. J. Thompson, J. Org. Chem., 26, 3511 (1990).

3. C. M. Atkinson, C. W. Brown and Simpson, J. Chem. Soc., 26 (1956).

4. H. Ohle, M. Heilscher, Ber., 74B , 13 (1941).

5. G. Henseke and W. Lemke, Chem. Ber., 91, 101 (1958).

6. L.Hormer, U. Schwenk and E. Junghanns, Ann., 579, 212 (1953).

7. V. M. Berezoviskii, N. A. Polyakova and L. S. Tulchinskaya, K.m Geterotsike Soedin, 729 (1967). Chem Abstr. 68, 78254 (1968)

8. Y. Matsumoto, Y, Matsumara, A. Lio and T. Yomezwa, Bull.Chem. Soc. Japan, 43, 1496 (1970).

9. A. Maxer, U. Salzmann and F. Hofler, Helv. Chim. Acta., 54, 2507 (1971).

10. A. Takaski and H. Otomasu, Chem. Pharm. Bull., 18, 22 (1970).

11. J. A. Barltrop, C. G. Richards and D. M. Russel, J. Chem. Soc., 1423 (1959).

12. J. Hammer and R. E. Halliday, J. Org. Chem., 28, 2488 (1963).

13. W. J. Ribel and T. N. Blach, J. Org. Chem.,24, 205 (1959).

14. K.V. Rao and D. Jackman, J. Heterocycl. Chem., 10, 213 (1973).

15. R. C. DeSelms, R. J. Greaves and W. R. Schleigh, J. Herterocycl. Chem., 11, 595 (1974).

16. H. Smith, M. S. Habib, M. Iqbal and M. I. Qureshi, J. Chem. Soc., 4053-56 (1964). 
17. J. K. Landquist, J. Chem. Soc., 2816 (1953).

18. A. S. Elina and O. Yu. Magidson, J. Gen. Chem.,(USSR), 25, 145 (1955).

19. T. Kimura, Yakugaku Zasshi, 77, 891 (1957).

20. A. Monge and J. A. Palop, Ann. Quim, 84C, 3644 (1988).

21. Y. Kurusawa and M. Muramatsu, J. Heterocycl. Chem., 23, 637 (1986).

22. D. Womanrao, Bull. Chem. Soc. Japan, 59, 1245 (1986).

23. N. P. Bun-Hoi, J. N. Vallat and R. S. Ruff, Chem. Ber., 6, 245 (1971).

24. A. Dell, D. H. Williams, and H. R. Morris, J. Amer. Chem. Soc. 97, 2497 (1975)

25. T. Miyagi and H. Yamamoto, Japanese Patent, 17747 (1967). Chem. Abstr. 69 $10475(1968)$.

26. Q. S. Soper, U. S. Patent, 3647793, Chem. Abstr. 77, 30339 (1972).

27. H. Zellner and M. Pailer, U. S. Patent, 3028384. Chem. Abstr. 57, 841 (1964).

28. J. S. Housley, H. C. Richards and D. F. Spooner, British Patent, 867890.

Chem. Abstr. 61, $13316(1964)$.

29. L. W. Deadly, A. J. Kaye, and G. J. Finlay, J. Med. Chem.,40, 2040, (1997).

30. M. C. Eric and S. Alan, Eur. Pat. 792,874(1997). Chem. Abstr. 127, 262701 (1997).

31. Y. Kurasawa and A. K. Takada, Heterocycl., 23, 2083 (1985).

32. A. Weissberger and T. C. Taylor, Chemistry. of Heterocyclic. Compounds, Wiley Inter. Sci., New York, N. Y., p 39 (1980). 
33. H. Ohle and M. Heilscher, Ber., 74, 13 (1941).

34. H. Ohle and G. Melkonian, Ber., 74, 279 (1941).

35. P. Nordin, Methods Carbohyd. Chem., 2, 136 (1965).

36. J. H. Pozur and D. French., J. Biol. Chem., 196, 265 (1952).

37. G. Heneske, N. Dose and K. Dittrich, Angew. Chem., 69, 479 (1957).

38. H. Ohle and G. Melkonian, Ber., 74, 398 (1941).

39. J. Klincar, Coll. Czech. Chem.Commun., 30, 3087 (1965).

40. P. M. Pillai and P. Ramabhadran., Indian J. Chem., 25B, 960 (1986).

41. W. Saver and G. Henseke, Z. Chem., 10, 381 (1970).

42. V. D. Romanenko and S. I. Burnistrov, Khim. Geterotsiki soedin., 6, 852 (1973). Chem. Abstr., 79, 92158 (1973).

43. N. P. Bu-Hoi, J. N. Vallat, G. S. Ruf and G. Lambelin, Chim. Ther., 6, 245 (1971). Chem. Abstr., 76, 3794 (1972).

44. Y. Yoshida, and H. Otamasu, Chem. Pharm. Bull., 32(9), 3361 (1970).

45. G. Henseke, D. Lehmann and K. Dittrich, Chem. Ber., 94, 1943 (1961).

46. E. S. H. ElAshry, M. M. A. Rahman, Y. El. Kilani and A. Amer, Carbohyd. Res., $87 \mathrm{C}_{5}-\mathrm{C}_{7}(1981)$

47. N. P.Buu-Hoi, J. N. Vallat, G. S. Ruf and G. Lambelin, Chim. Ther., 7, 210 (1972). Chem. Abstr. 77, 152114 (1972).

48. H. Ohle and A. Iltgen, Ber.,76, 1 (1943).

49. B. Kohlstock and G. Heneske, Z. Chem., 13, 100 (1973). 
50. B. Kohlstock and . Henseke, Z. Chem., 12, 385 (1972).

51. P. M. Pillai and P. Ramabhadran, Indian. J. Chem., 25B, 215 (1986).

52. P. Ramabhadran, Synthesis and reactions of flavazoles, Ph.D thesis, University of Cochin (1984).

53. G. R. Wendt and K. W. Ludig, U. S. Patent, 3, 431, 262 (1969). Chem. Abstr 70, $106512(1969)$

54. V. G. Nair, and S. Bernstein, U. S. Patent, 4, 304, 903 (1981). Chem. Abstr. 96, $104686(1982)$.

55. V. G. Nair and S. Bernstein, U. S. Patent, 4, 304, 904 (1981). Chem. Abstr., 96, 104685 (1982).

56. J. E. Holchin, J. Gen, Microbiol.,5, 609 (1951).

57. J. Mc Inthosh and F. R. Selbie, Brit. J. Exptl. Path, 27, 46 (1946).

58. M .A. E. Sallam, R. L. Whistler and J. L. Markley, Carbohydrate Res., 87, 87, (1980).

59. M. A. E. Sallam, Nucleosides Nucleotides, 1, 297 (1982). Chem. Abstr. 98, $198646(1983)$.

60. C. Moreno, C. Hale, R. Hewlett and D. Cussel, Europ. J. Immunol., 9, 916 (1979).

61. J. H. Pazur, J. Amer. Chem. Soc., 77, 1055 (1955).

62. B. Teichmann, K. Himmelspach and O. Westphal, J. Pract. Chem., 314, 877 (1972). 
63. V. Harisdangkul and E. A. Kabat, J. Immunol., 108, 1232 (1972).

64. B. Teichmann, J. Prakt. Chem., 316,821 (1974).

65. H. Widtsoe and Dunlap, Amer. Chem. J. 9, 627 (1897).

66. H. Simmonis, Marhen and Mermond, Ber., 38, 3981 (1905).

67. H. B. Hill, Amer. Chem. J., 3, 46 (1882).

68. H. Mayer, Monatsh, 25, 491 (1904).

69. E. Beska, P.Rapos and P. Winternits, J. Chem. Soc.,Sect. C, 729 (1969).

70. D. T. Mowry, J. Am. Chem. Soc., 72, 2535 (1950).

71. E. I. Vinogradova and A. M. Shemyakin, J. Gen. Chem. (U.S.S.R), 16, 709, (1964).

72. H. H. Wasserman and M. Precopio, J. Amer. Chem. Soc., 76, 1242 (1954).

73. (A). H. Simmonis, Ber., 34, 509 (1901).

(B). H. B. Hill and A. W. Palmer, Amer. Chem. J.,9 147 (1887).

74. M. Semonsky, A. Cerny, R. Kotva, V. Zikan and R. Kakac, Collect. Czech. Chem. Commun. 33, 2698 (1968).

75 E. I. Vinogradova, A. M. Semjakin, Z. Obsc. Chim., 16 (1946).

76. Y. Hachihama, T. Shono and S. Ikeda, J. Org. Chem., 29, 1371 (1964).

77. M. Semonsky, A. Cerny, B. Kakac and V. Subrt, Collect. Czech. Chem. Commun., 28, 3278 (1960).

78. E. Winterfield, and J. M. Nelke, Chem. Ber., 101, 3163 (1968).

79. J. Clark and D. D. Perrin, Quart. Rev. (London), 18, 295 (1964). 
80. C. Qinghua, and G. Zhe, Youji Huaxue, 13, 299 (1993).

81. D. Wang, Shengi Li, Guangzhi Xu, J. Electron Spectrosc. Relat. Phenom. 70, $167,(1994)$.

82. X. Xu, L. Liang, H. Zou, Y. Liu,L. Wang and Z. Zhang, Chemosphere. 35, 1709 (1997).

83. J. B. Jones and J. M. Young, Can. J. Chem., 44, 1059 (1966).

84. H. Dahn and J. P. Fumeaux, Bull. Soc. Vaud. Sci. Natur., 70, 313 (1970).

85. G. Henseke, W. Dose and K. Dittrich, Angew Chem., 69479 (1957).

86. D. F. Morrow and L. A. Regan, J. Org. Chem., 36, 27 (1971).

87. W. Bradley and L. Watkinson, J. Chem. Soc., 319 (1956).

88. H. Dahn and H. Moll, Helv. Chim. Acta., 49, 2426 (1966).

89. H. Dahn and J. Nussbaum, Helv. Chim. Acta.,52, 1661 (1969).

90. H. Ohle and W. Gross, Ber., 68, 2262 (1935).

91. S. Astin, A. C. C. Newman and H. L. Riley, J. Chem. Soc., 393 (1933).

92. C. Bluckner, Ber., 24, 3001 (1891)

93. A. H. Gowenlock, G. T. Newbold and F. S. Spring, J. Chem. Soc., 622 (1945).

94.(A). Suzuki, Shimichi Japan Kokai Tokkyo Koho JP 02,240 084[90, 240, 084], Chem. Abstr. 114, 178382 (1991).

(B). Kokkai, Tokkyo Koho, JP. 06 80,570 (1994). Chem. Abstr. 121, 91797 , (1994) 
(C). Kokkai, Tokkyo Koho, JP. 03,287,513 (1991). Chem. Abstr., 116, $241729(1992)$.

95. C. F. H. Allen and F. W. Spangler, Organic Synthesis, Coll. Vol 3, John Wiley and Sons, Inc., New York, 621 (1967).

96. G. A. Taylor, Organic Synthesis, Coll. Vol 4, John Wiley and Sons, Inc., New York, 688 (1964).

97. H. Wasserman, Doctoral dessertation, Harvard University, (1948). D. Mowry, J. Am. Chem. Soc., 72, 2535 (1950).

98. E. Shaw, J. Am. Chem. Soc., 68, 2510, (1946).

99. G. Dupont, R. Dulou and G. Lefebare, Bull. Soc. Chim., (France), 339 (!951).

100. J. T. Braunholtz, K. B. Mallion and F. G. Mann, J. Chem. Soc., 4346 (1962).

101. E. Beska, P Rapos and P. Winternits. J. Chem. Soc., Sec. C 729 (1969).

102. L. M. Jackman, Application of Nuclear Magnetic Resonance Spectroscopy in Organic Chemistry, The Mcmillion Co. New York, (1964).

103. M. Du Four and P. Jacquiqnon, Bull. Soc. Chim. France 2999 (1971).

104. H. B. Hill and R. W. Cornelision, Am. Chem. J., 16, 188 --(1895).

105. H. Simonis, Ber., 34, 509 (1901).

106. H. B. Hill and A. W. Palmer, Am. Chem. J., 9, 147 (1887).

107. H. E. Sawyer, Proc. Am. Acad. Arts. Sci., 29, 242 (1894).8

108. E. Gudriniece and A. Karklins, Vertis Kim. Ser. 4474 (1967).

109. K. G. Taylor Unpublished work University of Louiswille, (1982)

110. F. Fowler, H. Hassner and A. Levy, J. Am. Chem. Soc., 89,2077, (1967). 
111. D. T. Mowry, J. Am. Chem. Soc., 72, 2535 (1950).

112. R. K. Smalley and H. Suschitzky, J. Chem. Soc., 755 (1964).

113. A. Hassner and F. W. Fowler, Tetrahedron letters, 1545 (1967).

114. A. Hassner and F. W. Fowler, J. Am. Chem. Soc., 90, 2869 (1968).

115. E. Winterfield and J. M. Nelke, Chem. Ber., 101, 3163 (1968).

116. W. P. Jencks, “Catalysis in Chemistry and Enzymology”, Mc. Graw Hill, New York, chapter 10, p. 51-511(1969).

117. S. C. Johnson, "Advances in Physical Organic Chemistry", Vol 5 V. Gold, Ed., Academic Press, New York, p. 294-299 (1967).

118. I. Heilbron, "Dictionary of Organic Compounds", Vol 4, Eyre and Spolliswoode, p. 2355 (1965).

119. J. R. Dyer, "Applications of Absorption Spectroscopy of organic compounds", Prentice Hall, Inc., Englewood Cliffs, (1965).

120 R. M. Silverstein, G. C. Claytron, "Spectometric Identification of Ogranic Compounds", John Wiley and Sons, Inc., New York (1966).

121. T. J. Culphey, “A Short Guide to the Spectroscopy of Organic Compounds". St. Louis University, St. Louis (1964).

122. V. Sanjeev Bhat, Synthesis and Reactions of Pyrazoloquinoxalines, $\mathrm{Ph} . \mathrm{D}$ thesis, Cochin University of Science and Technology, (1989). 